Nano-crystallised Carbon-Titanium Dioxide-Bismuth composite photocatalyst for clean water and hydrogen production
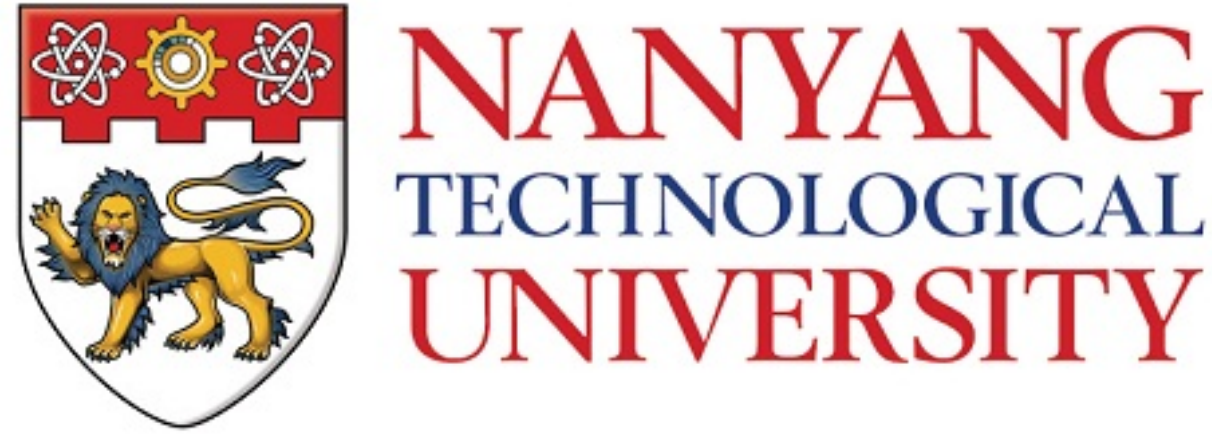

\title{
JERMYN JUAY
}

\section{Interdisciplinary Graduate School}

Nanyang Environment Water Research Institute

\footnotetext{
A thesis submitted to the Nanyang Technological University in partial fulfilment of the requirement for the degree of

Doctor of Philosophy
} 


\section{Acknowledgements}

This thesis would not have been possible without the guidance and the help of several individuals who in one way or another contributed and extended their valuable assistance in the preparation and completion of this study.

First and foremost, I would like to express my utmost gratitude to Assoc Prof Sun Delai, Darren for giving me the opportunity to conduct my research under him. Furthermore I would like to thank him for his patience and guidance during this period. His constant guidance and supervision has imparted valuable knowledge which helped me to complete my thesis.

Second, I would like to extend my appreciation to the thesis advisory committee comprising of Prof. Shen Zexiang and Assoc Prof Richard D. Webster who in their way have provided me advices and direction which helped me set the focus of my research direction.

Third, I would like to thank Interdisciplinary Graduate School (IGS) and Nanyang Environmental Water Research Institute (NEWRI) for providing with a stable financial platform for me to conduct my research. This has allowed me put my attention on establishing a sound research model instead of worrying of the financial burdens.

Fourth, I would like to express my gratitude towards the laboratory staff at the Environment Lab for their assistance in my research.

Finally I would like to thank and show my appreciation to the people who have willingly helped me out with during this period. 


\begin{abstract}
$\underline{\text { Abstract }}$
The use of Titanium Dioxide $\left(\mathrm{TiO}_{2}\right)$ nanostructures for photocatalytic environmental applications has received significant attention due to a growing emphasis on sustainability. Against this backdrop, this study proposes the use of nano-crystallised carbon composite one-dimensional $\mathrm{TiO}_{2}$ nanostructure with improved photocatalytic activity in the visible light region for such applications.
\end{abstract}

Amongst the studied one-dimensional nanostructures, nanofibrous anatase $\mathrm{TiO}_{2}$ provided a better medium for photocatalytic reactions. Thus a $\mathrm{Bi}_{2} \mathrm{Ti}_{4} \mathrm{O}_{11} / \mathrm{TiO}_{2}$ composite nanofiber was assembled through electrospinning. First, it was observed from the experimental results that the formation of the bismuth titanate $\left(\mathrm{Bi}_{2} \mathrm{Ti}_{4} \mathrm{O}_{11}\right)$ phase on the anatase $\mathrm{TiO}_{2}$ nanofiber enhanced its photocatalytic performance in the degradation of AO7 as well as $\mathrm{H}_{2}$ generation under visible light. The enhanced photocatalytic activity is attributed to the presence of the $\mathrm{Bi}_{2} \mathrm{Ti}_{4} \mathrm{O}_{11}$ which narrowed the band-gap and allowed for improved charge suppression. Moreover, after the formation of the nano-crystallised carbon layer which doped itself into the composite nanofiber, the appearance of the composite nanofiber changed from cream to black. It was observed that there was a significant reduction to the optical band gap which narrowed to $2.55 \mathrm{eV}(\sim 480 \mathrm{~nm})$. Furthermore, through the characterisation study using TEM it demonstrated that the carbon has fully crystallised into the lattice of the composite nanofiber. This indicates that the crystallisation process was a result from the substitution of anions and cations with C-elements into the lattice of the composite nanofiber which triggered the formation of a $\sim 2.5 \mathrm{~nm}$ thick disorder lattice along the fringes.

The $\mathrm{H}_{2}$ evolution tests under sacrificial conditions showed that the nano-crystallised carbon composite nanofiber demonstrated excellent ability to generate $\mathrm{H}_{2}$ under visible 
light irradiation. The introduction of the nano-crystallised carbon dopant not only improved the visible light absorption capability of the composite nanofiber but also created more reaction sites to facilitate the access of reactant. Furthermore it is proposed that the formation of the nano-crystallised carbon layer permitted for an enhanced electrons transfer process through a sequential electron flow. As such, the combination of these factors enriches the photocatalytic performance of the synthesised complex nanofiber. These finding presents the tremendous potential of the complex nanofiber as it is of great importance and promise to utilise solar energy for water purification and energy harvesting applications. 


\section{List of Figures}

Figure 2.1 - Various crystalline structure of Titanium Dioxide $\left(\mathrm{TiO}_{2}\right)$ (a) Brookite (b) Anatase and (c) Rutile

Figure 2.2 - Band-gap properties of various semiconductor photocatalysts............... 9

Figure 2.3 - Schematic representation of an electrochemical anodization set up ....... 13 Figure 2.4 - Schematic representation of the Ti anodization (a) in absence of fluorides (results in flat layers), and (b) in presence of fluorides (results in the tube growth) ... 16 Figure 2.5 - Formation of Taylor Cone ................................................................ 17

Figure 2.6 - Stages in Electrospinning.......................................................... 18

Figure 2.7 - X-ray diffraction pattern $\mathrm{TiO}_{2}$ electrospun nanofibers ......................... 19

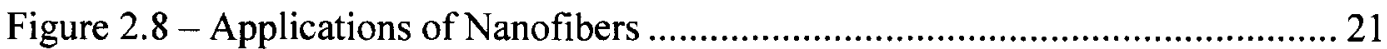
Figure 2.9- (a) Schematic representation of band-gap formation and electron transfer process, (b) typical band-gap engineering; Metal doping, Dye-sensitized and

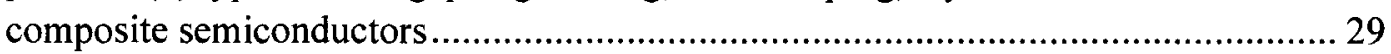

Figure 3.1 - Schematic Diagram of Electrospinning Chamber ............................... 34

Figure 3.2 - Schematic diagram of Photocatalytic Oxidation Reactor ....................... 37

Figure 3.3 - Schematic diagram of $\mathrm{H}_{2}$ generation set up ....................................... 37

Figure 3.4 - Schematic diagram of BET instrument............................................. 39

Figure 3.5 - Schematic diagram of experimental apparatus used for thermogravimetric

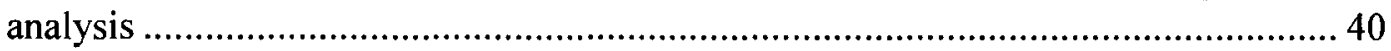

Figure 3.6 - Schematic diagram of TEM ........................................................ 41

Figure 3.7 - Schematic diagram of a SEM ..................................................... 42

Figure 4.1 - Digital image of Titanium Foil (a) before anodization (b) after

anodization (c) after anodization and calcination ............................................... 43

Figure 4.2 - (a) \& (b) FESEM Image of $\mathrm{TiO}_{2}$ nanotube at different magnification.... 44 Figure 4.3 - FESEM image of the cross-section view of $\mathrm{TiO}_{2}$ nanotubes after 2 hour

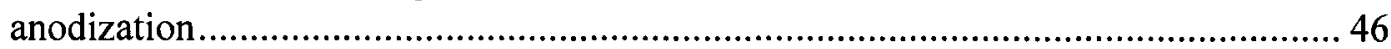

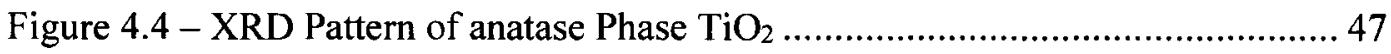
Figure 4.5 - (a) HRTEM image showing $\mathrm{TiO}_{2}$ nanotubes crystal lattice of anatase $\mathrm{TiO}_{2}$ (b) Selected area electron diffraction (SAED) pattern ......................................... 48 Figure 4.6 - FESEM images of uncalcined under different magnification (A-1 to A-3) and $\mathrm{TiO}_{2}$ nanofiber calcined at $550^{\circ} \mathrm{C}$ under different magnification (B-1 to B-3) .... 49 Figure 4.7 - XRD Diffraction pattern of uncalcined and calcined $\mathrm{TiO}_{2}$ nanofibers... 50 Figure 4.8 - (a) HRTEM image of $\mathrm{TiO}_{2}$ nanofiber indicating lattice of anatase $\mathrm{TiO}_{2}$ (b) Selected area electron diffraction (SAED) pattern..................................................5 50 Figure 4.9 - Pseudo-First order degradation kinetics of one-dimensional $\mathrm{TiO}_{2}$

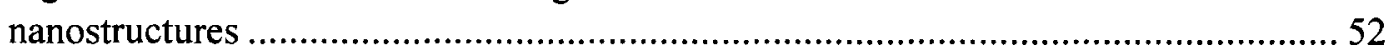
Figure 4.10 - Plot of Normalised concentration against time comparing photocatalytic performance of different one-dimensional nanostructures ..................................... 53

Figure 4.11 - FESEM images of $\mathrm{TiO}_{2} \mathrm{NFs}$ calcined at (a) $450^{\circ} \mathrm{C}$; (b) $550^{\circ} \mathrm{C}$; (c)

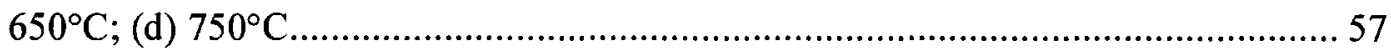

Figure 4.12 - Diffraction pattern $\mathrm{TiO}_{2}$ nanofibers................................................. 59

Figure 4.13 - Adsorption/Desorption isotherms of $\mathrm{TiO}_{2}$ nanofibers calcined at various

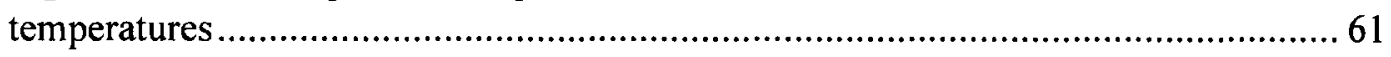

Figure 4.14 - Plot of Normalised concentration against time of $\mathrm{TiO}_{2}$ nanofiber calcined at various temperatures 
Figure 4.15 - Plot of logarithm of first order degradation rate of $\mathrm{TiO}_{2}$ nanofiber calcined under various temperature

Figure 4.16 - Photochemical stability of $\mathrm{TiO}_{2} \mathrm{NFs}$

Figure 4.17 - XRD diffraction patterns of $\mathrm{Bi}_{2} \mathrm{Ti}_{4} \mathrm{O}_{11} / \mathrm{TiO}_{2}$ composited nanofiber which was calcined at various temperatures

Figure 4.18 - (a) Elemental Mapping of the selected area for Ti element, Bi Element and $\mathrm{O}$ element (b) EDX spectrum of electron image shown in (a).

Figure 4.19 - (a) Low magnification FESEM of $\mathrm{Bi}_{2} \mathrm{Ti}_{4} \mathrm{O}_{11} / \mathrm{TiO}_{2}(\mathrm{Bi}-550 \mathrm{C}$ ) composite nanofiber after calcination $550^{\circ} \mathrm{C}$ (b) High magnification of FESEM image of Bi-550C (c) TEM image of $\mathrm{Bi}-550 \mathrm{C}$ (d) HRTEM image of $\mathrm{Bi}-550 \mathrm{C}$ showing corresponding lattice of $\mathrm{TiO}_{2}$ and $\mathrm{Bi}_{2} \mathrm{Ti}_{4} \mathrm{O}_{11}$

Figure 4.20 - Nitrogen adsorption/desorption isotherms for calcined $\mathrm{Bi}_{2} \mathrm{Ti}_{4} \mathrm{O}_{11} / \mathrm{TiO}_{2}$

composite nanofibers

Figure 4.21 - (a) Normalised concentration showing the degradation of AO7 with reaction time for the various photocatalysts (b) Modelled pseudo-first order degradation kinetics for the various photocatalysts

Figure 4.22 - Photocatalytic stability of the composite nanofiber calcined at $550^{\circ} \mathrm{C} .75$

Figure $4.23-\mathrm{H}_{2}$ evolution comparison of the TNF550C and Bi-550C.

Figure 4.24 - Kulbeka-Munk transformed reflectance spectra to determine band-gap

and insert of absorbance spectra

Figure 4.25 - Schematic diagram of the photogenerated electrons and holes in the

$\mathrm{Bi}_{2} \mathrm{Ti}_{4} \mathrm{O}_{11} / \mathrm{TiO}_{2}$ composite nanofibers.

Figure 4.26 - (a) Digital photo comparing the Bi550C nanofiber and the C-Bi550C nanofiber. (b) FESEM image of the C-Bi550C nanofiber (c) TEM image of the CBi550C nanofiber with disordered outer fringe layer (d) HRTEM images of $\mathrm{TiO}_{2}$ nanocrystals, $\mathrm{Bi}_{2} \mathrm{Ti}_{4} \mathrm{O}_{11}$ nanocrystals and the outer layer of the carbon dopant layer .81 Figure 4.27 - (a) Elemental mapping of Carbon doped Bi-550C (C-Bi550C) nanofiber (b) Corresponding EDS spectrum of Carbon doped Bi-550C nanofiber .83 Figure 4.28 - Diffraction pattern of Bi-550C and C-Bi550C nanofiber ... .84

Figure 4.29 - Diffused Absorbance and Transformed Kubelka-Munk function of Bi$550 \mathrm{C}$ and $\mathrm{Bi}-550 \mathrm{C}$.

Figure $4.30-\mathrm{H}_{2}$ evolution comparison of the $\mathrm{Bi}-55 \mathrm{C}$ and $\mathrm{C}-\mathrm{Bi} 550 \mathrm{C}$...................... 86

Figure 4.31 - Schematic illustration of nano-crystallisation process......................... 87 Figure 4.32 - (a) Schematic illustration of electrons-holes generation process on nanocrystallised carbon $\mathrm{Bi}_{2} \mathrm{Ti}_{4} \mathrm{O}_{11} / \mathrm{TiO}_{2}$ nanofiber (b) "Waterfall" illustration of proposed flow of electrons 


\section{List of Tables}

Table 2.1 - Potential applications of titanium dioxide Photocatalyst ........................... 7

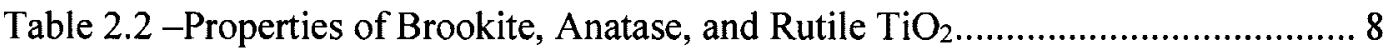

Table 2.3 - Photocatalytic reactions at the semiconductor surface .......................... 11

Table 2.4 - Effect of process parameter on resultant nanotubes morphology ............. 14

Table 2.5 - Effect of process parameter on the resultant nanofiber morphology ........ 20

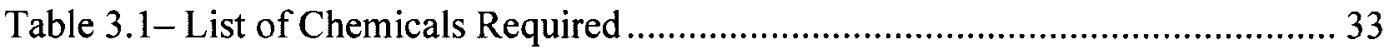

Table 4.1 - Photocatalytic performance of $\mathrm{TiO}_{2}$ nanotubes and nanofibers ............... 54

Table 4.2 - Adjusted electrospinning precursor to accommodate the dissolution of

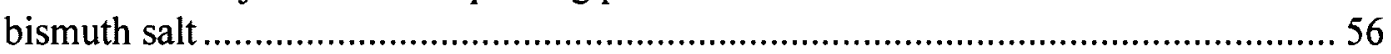

Table 4.3 - Description of nanofiber sample and its associated IDs ........................56 56

Table 4.4 - Diameter distribution of $\mathrm{TiO}_{2} \mathrm{NFs}$................................................5 58

Table 4.5 - Physiochemical properties of $\mathrm{TiO}_{2}$ nanofiber calcined at various

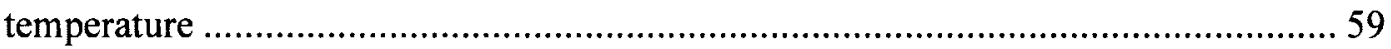

Table 4.6 - Summary of XRD profiles of $\mathrm{TiO}_{2}$ nanofibers.....................................6 60

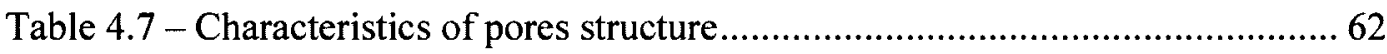

Table 4.8 - Modelled Pseudo-first order degradation rate of $\mathrm{TiO}_{2}$ nanofibers ........... 64

Table 4.9 - Physiochemical characteristics of synthesised $\mathrm{Bi}_{2} \mathrm{Ti}_{4} \mathrm{O}_{11} / \mathrm{TiO}_{2}$ composite

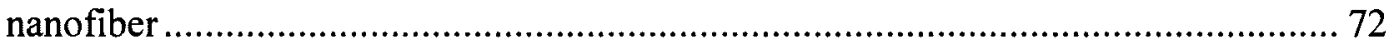

Table 4.10 - Modelled degradation kinetics of $\mathrm{Bi}_{2} \mathrm{Ti}_{4} \mathrm{O}_{11} / \mathrm{TiO}_{2}$ nanofiber in the degradation of Acid Orange 7 ............................................................................ 74 


\section{Table of Contents}

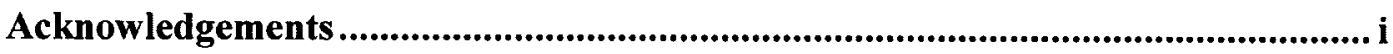

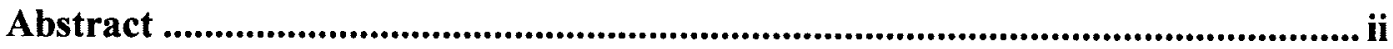

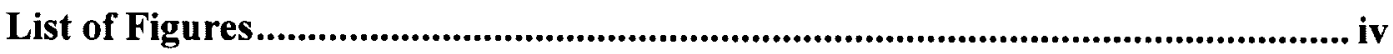

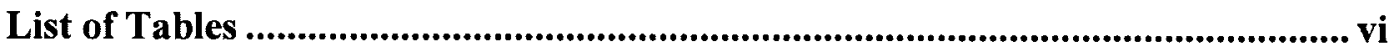

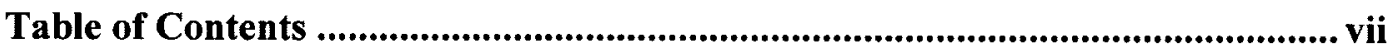

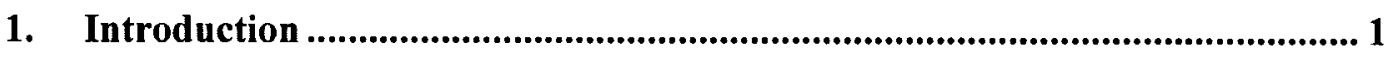

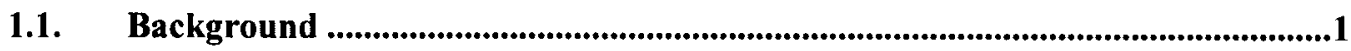

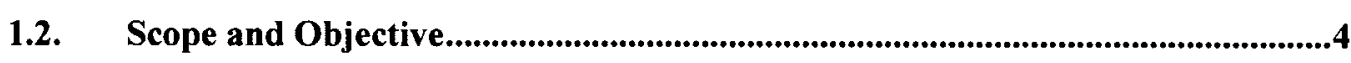

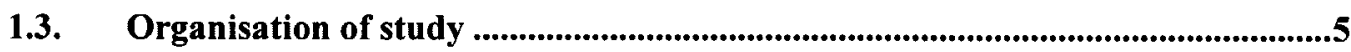

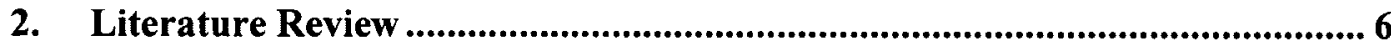

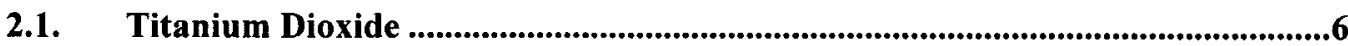

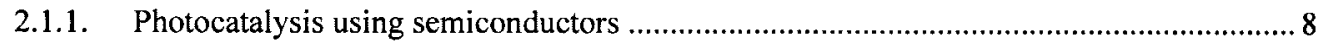

2.2. One-Dimensional $\mathrm{TiO}_{2}$ semiconductor photocatalysts ......................................12

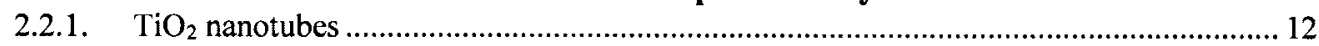

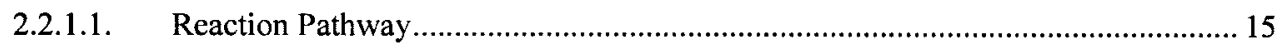

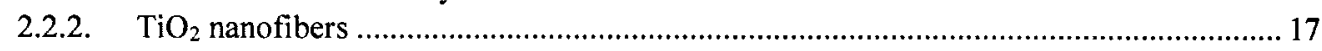

2.3. Strategies to enhance photocatalytic performance ..................................................22

2.3.1. Electronic band structure for visible-light harvesting .......................................22

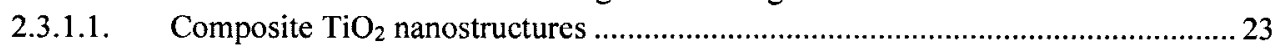

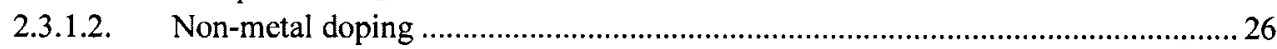

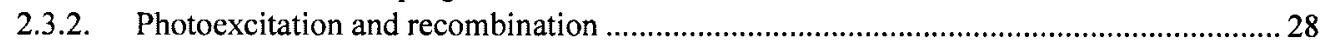

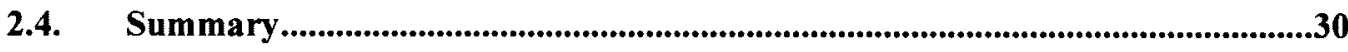

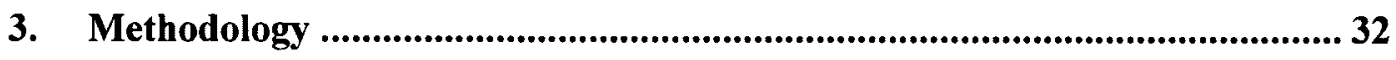

3.1. Synthesis one-dimensional $\mathrm{TiO}_{2}$ nanostruetures.............................................32

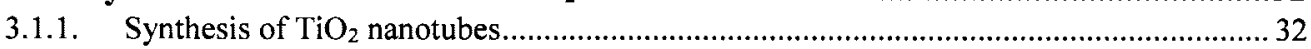

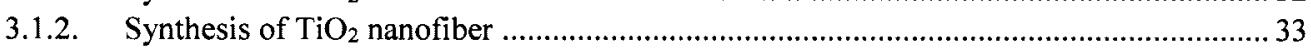

3.2. Synthesis and band gap engineering of $\mathrm{TiO}_{2}$ nanofiber ........................................34

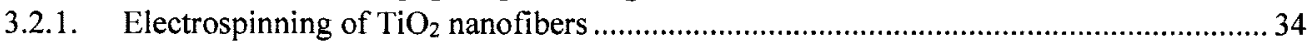

3.2.2. Synthesis of composite Bismuth Titanate/Titanium dioxide nanofiber ...........................35

3.2.3. Synthesis of nano-crystallised carbon Titanium dioxide-Bismuth composite nanofiber. 36

3.3. Photocatalytic Performance .................................................................................36

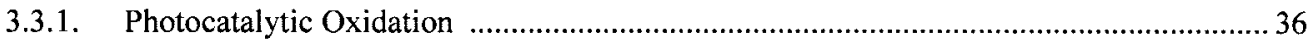

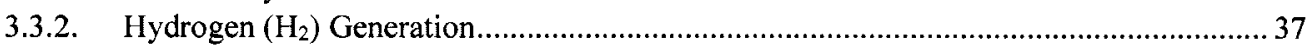

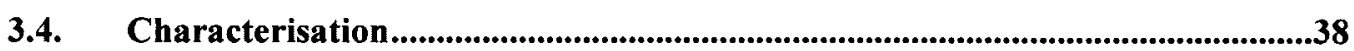

3.4.1. Brunauer-Emmett-Teller (BET) Surface Area Analysis............................................... 38

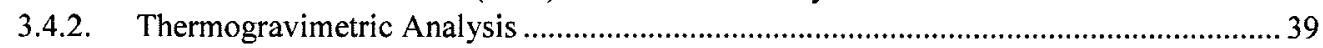

3.4.3. Transmission Electron Microscopy Analysis (TEM) ……………................................ 40

3.4.4. Scanning Electron Microscopy ................................................................................ 41

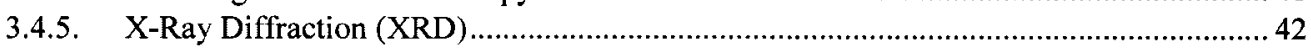

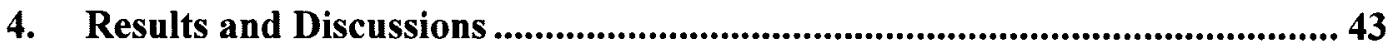

4.1. Comparison of One-dimensional nanostructures ................................................43 


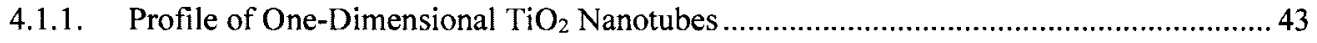

4.1.2. Profile of one-dimensional $\mathrm{TiO}_{2}$ Nanofiber............................................................. 48

4.1.3. Review of Photocatalytic Performances ............................................................... 51

4.2. Optimisation of $\mathrm{TiO}_{2}$ Nanofibers for Band gap engineering.............................55

4.2.1. Physiochemical Properties of $\mathrm{TiO}_{2}$ nanofibers ......................................................... 59

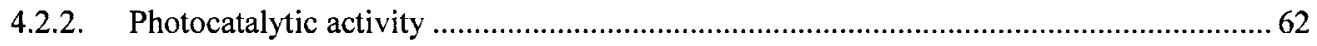

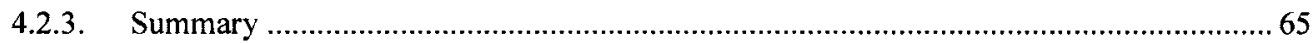

4.3. $\mathrm{Bi}_{2} \mathrm{Ti}_{4} \mathrm{O}_{11} / \mathrm{TiO}_{2} \mathrm{Composite} \mathrm{nanofibers.................................................................66}$

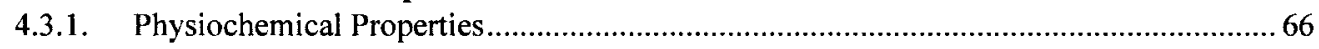

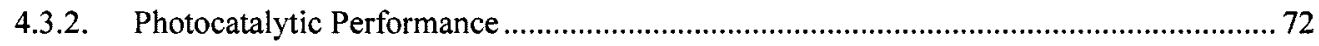

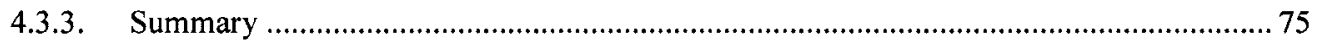

4.4. Comparison of Hydrogen production potential ................................................77

4.4.1. Comparison of Energy band gap between $\mathrm{TiO}_{2}$ Nanofiber and $\mathrm{Bi}_{2} \mathrm{Ti}_{4} \mathrm{O}_{11} / \mathrm{TiO}_{2}$ Composite

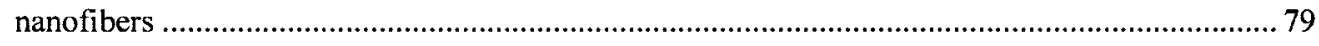

4.5. Formation of nano-crystallised carbon Titanium Dioxide/Bismuth composite

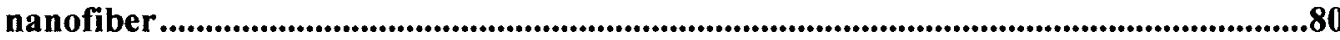

4.5.1. Properties of carbon-doped $\mathrm{Bi}_{2} \mathrm{Ti}_{4} \mathrm{O}_{11} / \mathrm{TiO}_{2}$ composite nanofiber ................................ 81

4.5.2. Growth mechanism of Carbon Doped $\mathrm{Bi}_{2} \mathrm{Ti}_{4} \mathrm{O}_{11} / \mathrm{TiO}_{2}$ composite nanofiber...................86

5. Conclusion ............................................................................................................. 89

6. Recommendations............................................................................................ 92

7. References ............................................................................................................ 93

\section{List of Appendices}

Stages of growth and Formation of $\mathrm{TiO}_{2}$ Nanotubes .......................................................... A - 1

Scherrer Equation .................................................................................................................. B - 1

BJH Pore Size Distribution of $\mathrm{TiO}_{2}$ Nanofibers .................................................................. - 1

Profiles of $\mathrm{Bi}_{2} \mathrm{Ti}_{4} \mathrm{O}_{11} / \mathrm{TiO}_{2}$ composite Nanofiber ............................................................

FESEM images of nano-crystallised carbon $\mathrm{Bi}_{2} \mathrm{Ti}_{4} \mathrm{O}_{11} / \mathrm{TiO}_{2}$ composite nanofiber........ $\mathrm{E}-1$

Adsoprtion Properties of nanocrystallised carbon $\mathrm{TiO}_{2}-\mathrm{Bi}$ composite nanofiber ......... F - 1 


\section{Introduction}

\subsection{Background}

Population growth and mobility, as well as energy production have contributed to a heightening global demand to access for clean and safe drinking water (P. Aldhous, 2003). There are many combinations of conventional wastewater treatment technologies that employ physical and chemical treatment techniques available in the industry to convert raw water and wastewater into clean water. Examples of such approaches include the use of activated carbon, chlorination, ozonation, UV-irradiation, coagulation/flocculation, sand filtration, and membrane technologies. However, some of these conventional technologies including activated carbon, coagulation/flocculation and sand filtration only separate the contaminants from the polluted water or wastewater to other solid forms for further safe disposal. To a great extent, these processes not only produce toxic by-products, have low water production rates and quality, it also has large carbon footprints (Georges, Thornton, \& Sadle, 2009). Hence, the collective effect of such impacts had since accentuated the need for 'cleaner' alternatives.

In addition, to the influence on the basic human demand the availability of clean drinking water also strongly affects the production of energy and food, industrial activities, quality of environment and global economies of both the developing and developed nations. Moreover, fresh water resources from rivers and lakes have been severely diminished due to increasing global population and industrialisation. Hence, the conflicts that arise due to the decline of water quality, water supply capacity and the exacerbation of water deteriorating situation are becoming more prominent and hard for reconciliation (Peter Aldhous, 2003). Therefore, by temporally discarding global political debates pertaining to water resources and address water resource availability as 
a strategic component to national development; it will undoubtedly become an important and severely pressing issue in the coming decades

To further compound the global interests arising from lack of access to clean drinking water, global energy issue is another subject of concern. Energy, is a key driving force behind a nation's development and it warrants its' competitive advantage due to the fact that it is the vital for technological and economic advancements (Chow, Kopp, \& Portney, 2003). However, the overdependence of global energy on fossil fuels has accelerated its depletion. The generation of energy from fossil fuels also contributes to the emission of greenhouse gases which instigates global climate change. These resulting factors have led to the world-wide attention on energy issues (Chow et al., 2003; Davis, Caldeira, \& Matthews, 2010).

Facing these challenges, scientists and researchers have been seeking for novel and alternative technologies to produce clean energy and water. With the growing emphasis on sustainability and advancement in technology, the use of Titanium Dioxide $\left(\mathrm{TiO}_{2}\right)$ photocatalyst has begun to receive increasing attention (Fujishima \& Honda, 1972; Lazar, Varghese, \& Nair, 2012). Significant research has demonstrated the potential of Titanium Dioxide $\left(\mathrm{TiO}_{2}\right)$ nanomaterials for photocatalytic oxidation (PCO) technologies. In contrast, to conventional water treatment technologies PCO processes using nanostructured $\mathrm{TiO}_{2}$ (Shannon et al., 2008) offer an efficient and cost effective way for producing reliable drinking water from raw water or heavily polluted wastewater due to its strong degradation ability of refractory organic pollutants (Arana et al., 2002). Moreover, researchers have further illustrated the potential of $\mathrm{TiO}_{2}$ nanomaterials employed as photocatalysts in a concurrent photocatalytic and membrane filtration system for the simultaneous purification of water and the mitigation of membrane fouling under UV irradiation (Bae \& Ohno, 2009). In addition to these 
studies, the ability of $\mathrm{TiO}_{2}$ nanomaterials for clean energy generation have also been proven (O'Regan \& Gratzel, 1991). Of which, hydrogen generation through water splitting with the use of $\mathrm{TiO}_{2}$ is considered as a promising solution to global energy crisis due to its potential as a clean and perpetual resource of solar energy (Kudo \& Miseki, 2009). The process of $\mathrm{H}_{2}$ generation does not create undesirable by-products and pollutants. Furthermore, $\mathrm{H}_{2}$ energy is a form of storable energy which can be used to overcome the irregular characteristics and seasonal variation associated with solar energy.

However, the potential to photocatalytically degrade pollutants and generate renewable energy is very much dependent on the properties of the photocatalysts which influences its photocatalytic ability (Centi \& Perathoner, 2009). Despite the known advantages of $\mathrm{TiO}_{2}$ photocatalysts, there are two key limitations of $\mathrm{TiO}_{2}$ which limits its potential. First the generation of the photo-excited holes and electrons can only be achieved by UV irradiation $(\lambda<380 \mathrm{~nm})$ which renders the use of solar irradiation ineffective due to wide band gap of $\mathrm{TiO}_{2}$ (3.2 eV anatase) (Devi \& Kavitha, 2013). Second, the life time of photo-excited electrons are holes have limited mobility (Santato, Ulmann, \& Augustynski, 2001) arising from the recombination of electron-hole pair (Ansari \& Cho, 2016).

Therefore, it is essential to develop a nanomaterial in a favourable morphology with desirable photocatalytic properties. These include the ability to adsorb a larger spectrum of the wavelength and provide sufficient suppression to the recombination of electronhole pair. Hence, in this study the author will explore the use of composite nanostructures coupled with non-metal and metal dopants with emphasis to Bismuth and Carbon based materials due to its known advantages which will be deliberated in the subsequent sections. 


\subsection{Scope and Objective}

In this study, a novel nano-crystallised carbon composite one-dimensional $\mathrm{TiO}_{2}$ nanostructure will be employed for clean water and energy generation. The photocatalyst will be synthesised through novel approach of using sucrose as an external carbon source and to decompose the carbonaceous crystal in an inert calcination environment.

The objective of the study is as follows;

i. To synthesise one-dimensional $\mathrm{TiO}_{2}$ nanotubes and $\mathrm{TiO}_{2}$ nanofibers through electrochemical anodization and electrospinning methods respectively

ii. To characterise and study the photocatalytic performance of the different onedimensional $\mathrm{TiO}_{2}$ nanostructures under $\mathrm{UV}$ and visible light irradiation.

iii. To optimise the properties for photocatalytic applications through the study of the calcination temperature on the selected one-dimensional $\mathrm{TiO}_{2}$ nanostructures for subsequent band gap engineering.

iv. To determine the formation mechanism of the composite and nano-crystallised carbon composite one-dimensional $\mathrm{TiO}_{2}$ nanostructure using a variety analysis techniques.

v. To examine the nano-crystallised carbon composite one-dimensional $\mathrm{TiO}_{2}$ nanostructure and assess its potential to photocatalytically generate $\mathrm{H}_{2}$ under visible light. 


\subsection{Organisation of study}

This study is structured as follows:

Chapter One consists of an introduction to the theme research and general information of nanomaterials in water reclamation and energy generation. The rationale for research, objective and the organisation of report are also included.

Chapter Two reviews literature and past studies on the use and synthesis of Titanium Dioxide $\left(\mathrm{TiO}_{2}\right)$ nanomaterials and various morphological modification studies using metal and non-metal dopants.

Chapter Three presents the methods used in the synthesis of the one-dimensional nanostructures and provides details on the materials and equipment used in the study.

Chapter Four focuses on data analysis and discussion in which the results obtained from the characterisation and application study would be examined. The findings would be interpreted to determine the formation mechanism and photocatalytic ability of the novel photocatalyst.

Chapter Five comprises the research's conclusion, recommendations and proposes further study that can be conducted. 


\section{Literature Review}

The chapter reviews academic literature relating to Titanium Dioxide $\left(\mathrm{TiO}_{2}\right)$ based photocatalyst and presents a discussion on the environmental applications. Finally, a critique on the various methods and research would be discussed.

\subsection{Titanium Dioxide}

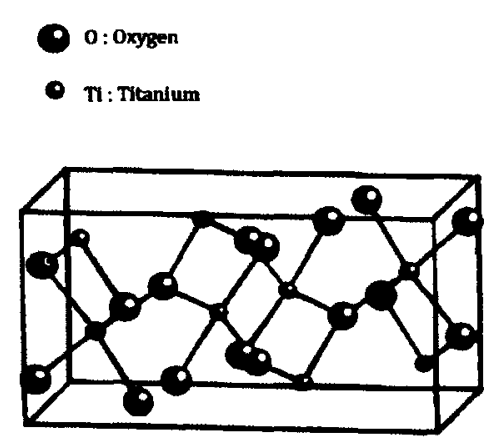

a) Brookite

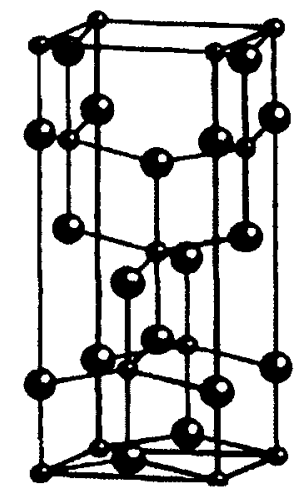

b) Anatase

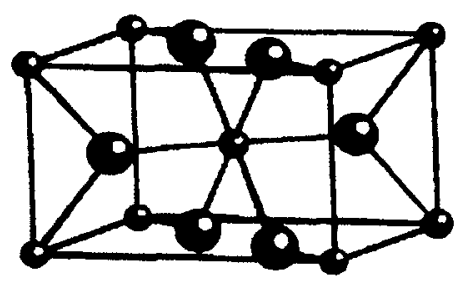

c) Rutile

Increasing Calcination Temperature

Figure 2.1 - Various crystalline structure of Titanium Dioxide $\left(\mathrm{TiO}_{2}\right)$ (a) Brookite (b) Anatase and (c) Rutile

Adapted from Esch, Bredow, and Gadaczek (2014)

Amongst the various semiconductor materials which have been extensively studied by researchers, Titanium Dioxide $\left(\mathrm{TiO}_{2}\right)$ has emerged as the most promising candidate. $\mathrm{TiO}_{2}$ was first developed and used by Fujishima and Honda (1972) for splitting of water on $\mathrm{TiO}_{2}$ electrode under ultraviolet (UV) light. Thenceforward, it has led to enormous efforts to further develop $\mathrm{TiO}_{2}$ for a broader range of applications which varies from common products such as sunscreen to advanced devices such as photovoltaic cells (Chen \& Selloni, 2014). Table 2.1 provides an overview of the applications of photocatalytic $\mathrm{TiO}_{2}$ in different sectors. 
Table 2.1 - Potential applications of titanium dioxide Photocatalyst

\begin{tabular}{|c|c|c|}
\hline Properties & Sub-category & Application \\
\hline Self-Cleaning & $\begin{array}{l}\text { Residential, } \\
\text { construction and other } \\
\text { practical applications }\end{array}$ & $\begin{array}{l}\text { - Exterior and interior furnishing } \\
\text { - Titles for kitchen and bathroom } \\
\text { - Indoor lightning } \\
\text { - Coatings on fluorescents lamps and } \\
\text { highway tunnel cover glass } \\
\text { - Tunnel walls, soundproof walls, traffic } \\
\text { signs and deflectors } \\
\text { - Spray coating for windscreens }\end{array}$ \\
\hline Disinfection & Air purifiers & $\begin{array}{l}\text { Room air cleaner, photocatalysts- } \\
\text { equipped air conditioners and interior } \\
\text { cleaner for factories } \\
\text { - Concrete for highways, roadways and } \\
\text { food paths }\end{array}$ \\
\hline Water purification & Water Reclamation & $\begin{array}{l}\text { River water, Ground water, lake and } \\
\text { Water storage tanks } \\
\text { - Drainage water and industrial wastewater } \\
\text { treatment }\end{array}$ \\
\hline Anti-carcinogenic & Therapy & - Endoscopic instruments \\
\hline Self-sterilisations & Hospitals, clinics & $\begin{array}{l}\text { - Titling and walls of operating rooms } \\
\text { - Silicon rubber for medical catheters } \\
\text { - Hospital uniforms } \\
\text { - Public restrooms, bathrooms }\end{array}$ \\
\hline
\end{tabular}

The wide array of its application can be attributed to its powerful oxidation and superior charge transport properties (Varghese, Paulose, LaTempa, \& Grimes, 2009) and the wide-band gap of $\mathrm{TiO}_{2}\left(\mathrm{E}_{\mathrm{g}} \approx 3.2 \mathrm{eV}\right)$ with suitable band-edge position which permits its use for photocatalytic reactions and in photovoltaic cells. Moreover, $\mathrm{TiO}_{2}$ is also known for its chemical stability where its non-involvement in mass transfer has led to an exponential growth of research to be conducted on the interactions of $\mathrm{TiO}_{2}$ materials with the environment (G. H. Liu, N. Hoivik, K. Y. Wang, \& H. Jakobsen, 2012).

In general, $\mathrm{TiO}_{2}$ exists in three main phases namely, anatase, brookite and rutile. Out of these, anatase and brookite subsist at lower temperatures and can be readily transformed into the most thermodynamically stable rutile phase at high temperature (Figure 2.1). In the anatase phase, it has been found that the surface energy of anatase is lower than those 
of rutile and brookite and has shown greater activity as a photocatalyst (Jagtap, Bhagwat, Awati, \& Ramaswamy, 2005). Further, the structural features of anatase titania coupled with its formation in various solution phase preparation method, has resulted in significant studies on single-phase nano-crystalline anatase titania (ReyesCoronado et al., 2008). The physiochemical properties of the various $\mathrm{TiO}_{2}$ crystalline phase is shown in Table 2.2.

Table 2.2 -Properties of Brookite, Anatase, and Rutile $\mathrm{TiO}_{2}$

\begin{tabular}{|l|c|c|c|}
\hline & Brookite & Anatase & Rutile \\
\hline Crystal structure & Orthorhombic & Tetragonal & Tetragonal \\
\hline Density $\left(\mathbf{g} / \mathrm{cm}^{3}\right)$ & 4.13 & 3.84 & 4.26 \\
\hline Cell Volume $\left(\mathbf{m}^{3}\right)$ & 257.63 & 34.061 & 31.216 \\
\hline Band gap, E $(\mathrm{eV})$ & 3.14 & 3.23 & 3.02 \\
\hline Refractive Index & 2.58 & 2.52 & 2.76 \\
\hline Permittivity & 50 & 48 & 86 \\
\hline Thermal Stability & Change to rutile type at high temperature & $\begin{array}{c}\text { High compared to } \\
\text { anatase }\end{array}$ \\
\hline
\end{tabular}

Source: (Di Paola, Bellardita, \& Palmisano, 2013; Shojaee, Abbasnejad, Saeedian, \& Mohammadizadeh, 2011)

\subsubsection{Photocatalysis using semiconductors}

Photocatalysis with the use of semiconductors photocatalysts is a viable approach to solve environmental challenges, it is a straightforward technique that utilises light energy in the form of photons to induce chemical transformation. The use of these semiconductor photocatalysts for the degradation of pollutants in aqueous solution has been considerably studied. To add to its benefits for pollutant degradation, the photocatalysis process also provides a viable alternative to produce green fuels such as hydrogen.

The general properties of a semiconductor photocatalyst is that it should be; (1) photostable, (2) chemically and biologically inert as well as most essentially (3) capable 
of adsorbing reactants under sufficient photonic activation $\left(h v \geq E_{g}\right)$. As illustrated in Figure 2.2, many semiconductors such as $\mathrm{TiO}_{2}, \mathrm{WO}_{3}, \mathrm{ZnS}$ etc have been examined for use as photocatalyst in environmental applications (Konstantinou, Sakkas, \& Albanis, 2002).

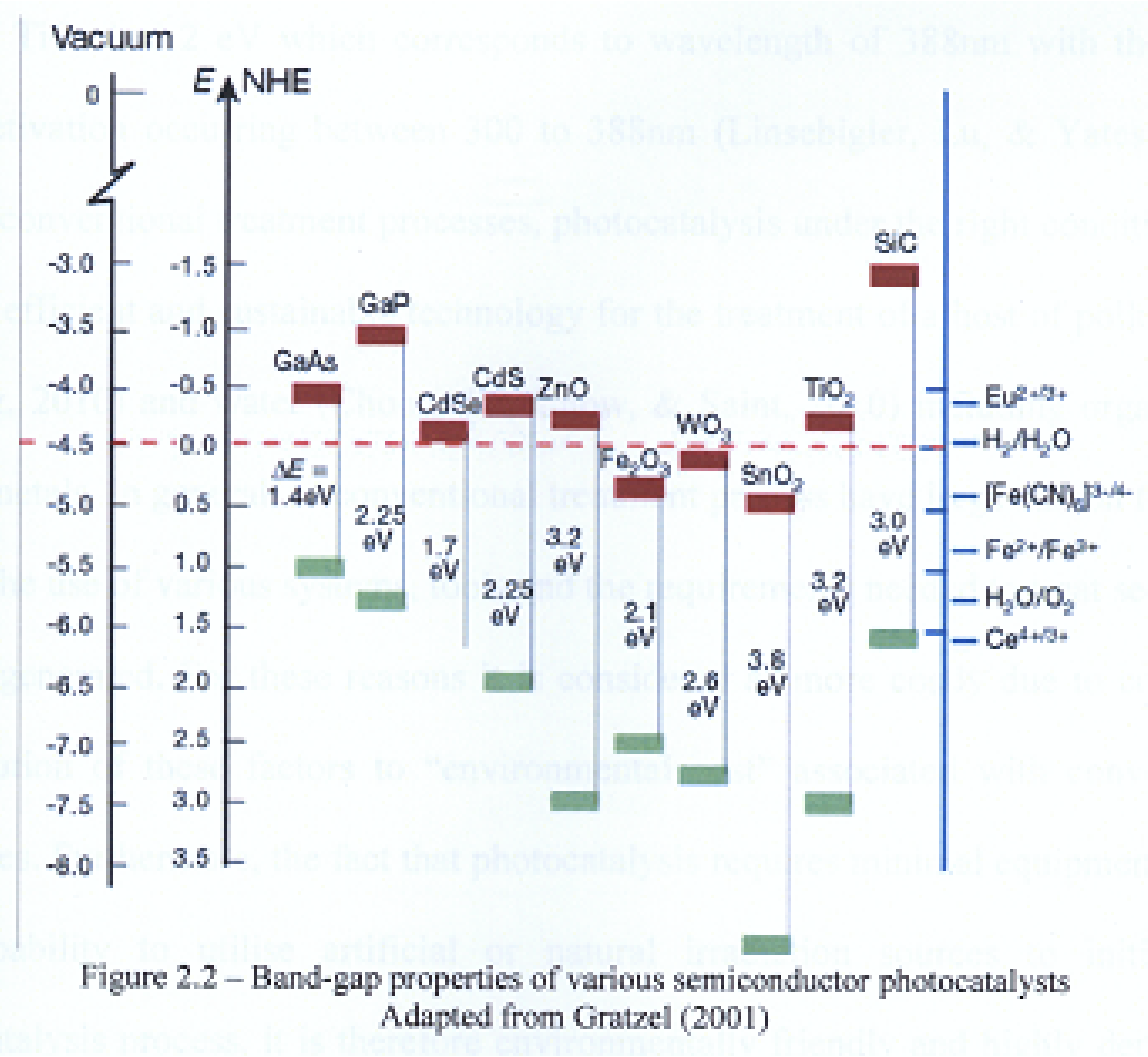

Currently, titanium dioxide $\left(\mathrm{TiO}_{2}\right)$ is the most widely used photocatalyst as it comprises the best balance of properties among the known or assessed semiconductors. $\mathrm{TiO}_{2}$ semiconductor photocatalyst is the most widely known for the stability of its chemical structure, biocompatibility, optical and electrical properties and can be found at low cost (G. H. Liu et al., 2012). Therefore, heterogeneous photocatalysis in the presence of $\mathrm{TiO}_{2}$ has been a research highlight in the past decades. As one of the promising technologies for water and wastewater treatment, heterogeneous photocatalysis is characterised by the generation of hydroxyl radicals $(\mathrm{OH} \cdot)$, which is a robust oxidant for organic pollutant 
degradation in water. Their appropriate band structures favour the generation and separation of photo-induced electron-hole pairs by the adsorption of UV irradiation.

The minimum activation energy required for photon to cause photogeneration of charge carriers from the filled valence band (VB) to the empty conduction band (CB) for anatase $\mathrm{TiO}_{2}$ is $3.2 \mathrm{eV}$ which corresponds to wavelength of $388 \mathrm{~nm}$ with the actual photoactivation occurring between 300 to $388 \mathrm{~nm}$ (Linsebigler, Lu, \& Yates, 1995). Unlike conventional treatment processes, photocatalysis under the right conditions can be cost efficient and sustainable technology for the treatment of a host of pollutants in air (Paz, 2010) and water (Chong, Jin, Chow, \& Saint, 2010) including organic and heavy metals. In general, as conventional treatment process have large carbon footprint due to the use of various systems, tools and the requirements needed to treat secondary wastes generated. For these reasons it is considered as more costly due to collective contribution of these factors to "environmental cost" associated with conventional processes. Furthermore, the fact that photocatalysis requires minimal equipment due to the capability to utilise artificial or natural irradiation sources to initiate the photocatalysis process, it is therefore environmentally friendly and highly deployable for developing countries.

Photocatalytic reactions involve three key stages: (i) adsorption of photons with sufficient energy that is equal to or higher than the band energy $\left(\mathrm{E}_{\mathrm{bg}}\right)$ of the photocatalyst; (ii) charge separation due to promotion of electrons $\left(\mathrm{e}^{-}\right)$from the valence band to the conduction band, thereby generating a hole $\left(\mathrm{h}^{+}\right)$in the valence band; and (iii) surface chemical reactions between these charge-carriers by various compounds. Following these key principles, the activated electron reacts with an oxidant or electron acceptors to produce a reduced product, while the generated holes reacts with a reductant to produce an oxidised product. Table 2.3 summarises the various photocatalytic 
reactions occurring on the surface of a $\mathrm{TiO}_{2}$ based semiconductor photocatalyst which includes an array of oxidation and reduction processes. For example, the photogenerated electrons react with oxygen $\left(\mathrm{O}_{2}\right)$ and reduces it to superoxide radical anion $\left(\mathrm{O}_{2}^{-}\right)$, which then forms hydroperoxyl radical (HOO) and subsequently hydrogen peroxide $\left(\mathrm{H}_{2} \mathrm{O}_{2}\right)$. Whilst the photogenerated holes react with water $\left(\mathrm{H}_{2} \mathrm{O}\right)$ and oxidises them into hydroxyl $(\mathrm{OH} \cdot)$ and hydrogen $\left(\mathrm{H}^{+}\right)$radicals that is responsible for the heterogeneous $\mathrm{TiO}_{2}$ photodecomposition of organic substrates (Cohen \& Heikkila, 1974).

Table 2.3 - Photocatalytic reactions at the semiconductor surface

\begin{tabular}{|c|c|c|}
\hline Reaction: & Equation: & \\
\hline Photo excitation & $\mathrm{TiO}_{2}+h v\left(U V_{\text {excitation }}\right) \rightarrow e_{\bar{C}_{\sigma}}^{-}+h_{V s}^{+}$ & $\ldots$ (1) \\
\hline $\begin{array}{l}\text { Oxidation of generated holes with } \\
\text { reductant }\end{array}$ & $h_{V B}^{+}+H_{2} \mathrm{O} \rightarrow \mathrm{H}^{+}+\mathrm{OH}$. & $\ldots(2)$ \\
\hline $\begin{array}{l}\text { Reduction of generated holes with } \\
\text { hydroxide }\end{array}$ & $h_{V B}^{+}+\mathrm{OH}^{-} \rightarrow \mathrm{OH}$ & $\ldots(3)$ \\
\hline Oxygen ionsoption & $\left(O_{2}\right)_{a d s}+e^{-} \rightarrow O_{2}^{-}$ & $\ldots(4)$ \\
\hline Ionization of water & $\mathrm{H}_{2} \mathrm{O} \rightarrow \mathrm{OH}^{-}+\mathrm{H}^{+}$ & $\ldots(5)$ \\
\hline Protonation of superoxides & $\mathrm{O}_{2}^{-}+\mathrm{H}^{+} \rightarrow \mathrm{HOO}$ & $\ldots(6)$ \\
\hline Co-scavenging of electrons & $\mathrm{HOO}+\mathrm{e}^{-} \rightarrow \mathrm{HOO}^{-}$ & $\ldots(7)$ \\
\hline Formation of hydrogen peroxide & $\mathrm{HOO}^{-}+\mathrm{H}^{+} \rightarrow \mathrm{H}_{2} \mathrm{O}_{2}$ & $\ldots(8)$ \\
\hline Formation of hydroxyl radical & $\mathrm{H}_{2} \mathrm{O}_{2}+\mathrm{O}_{2}^{-} \rightarrow \mathrm{OH} \cdot+\mathrm{OH}^{-}+\mathrm{O}_{2}$ & $\ldots(\theta)$ \\
\hline Degradation of Organic matter & $O M+O H \rightarrow$ degradation products & $\ldots(10)$ \\
\hline Oxidation of organic matter & $O M+h_{V B}^{*} \rightarrow$ oxidation products & $\ldots\langle 11\rangle$ \\
\hline Reduction of organic matter & $O M+\varepsilon_{C B}^{-} \rightarrow$ reduced products & $\ldots(12)$ \\
\hline Charge carrier trapping & $e_{C B}^{-} \rightarrow e_{T R}^{-}$or $h_{V B}^{+} \rightarrow h_{\tau R}^{+}$ & $\ldots(13)$ \\
\hline Recombination of electron hole pair & $e_{\bar{T} B}^{-}+h_{T R}^{+}\left(h_{v B}^{+}\right) \rightarrow e_{C B}^{-}+h e a t$ & $\ldots(14)$ \\
\hline
\end{tabular}

The photoinduced generation of electrons that occurs with an adsorbed species over a semiconductor photocatalyst depends on the band-edge position of the semiconductor and the redox potentials of the adsorbates (Fujishima, Rao, \& Tryk, 2000). Despite the extensive research activities conducted over the past two decades to search for an ideal photocatalyst, titania in its anatase form has remained a benchmark (W. F. Zhang, He, Zhang, Yin, \& Chen, 2000) for any emerging material candidate. The anatase form of 
$\mathrm{TiO}_{2}$ is reported to provide the best combination of photoactivity as well as stability photostability (Gaya \& Abdullah, 2008).

\subsection{One-Dimensional $\mathrm{TiO}_{2}$ semiconductor photocatalysts}

The efficiency of $\mathrm{TiO}_{2}$ semiconductor photocatalyst nanomaterials in its applications depends on two crucial factors; first the geometry of the nanomaterial to allow for better overall efficiency through maximisation of the specific surface area. Second the optical properties, which is related to the ability to absorb activation energy to generate photons for the reactions. Therefore this shows that the physiochemical properties of the semiconductor nanomaterials not only depend on the composition but as well as the structure, morphology, phase, shape, size, distribution and spatial arrangements (J. G. Hou et al., 2010).

In this section, the author will review the literature relating to one dimensional nanotublar and nanofibrous materials as they offer excellent mechanical properties and confined transport of electrons or photons which are ideal for photocatalytic reactions. Moreover, it is strongly suggested that these one-dimensional $\mathrm{TiO}_{2}$ nanostructures provides an excellent platform for the subsequent modifications to maximisation its photocatalytic efficiency.

\subsection{1. $\mathrm{TiO}_{2}$ nanotubes}

There are several different approaches that can be used to synthesis these onedimensional nanotubes which include electrochemical anodization, template techniques, hydrothermal process and soft chemical processes (X. Xu et al., 2011). Amongst these methods, $\mathrm{TiO}_{2}$ nanotubes synthesised from electrochemical anodization have shown potential due to the ability to form highly self-organised nanotubes with regular and controllable geometry (Roy, Berger, \& Schmuki, 2011). These nanotublar structures also possess higher photocatalytic activity as compared to other nanostructures due to 
high surface-to-volume ratio and vectorial electron percolation pathways $(\mathrm{Qu}, \mathrm{Zhang}$, Wang, \& Xie, 2005). Additionally, this technique used to synthesis $\mathrm{TiO}_{2}$ nanotubes is a simple and low-cost parallel process thus making it a favourable.

The synthesis of $\mathrm{TiO}_{2}$ nanotubes using the electrochemical anodization process is a versatile process. Self-organised oxide nanotubes or nanopores arrays can be obtained from a variety of metals in different electrolyte solutions. Essentially, this nonmechanical technique relies on an oxidation reaction which will be initiated when the metals are exposed to an anodic voltage in a configuration as shown in Figure 2.3.

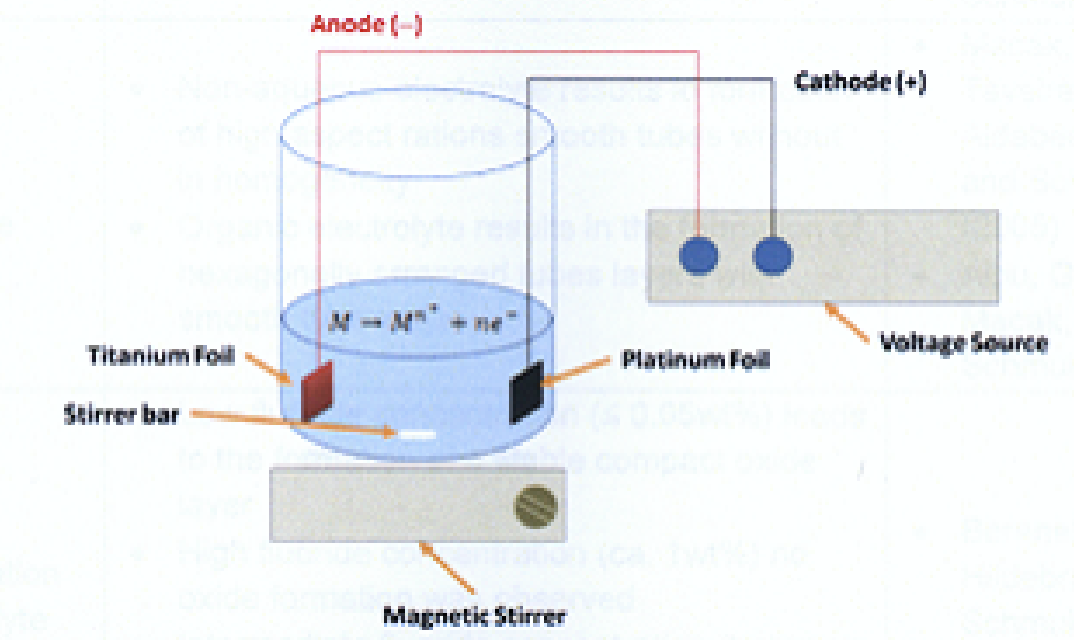

Figure 2.3 - Schematic representation of an electrochemical anodization set up Source: Author's

During the oxidation reaction the surface of the substrate is being converted, leading to the formation of an array of oxide nanotubes which self-orientates itself perpendicular to the substrate. However, the initiation of the oxidation reaction is affected by the properties of the electrolyte solution and various anodization parameters (Roy et al., 2011). The variation of the anodization conditions may result in the initiation of three reaction possibilities;

a. The metal ions are continuously being dissolved (i.e. corrosion or electro-polishing of the metal surface observed) 
b. The metal ions formed reacts with $\mathrm{O}^{2-}$ (provided by $\mathrm{H}_{2} \mathrm{O}$ in the electrolyte) and form a compact metal oxide (MO) layer if the $\mathrm{MO}$ is not soluble in the electrolyte

c. Formation of porous MO due to competition of "electro-polishing" and oxide formation

Table 2.4 - Effect of process parameter on resultant nanotubes morphology

\begin{tabular}{|c|c|c|}
\hline $\begin{array}{l}\text { Process } \\
\text { parameter }\end{array}$ & Effect on morphology & Reference \\
\hline $\begin{array}{l}\text { Multistage } \\
\text { Anodization }\end{array}$ & $\begin{array}{l}\text { - An optimised two-step anodization leads to } \\
\text { formation of perfect hexagonally ordered } \\
\text { arrays of } \mathrm{TiO}_{2}\end{array}$ & $\begin{array}{l}\text { - Macak, Albu, and } \\
\text { Schmuki (2007) }\end{array}$ \\
\hline $\begin{array}{l}\mathrm{pH} \text { of the } \\
\text { electrolyte }\end{array}$ & $\begin{array}{l}\text { - Affects the tube layer thickness } \\
\text { - Neutral PH allows tube to be grown longer }\end{array}$ & $\begin{array}{l}\text { Macak, Tsuchiya, } \\
\text { and Schmuki } \\
\text { (2005) and Macak, } \\
\text { Sirotna, and } \\
\text { Schmuki (2005) }\end{array}$ \\
\hline $\begin{array}{l}\text { Use of } \\
\text { different } \\
\text { Electrolyte } \\
\text { solutions }\end{array}$ & $\begin{array}{l}\text { Non-aqueous electrolyte results in formation } \\
\text { of high aspect rations smooth tubes without } \\
\text { in homogeneity } \\
\text { - Organic electrolyte results in the formation of } \\
\text { hexagonally arranged tubes layers with } \\
\text { smooth tube walls }\end{array}$ & $\begin{array}{l}\text { Macak, Tsuchiya, } \\
\text { Taveira, } \\
\text { Aldabergerova, } \\
\text { and Schmuki } \\
\text { (2005) } \\
\text { Albu, Ghicov, } \\
\text { Macak, and } \\
\text { Schmuki (2007) }\end{array}$ \\
\hline $\begin{array}{l}\text { Fluoride } \\
\text { concentration } \\
\text { in electrolyte }\end{array}$ & $\begin{array}{l}\text { - Low fluoride concentration ( } \leq 0.05 w t \% \text { ) leads } \\
\text { to the formation of a stable compact oxide } \\
\text { layer } \\
\text { - High fluoride concentration (ca. } 1 w t \%) \text { no } \\
\text { oxide formation was observed } \\
\text { - Intermediate fluoride concentration (between } \\
0.05 \% \text { to } 1 w t \% \text { ) results in the formation of } \\
\text { porous oxide or nanotubes. }\end{array}$ & $\begin{array}{l}\text { Beranek, } \\
\text { Hildebrand, and } \\
\text { Schmuki (2003) }\end{array}$ \\
\hline $\begin{array}{l}\text { Water content } \\
\text { in electrolyte }\end{array}$ & $\begin{array}{l}\text { - Controls the morphology of the nanotubes } \\
\text { walls by affecting growth rate and chemical } \\
\text { dissolution rate. } \\
\text { - Low water content, formation of smooth walls } \\
\text { - High water content, the walls ripples }\end{array}$ & $\begin{array}{l}\text { (Jan M. Macak, } \\
\text { Hiroaki Tsuchiya, } \\
\text { et al., 2005) } \\
\text { Macak, Hildebrand, } \\
\text { Marten-Jahns, and } \\
\text { Schmuki (2008) }\end{array}$ \\
\hline $\begin{array}{l}\text { Anodization } \\
\text { Voltage }\end{array}$ & $\begin{array}{l}\text { - Linearly controls the length of the nanotubes } \\
\text { - Higher applied voltage, larger the nanotubes } \\
\text { diameter resulting from changes in the } \\
\text { conductivity of the electrolyte over time }\end{array}$ & - Macak et al. (2008) \\
\hline $\begin{array}{l}\text { Anodization } \\
\text { Time }\end{array}$ & $\begin{array}{l}\text { Controls the diameter of nanotubes it was } \\
\text { observed that at higher voltage, larger } \\
\text { diameter will be obtained } \\
\text { - Longer anodization time leads to formation } \\
\text { of "V-shaped nanotubes" }\end{array}$ & - K. Lee et al. (2009) \\
\hline
\end{tabular}


Therefore it is important to understand the impacts of these process parameters on the morphology of the nanotubes. It will allow the optimisation so as to achieve the desired $\mathrm{TiO}_{2}$ morphology for its relevant application. The cause and effect of these parameters were studied in detailed by several researchers and their findings are summarised in Table 2.3.

\subsubsection{Reaction Pathway}

The growth of the $\mathrm{TiO}_{2}$ nanotubes on surface of the titanium foils are governed three possible reaction routes (J. M. Macak et al., 2007). These routes are controlled by the competition between the reactions in Equations 1 and 2.

$$
\begin{gathered}
\mathrm{Me}+2 \mathrm{H}_{2} \mathrm{O} \rightarrow \mathrm{MeO}_{2}+4 \mathrm{H}^{+}+4 e^{-} \ldots(1) \\
\mathrm{MeO}_{2}+6 \mathrm{~F}^{-} \rightarrow\left[\mathrm{MeF}_{6}\right]^{2-} \ldots(2)
\end{gathered}
$$

As well as the complexation of high-field transport cations at the oxide electrolyte interface.

$$
M e^{4+}+6 F^{-} \rightarrow\left[M^{2} F_{6}\right]^{2-}
$$

Equation 1 illustrates the growth of the oxide layer on the anodized metal surface in a fluoride-free electrolyte under a constant applied voltage. During this, the oxidised metals species reacts with the $\mathrm{O}^{2-}$ ion found in $\mathrm{H}_{2} \mathrm{O}$ resulting in the formation and growth of an oxide layer. Further oxide growth is controlled by field aided ion transport $\left(\mathrm{O}^{2-}\right.$ and $\mathrm{Ti}^{4+}$ ions) through the growing oxide. 


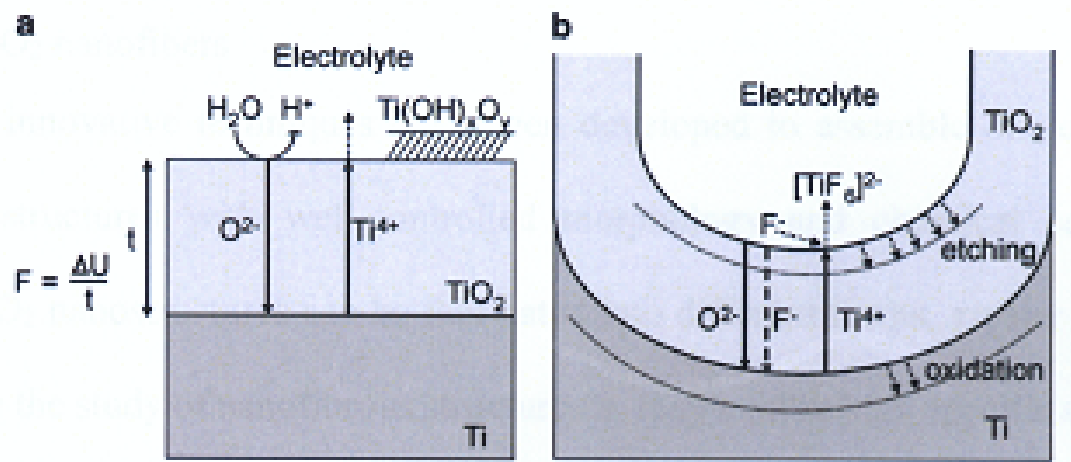

Figure 2.4-Schematic representation of the Ti anodization (a) in absence of fluorides (results in flat layers), and (b) in presence of fluorides (results in the tube growth) Adapted from J. M. Macak et al. (2007)

Figure 2.4(a) depicts a schematic current-time transient for anodization of $\mathrm{Ti}$ in a fluoride-free electrolyte. The decrease field strength leads to an exponential current decay which results in the growth of a compact oxide layer with a finite thickness. However, if the $\mathrm{Me}^{4+}$ ions arriving at the oxide/electrolyte interface are not made soluble, it will result in the precipitation of a hydroxide layer (Taveira, Macák, Tsuchiya, Dick, \& Schmuki, 2005). The formation of a porous hydroxide layer does not affect the electrical field effects, but retards the diffusivity of the $\mathrm{Me}^{4+}$ ions.

On the contrary, also demonstrated in J. M. Macak et al. (2007) work the presence of fluoride ions in the electrolyte clearly affects the anodization process owing to the formation of water soluble $\left[\mathrm{MeF}_{6}\right]^{2-}$ species in accordance to Equation 3. The formation of these metal fluoride complex leads to a permanent dissolution at the surface of the metal substrate and thus prevents the precipitation of the hydroxide layer due the fact that the $\mathrm{Me}^{4+}$ ions arriving at the interface can be solvatised into $\left[\mathrm{MeF}_{6}\right]^{2-}$ before it precipitates (Equation 2). In addition to formation of complexes, the development of a small ionic radius allows the diffusion transport of these complexes to the growing $\mathrm{TiO}_{2}$ lattice through the oxide due to the applied electrical field. 


\subsection{2. $\quad \mathrm{TiO}_{2}$ nanofibers}

Numerous innovative techniques have been developed to assemble one-dimensional $\mathrm{TiO}_{2}$ nanostructures with well-controlled morphology and chemical composition. Though $\mathrm{TiO}_{2}$ nanostructures can be fabricated into different forms, greater attention is accorded to the study of nanofibrous structures as they exhibit high specific surface area for photocatalytic applications. Accordingly, nanofibers can be synthesised using several methods which includes electrospinning, electrodeposition, pulsed laser deposition, micelle, and hydrothermal (Ashkarran \& Mahmoudi, 2010). Electrospinning has been proven to be one of the simplest and most versatile methods in producing nanofibers amongst them.

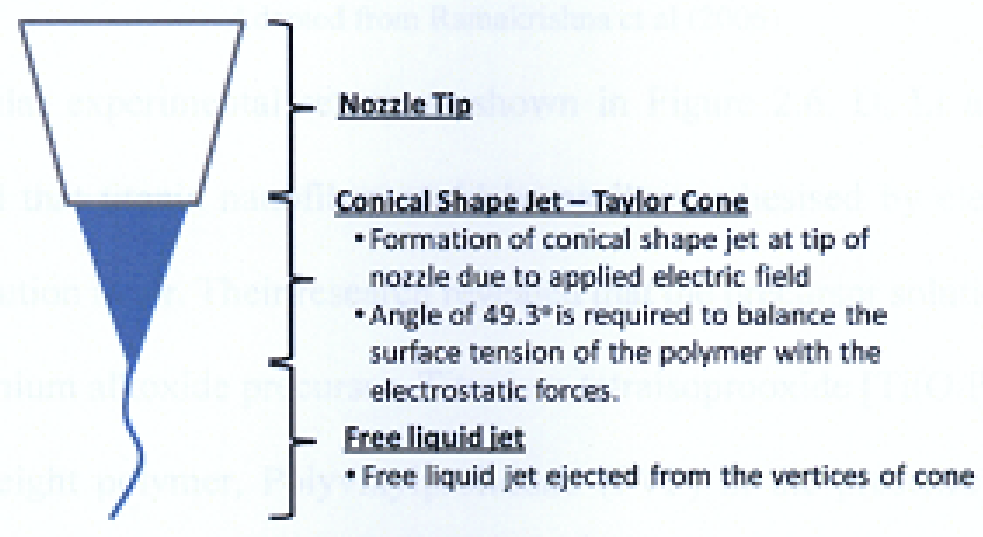

Figure 2.5 - Formation of Taylor Cone Source: Author's

The electrospinning process is capable of synthesising nanofiber from a rich variety of materials including polymer, composite and ceramics (Chronakis, 2005). This nonmechanical technique relies on an electric field to deform a conical droplet (Taylor cone - Figure 2.5) of polymer solution injected from a nozzle tip to form ultra-fine fibers. Renker and Chun (1996) elaborated that as the polymer emerged from the nozzle tip, it would be accelerated and stretched by the electric field, causing the diameter of the jet to decrease and the length to increase (Figure 2.6). In addition, the evaporation of high 
vapour pressure solvents would cause the jet diameter and velocity to decrease. This jet eventually solidifies on the collector in the form of nanofibers.

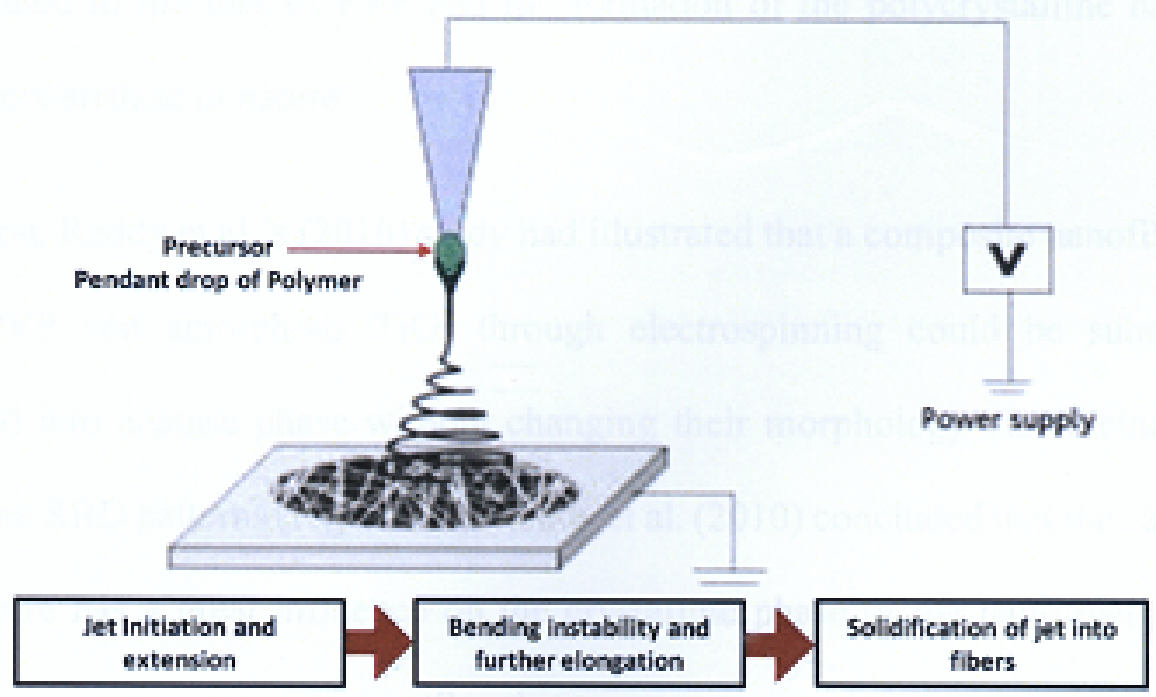

Figure 2.6 - Stages in Electrospinning

Adapted from Ramakrishna et al (2006)

Using a similar experimental set up as shown in Figure 2.6, D. Li and Xia (2003) demonstrated that titania nanofiber could be easily synthesised by electrospinning a precursor solution in air. Their research revealed that the precursor solution prepared by mixing a titanium alkoxide precursor, Titanium tetraisoprooxide $\left[\mathrm{Ti}(\mathrm{O} i \mathrm{Pr})_{4}\right]$ and a high molecular weight polymer, Polyvinylprolidone (PVP) in the presence of an alcohol solution could be used to prepare a $\mathrm{TiO}_{2} / \mathrm{PVP}$ composite nanofiber. In the same study, D. Li and Xia pointed out that PVP was an ideal base polymer due to its solubility in alcohols and its compatibility to some titania precursor despite its high molecular weight. Furthermore, the inclusion of acetic acid in the solution has the ability to stabilise and control the hydrolysis reaction of the sol-gel precursor.

In their characterisation of the $\mathrm{TiO}_{2} / \mathrm{PVP}$ composite nanofibers, it was observed that these nanofibers ejected from a solution of $0.03 \mathrm{~g} / \mathrm{mL} \mathrm{PVP} \mathrm{and} 0.1 \mathrm{~g} / \mathrm{mL} \mathrm{Ti}(\mathrm{O} i \mathrm{Pr})_{4}$ were uniform in cross section with an average sample diameter of $78 \pm 9 \mathrm{~nm}$. However, it was found that the structures remained continuous (i.e. the morphology was not affected) 
and their average diameters were reduced to $53 \pm 8 \mathrm{~nm}$ after going through calcination at $500^{\circ} \mathrm{C}$ for 3 hours. $\mathrm{D}$. Li and $\mathrm{Xia}(2003)$ hence deduced that the size reduction could be attributed to the loss of PVP and the formation of the polycrystalline nanofibers which were anatase in nature.

In addition, Reddy et al.'s (2010) study had illustrated that a composite nanofiber made up of PVP and amorphous $\mathrm{TiO}_{2}$ through electrospinning could be subsequently converted into anatase phase without changing their morphology via calcination. As seen in the XRD patterns (Figure 2.7), Reddy et al. (2010) concluded that the calcination temperature has a great influence on the crystalline phase of the nanofiber since the crystallisation of anatase and rutile phases was occurred at $\sim 450^{\circ} \mathrm{C}$ and $\sim 550^{\circ} \mathrm{C}$, respectively.

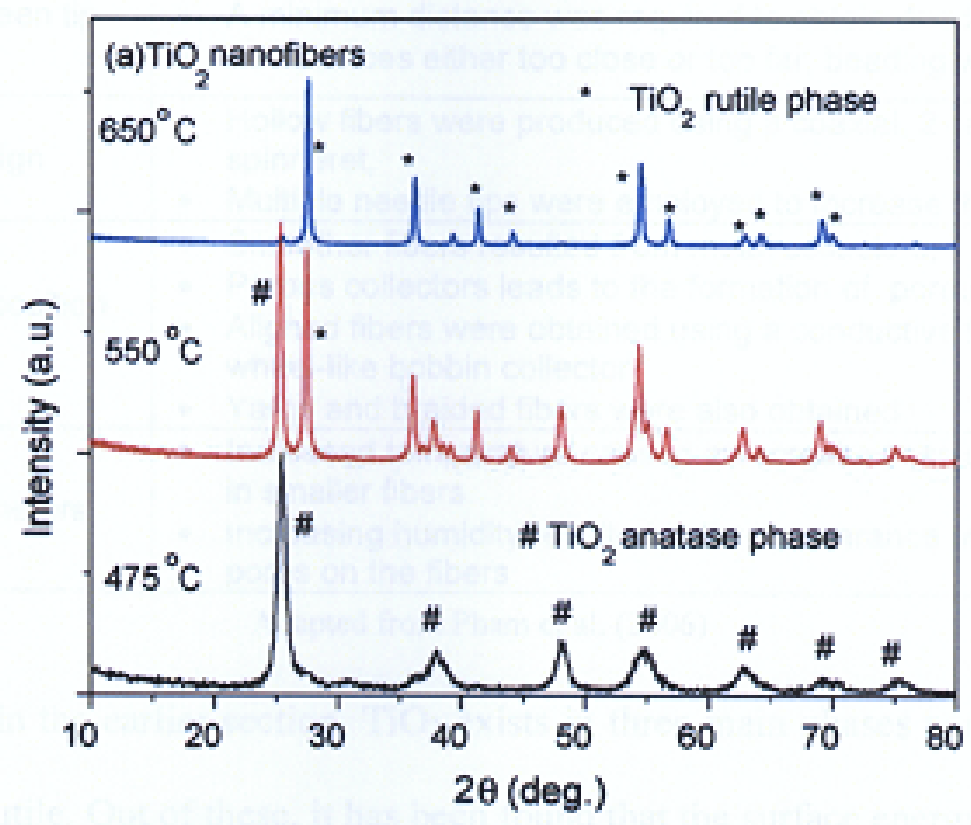

Figure 2.7 - X-ray diffraction pattern $\mathrm{TiO}_{2}$ electrospun nanofibers Adapted from Reddy et al. (2010) 
Table 2.5 - Effect of process parameter on the resultant nanofiber morphology

\begin{tabular}{|c|c|}
\hline Process parameter & Effect on fiber morphology \\
\hline Viscosity/concentration & $\begin{array}{l}\text { Low concentrations/viscosities yielded defects in the form of } \\
\text { beads and junctions; increasing concentration/viscosity } \\
\text { reduced the defects } \\
\text { - Fiber diameters increased with increasing } \\
\text { concentration/viscosity }\end{array}$ \\
\hline $\begin{array}{l}\text { Conductivity/solution } \\
\text { charge density }\end{array}$ & $\begin{array}{l}\text { - Increasing the conductivity aided in the production of uniform } \\
\text { bead-free fibers } \\
\text { - Higher conductivities yielded smaller fibers in general } \\
\text { (exceptions were PAA and polyamide-6) }\end{array}$ \\
\hline Surface tension & $\begin{array}{l}\text { - No conclusive link established between surface tension and } \\
\text { fiber morphology }\end{array}$ \\
\hline $\begin{array}{l}\text { Polymer molecular } \\
\text { weight }\end{array}$ & $\begin{array}{l}\text { - Increasing molecular weight reduced the number of beads and } \\
\text { droplets }\end{array}$ \\
\hline $\begin{array}{l}\text { Dipole moment and } \\
\text { dielectric constant }\end{array}$ & $\begin{array}{l}\text { - Successful spinning occurred in solvents with a high dielectric } \\
\text { constant }\end{array}$ \\
\hline Flow rate & $\begin{array}{l}\text { - Lower flow rates yielded fibers with smaller diameters } \\
\text { - High flow rates produced fibers that were not dry upon } \\
\text { reaching the collector }\end{array}$ \\
\hline Field strength/voltage & $\begin{array}{l}\text { - At too high voltage, beading was observed } \\
\text { - Correlation between voltage and fiber diameter was } \\
\text { ambiguous }\end{array}$ \\
\hline $\begin{array}{l}\text { Distance between tip } \\
\text { and collector }\end{array}$ & $\begin{array}{l}\text { - A minimum distance was required to obtain dried fibers } \\
\text { - At distances either too close or too far, beading was observed }\end{array}$ \\
\hline Needle tip design & $\begin{array}{l}\text { - Hollow fibers were produced using a coaxial, } 2 \text { capillary } \\
\text { spinneret, } \\
\text { - Multiple needle tips were employed to increase throughput }\end{array}$ \\
\hline $\begin{array}{l}\text { Collector composition } \\
\text { and geometry }\end{array}$ & $\begin{array}{l}\text { - Smoother fibers resulted from metal collectors; } \\
\text { - Porous collectors leads to the formation of porous fiber } \\
\text { - Aligned fibers were obtained using a conductive frame or a } \\
\text { wheel-like bobbin collector } \\
\text { - Yarns and braided fibers were also obtained }\end{array}$ \\
\hline Ambient parameters & $\begin{array}{l}\text { - Increased temperature caused a decrease in solution viscosity } \\
\text { in smaller fibers } \\
\text { - Increasing humidity resulted in the appearance of circular } \\
\text { pores on the fibers }\end{array}$ \\
\hline
\end{tabular}

Adapted from Pham et al. (2006)

As suggested in the earlier section, $\mathrm{TiO}_{2}$ exists in three main phases namely, anatase, brookite and rutile. Out of these, it has been found that the surface energy of anatase is lower than those of rutile and brooktite and has shown greater activity as a photocatalyst (Jagtap et al., 2005). Further, the structural features of anatase titania coupled with its favoured formation in a solution phase preparation method for $\mathrm{TiO}_{2}$, has resulted in significant studies on single-phase nanocrystalline anatase titania nanofibers (Reyes- 
Coronado et al., 2008). Though the above mentioned electrospinning process may be simple, understanding the impacts of the process parameters on the morphology of the electrospun nanofibers would allow experimental conditions to be regulated to achieve the desired $\mathrm{TiO}_{2}$ fiber morphology for its relevant application. The cause and effect of these parameters were studied in detailed by Pham et al. (2006). Their findings are summarised in Table 2.4 .

Researchers has found that these nanofibers have exhibited effective removal $(\sim 100 \%$ rejection) of airborne particles with diameter between 1 to $5 \mu \mathrm{m}$ by means of physical trapping and adsorption (Kulkarni, Bambole, \& Mahanwar, 2010) and it is also instrumental in mitigating of air pollution. Besides, (Ramakrishna et al., 2006) revealed that nanofiber membranes allow for both the physical separation of particles in aqueous solution and can be recovered easily. Electrospun nanofibers also have the ability of removing organic wastes and volatile organic carbons (Oh et al., 2008). Heavy metals can be eliminated by nanofibers as they are carriers of reactive nanomaterial which attract heavy metals by adsorption and electrostatic attraction (Lu, Wang, \& Wei, 2009).

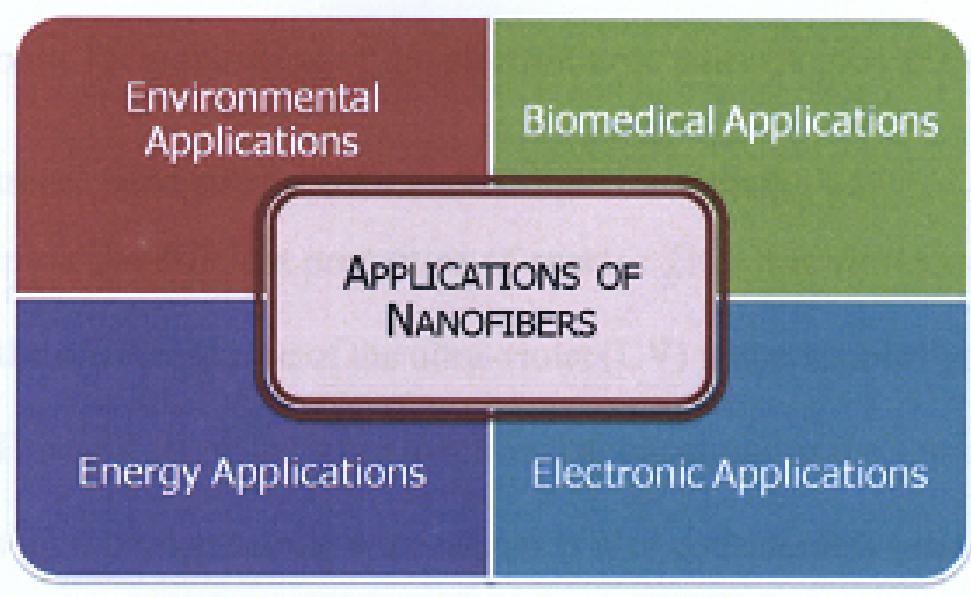

Figure 2.8-Applications of Nanofibers Source: Author 
With the rapid advancement in the field of science and engineering, recent studies have found that the fabrication of composite nanomaterials with the broadest range of properties and applications is achievable ( $\mathrm{Lu}$ et al., 2009). The advantages of these composite nanomaterials include having higher mobility of charge carriers which enhances the photocatalytic performance (Shang et al., 2010) as well as improve absorption of irradiation. Essentially, the above characteristics and potential when harnessed would create more opportunitics in environmental applications.

\subsection{Strategies to enhance photocatalytic performance}

The suitability of a one-dimensional $\mathrm{TiO}_{2}$ nanostructures for a photocatalytic applications is heavily reliant on the development of well-engineered composition, geometry, crystallography, and the successful integration with other dopants (X. Wang, $\mathrm{Li}$, Shi, \& Yu, 2014). As previously discussed, there are two key limitations of $\mathrm{TiO}_{2}$ which restricts its potential. First the generation of the photo-excited holes and electrons can only be achieved by UV irradiation $(\lambda<380 \mathrm{~nm})$ which renders the use of solar irradiation inefficient due to wide band gap of $\mathrm{TiO}_{2}$ (3.2 eV anatase) (Devi \& Kavitha, 2013). Second, these photo-excited electrons are holes have limited mobility and lifetime due to the recombination of the electron-hole pairs (Ansari \& Cho, 2016).

\subsubsection{Electronic band structure for visible-light harvesting}

In order to exploit the efficient properties of anatase $\mathrm{TiO}_{2}$ it is vital to shift the optical activity from the onset response of the ultra-violet (UV) to the visible light region (Chen et al., 2005). This will allow for more functional applications as the suitability of a $\mathrm{TiO}_{2}$ nanomaterials for a photocatalytic applications is also considerably related to its optical properties.

There are serval approaches that can be employed to tackle these issues. The first approach is the coupling of metal oxides aimed to modify the properties of the 
conduction band of the $\mathrm{TiO}_{2}$ nanomaterials thereby improving its performance and simultaneously altering the surface properties. Furthermore this will allow for enhanced the charge transfer properties of $\mathrm{TiO}_{2}$ to the surrounding environment. The second approach is the doping of elements with $\mathrm{TiO}_{2}$ nanomaterials to narrow the electronic properties thereby altering its optical properties to absorb a larger spectrum of wavelength (Chen \& Mao, 2007).

\subsubsection{Composite $\mathrm{TiO}_{2}$ nanostructures}

It is desirable to maintain the crystal properties of the anatase $\mathrm{TiO}_{2}$ host material and to produce favourable changes in electronic structure. Chen and Mao (2007) suggests that is it simpler to substitute the $\mathrm{Ti}^{4+}$ cation in the $\mathrm{TiO}_{2}$ with other transition metals. This is due to the difference in charge states and ionic radii between the $\mathrm{Ti}^{4+}$ cation and $\mathrm{O}^{2-}$ anion. Chen \& Mao further implied that the size of the nanomaterial also influences the ability to form a composite couples with the metal oxides. The smaller the size of the $\mathrm{TiO}_{2}$ nanostructure the higher the tolerance to structural distortion therefore allowing easier modification to be made to the chemical composition of $\mathrm{TiO}_{2}$

The synthesis can be done by altering the crystalline phase, morphology, dimensionality and the specific surface area of the $\mathrm{TiO}_{2}$ nanotubes. This alteration may increase both their photocatalytic activities and adsorption efficiencies (J. Ng, J. H. Pan, \& D. D. Sun, 2011). Therefore, it is likely by simply altering the crystalline phase, morphology, dimensionality and specific surface area of the nanotubes, it is possible to increase its photocatalytic activity and adsorption efficiencies by virtue of their induced shape and size dependent properties (J. Ng et al., 2011).

Different metals have been used for formation of composite $\mathrm{TiO}_{2}$ nanostructure. Of recent, Bismuth titanates (BTO) (J. Xu et al., 2011) systems has drawn a significant 
amount of research emphasis owing to their unique optical properties and potential applications (T. Cao, Li, Wang, Zhang, et al., 2011). These nanostructural bismuth nanomaterials have shown to be a valuable photocatalyst that can effectively and efficiently break down Rhodamine $\mathrm{B}(\mathrm{RhB})$ and Methyl Orange $(\mathrm{MO})$ pollutant in water under UV and visible light, respectively (C. Wang et al., 2009).

BTO systems comprises various molecular composition of Bi:Ti:O but it is widely revealed that these systems are known to be photoactive in the visible light region. As demonstrated by Murugesan, Huda, Yan, Al-Jassim, and Subramanian (2010), they highlighted the properties of BTO structure. Their observed findings indicated that the Bi 6 s orbital helps to shift the valence band upwards. It was observed that there was a shift in conduction band that was attributed to the empty d orbitals of the $\mathrm{Ti}$ atoms coupled with the $\mathrm{Bi} 6 \mathrm{p}$ states. This further illustrates the presence of the Bi does not only aid in the shift of the valance band but also enhances the synchronised mixing of the p-orbital in the conduction band which improves the electron transfer process.

Feng Yao et al. (2003) also demonstrated the potential of $\mathrm{Bi}_{12} \mathrm{TiO}_{20}$ nanocrystals prepared by chemical solution decomposition method for the photo-degradation of MO under UV irradiation. It was reported that the prepared nanocrystals had improved photocatalytic performance as compared to pure anatase $\mathrm{TiO}_{2}$ nanoparticles. Similarly, J. G. Hou et al. (2010) fabricated variations of BTO hierarchical assemblies under hydrothermal conditions and studied the visible light photocatalytic performance of these assemblies. In their work, they showed that the BTO structure exhibited significant increase in photoabsorption and shift of the adsorption edge to a longer wavelength in the visible light region. Moreover, through their morphological studies, it is understood that "microflower" and nanowires (nanofiber) morphologies provided better photocatalytic ability in the degradation of $\mathrm{RhB}$ under visible light irradiation. 
BTO nanosheets synthesised by T. Zhou and Hu (2010) through wet chemical synthesis reported to possess efficient separation of electron-hole pair thus results in improved photocatalytic activity. They revealed that optimum condition for the synthesis at a ratio of UREA/Bismuth $=3$ resulted in smaller sheet size comprising of highly crystalline metastable titanate. It was also proposed in their work that the surface structure has a significant impact on the photocatalytic performance.

Bi-doped $\mathrm{TiO}_{2}$ electrospun nanofiber prepared by J. Xu et al. (2011) showed improved photocatalytic activity in the degradation of $\mathrm{RhB}$ under visible light irradiation resulting from efficient separation of photogenerated electron and holes. In their work, they demonstrated that $3 \%$ percent Bismuth content was ideal for improving the visible light absorption capacity due to the introduction of new energy states formed by $\mathrm{Bi}$.

Cao et al. (2011) also demonstrated the possibility of the formation of BTO system heterostructures. The $\mathrm{Bi}_{4} \mathrm{Ti}_{3} \mathrm{O}_{12} / \mathrm{TiO}_{2}$ heterostructures were fabricated in a two-step synthesis comprising of an electrospinning and subsequent hydrothermal process at high temperatures. The heterostructured $\mathrm{BTO} / \mathrm{TiO}_{2}$ nanofiber showed enhanced visible light absorption and increased photocatalytic degradation of $\mathrm{RhB}$ under visible light illumination due to the fact that the $\mathrm{Bi}_{4} \mathrm{Ti}_{3} \mathrm{O}_{12}$ nanosheets could absorb visible light and produce electron-hole pairs. Cao et al. also proposed that the electrons will flow from the $\mathrm{Bi}_{4} \mathrm{Ti}_{3} \mathrm{O}_{12}$ nanosheets to the $\mathrm{TiO}_{2}$ submicron fibers thus increasing the lifetime of the charge carriers which is beneficial for improving the photoactivity. 


\subsubsection{Non-metal doping}

Non-metal doping is another approach used to modify UV-light active properties of $\mathrm{TiO}_{2}$ photocatalysts (3.2eV) to absorb visible light (Y un, Palanivelu, Kim, Kang, \& Lee, 2008). Unlike metal dopants, non-metal dopants are widely used to narrow the band gap and improve the visible light driven activity. This is achieved through shift of the valence band upwards instead of formation of donor levels (Chen, Shen, Guo, \& Mao, 2010).

Various non-metal elements have been successful doped into $\mathrm{TiO}_{2}$ nanomaterials with the intent to achieve the desired narrowing of band-gap. Carbon coating of photocatalyst anatase type $\mathrm{TiO}_{2}$ was found to provide several advantages such as the retention of the anatase phase, high photocatalytic activity, high adsoprtivity thus allowing to the employed for various photocatalytic processes (M. Inagaki, Kojin, Tryba, \& Toyoda, 2005).

Michio Inagaki, Hirose, Matsunaga, Tsumura, and Toyoda (2003) showed that with the use of carbon to coat $\mathrm{TiO}_{2}$ particles, it provides additional adsorption functionality to particles without reducing its photocatalytic efficiency. A subsequent work by Michio Inagaki et al. (2003), revealed that carbon coated anatase- $\mathrm{TiO}_{2}$ particles can be prepared by precipitating an aqueous solution of poly(vinyl alcohol) followed by heat treatment at elevated temperatures under high purity argon. The carbon coated anatase- $\mathrm{TiO}_{2}$ particles had a carbon layer with a BET surface area of $900 \mathrm{~m}^{2} / \mathrm{g}$ which enhanced its photocatalytic activity in the degradation of methylene blue. These findings were justified by M. Inagaki et al. (2005), where they demonstrated that the carbon-coated $\mathrm{TiO}_{2}$ samples had a relative large adsorption capacity due to its ability to degrade the model pollutant through its adsorptivity and its photodecompositon ability. 
Besides enhancing its absorption ability, M. Inagaki et al. (2005) believed that a carbon layer provides different roles in enhancing the efficiency of the semiconductor photocatalyst. The carbon layer on the photocatalyst allows the ability to suppress phase transformation from anatase to rutile allowing calcinations at higher temperature. This inhibits the formation of less active rutile crystals thereby maintaining the effectiveness of the anatase $\mathrm{TiO}_{2}$ photocatalyst.

Studies from several research also revealed that it is possible to substitute oxygen atoms with carbon atoms thus lowering the band gap of the $\mathrm{TiO}_{2}$ nanomaterials. Irie, Watanabe, and Hashimoto (2003) demonstrated the potential of C-doped anatase $\mathrm{TiO}_{2}$ powders that were obtained through oxidation of commercial TiC powders under extended hours. Through their study, it showed that the $\mathrm{C}$ substituted into and occupied the $\mathrm{O}$ sites thus shifting the absorbance edge to the visible light region. This finding was also supported by Khan, Al-Shahry, and Ingler (2002) where they revealed that the substitution achieved through a flame pyrolysis the $\mathrm{TiO}_{2}$ nanomaterials were chemically modified thus resulting in a decrease in the band-gap energy $(2.32 \mathrm{eV})$. This allowed the absorption of wavelengths below $545 \mathrm{~nm}$. Additionally, they demonstrated the ability of the chemically modified $\mathrm{TiO}_{2}$ for water splitting with a reported total conversion efficiency of $11 \%$ when illuminated with visible light irradiation.

Choi, Umebayashi, and Yoshikawa (2004) prepared C-doped anatase $\mathrm{TiO}_{2}$ samples prepared through acid-catalysed sol gel method and calcined the $400^{\circ} \mathrm{C}$. The formation of impurity states from the $\mathrm{C}$-doping process due to the incorporation of $\mathrm{C}$ on to the $\mathrm{O}$ sites of the $\mathrm{TiO}_{2}$ lattice. This inevitably resulted in the lowering of band energy which consequentially led to the red shift of the optical spectrum. This C-doped anatase $\mathrm{TiO}_{2}$ also demonstrated photocatalytic activity towards MB under visible light irradiation. 


\subsubsection{Photoexcitation and recombination}

The photocatalytic efficiency of $\mathrm{TiO}_{2}$ photocatalyst depends on the photoexcitation and recombination. This behaviour was studied in detail by G. Liu, N. Hoivik, K. Wang, and H. Jakobsen (2012). In a typical photocatalysis reaction shown in Equation 4 the holes $\left(h^{+}\right)$and electrons $\left(e^{-}\right)$are generated when photon energy, $h v$ equals or exceeds the band gap of the semiconductor is absorbed. This causes the photoexcited electrons $\left(\mathrm{e}^{\mathrm{e}}\right)$ to travel from the valence band to the empty conduction band thus leaving a hole in the valence band (Figure 2.3a).

$$
\mathrm{TiO}_{2}+h v \rightarrow h^{+}+e^{-}
$$

Note: The $h^{+}$denotes the holes left behind in the valence band and the $e^{-}$denotes the photo excited electrons

The generated photogenerated electrons and holes may undergo different reaction pathways as illustrated in Figure 2.9.a. The electrons and holes may experience intraband transitions, migration to the surfaces, get trapped at the trap sites or recombine. This rate of charge transfer depends on the band edge position of the band gap and the redox potential of the absorbate species as discussed by Inoue, Fujishima, Konishi, and Honda (1979) and Halmann, Ulman, and Aurian-Blajeni (1983)

When the electrons and holes migrate to the surface they are trapped at the edge of the conduction band and the valance band respectively. At the edge of conduction band, the trap sites serves as reduction zones where the semiconductors donates electrons to the acceptors. Whilst at the end of valence band, the holes behaves as oxidation sites where they combine with the electrons of the donor species (Phairat, Dena, Amornvadee, \& Paitoon, 2006). 


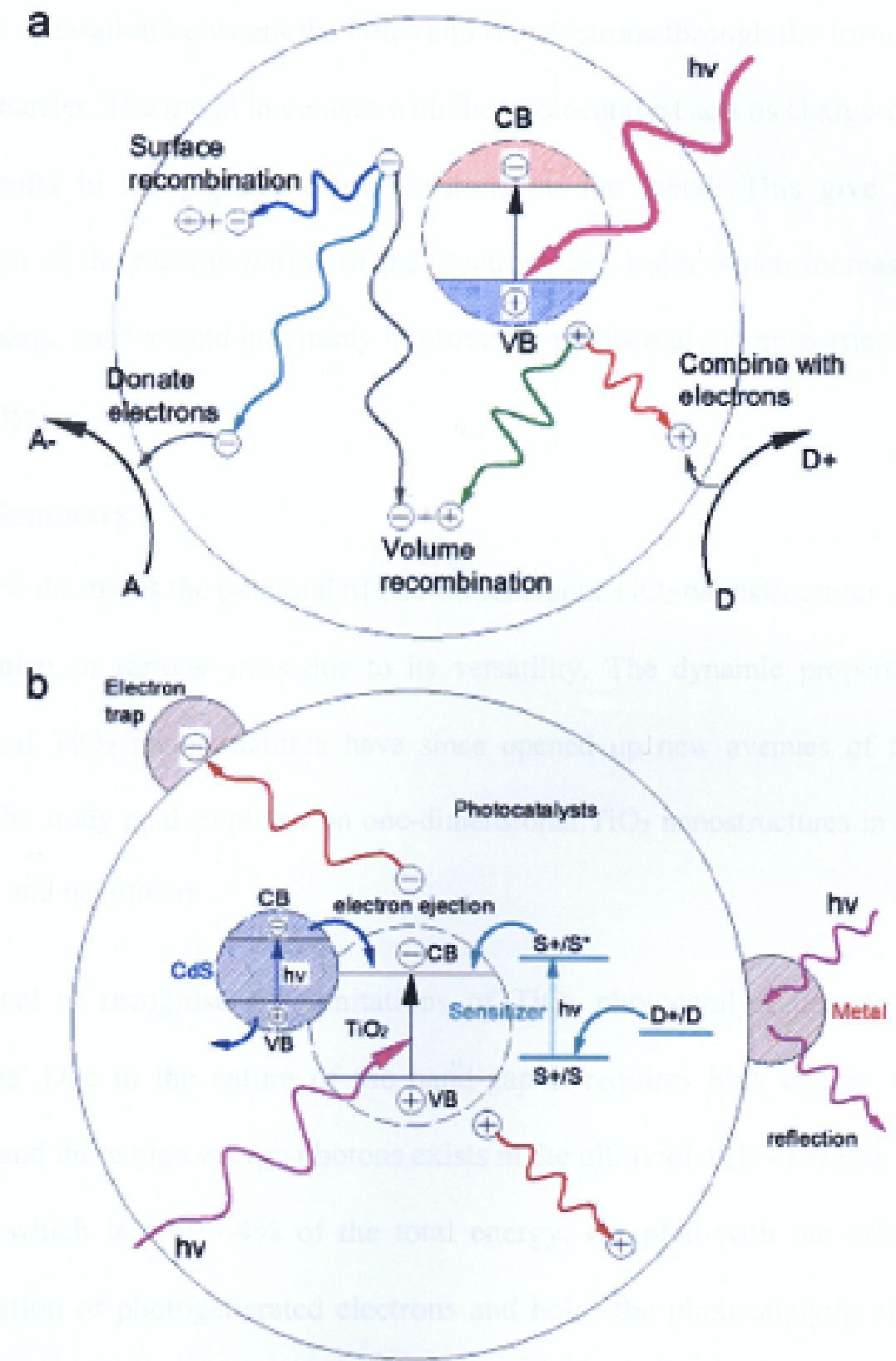

Figure 2.9 - (a) Schematic representation of band-gap formation and electron transfer process, (b) typical band-gap engineering; Metal doping, Dye-sensitized and composite semiconductors Adapted from (G. Liu et al, 2012)

However the recombination of the photogenerated electrons and holes within the volume of the semiconductor or at its surfaces prevents them from transferring to the surface to react with the absorbed species (Phairat et al., 2006). Therefore, it is imperative that the effect of recombination is suppressed in order to obtain higher yield during the reaction. As shown by Q. H. Zhang, Han, Hong, and Yu (2009) and Murdoch et al. (2011), when the photocatalyst are loaded with metals (Figure 2.9b) it enhances 
the charge spearation betweent the holes and the electrons through the formation of the Schottky barrier. The metal in contact with the photocatalyst acts as charge-carrier traps which results in the population of electrons on the metal. This give rise in the suppression of the recombination of the electrons and holes which increases the lifetime of charge carriers and inevitably improve the photocatalytic properties of the $\mathrm{TiO}_{2}$ photocatalyst.

\subsection{Summary}

This review discusses the potential of one-dimensional $\mathrm{TiO}_{2}$ nanostructures and the ease of application in various areas due to its versatility. The dynamic properties of onedimensional $\mathrm{TiO}_{2}$ nanostructures have since opened up new avenues of research. In addition, the study paid emphasis on one-dimensional $\mathrm{TiO}_{2}$ nanostructures in the form of nanotubes and nanofibers

It is critical to recognise the limitations of $\mathrm{TiO}_{2}$ photocatalyst despite its known advantages. Due to the nature of the band-gap it requires high energy input to be activated and these high energy photons exists in the ultraviolet (UV) region of the solar spectrum which is only $\sim 4 \%$ of the total energy. Coupled with the effect that the recombination of photogenerated electrons and holes the photocatalytic efficiency of these nanostructures are often reduced. As such, researchers have been exploring other effective and feasible methods in reducing electron-hole recombination and improving the photocatalytic ability of these $\mathrm{TiO}_{2}$ nanostructures in the visible light region. A potential approach is the coupling of both metals and doping non-metals with $\mathrm{TiO}_{2}$ nanomaterials. The coupling metal oxides aims to extend the life time of the photogenerated electrons-holes by providing trapping sites whereas the doping of the non-metals aims to reduce the optical band-gap through the up-shift of the valence band. 
Hence, reviewing the past literatures has allowed the author to investigate and evaluate the choice of metal oxides composite and non-metal elements that can be used in the formation of a novel one-dimensional $\mathrm{TiO}_{2}$ nanostructure.

For that reason, the use of various metal oxides in the fabrication of composite onedimensional $\mathrm{TiO}_{2}$ nanostructure was examined and Bismuth Titanates was found to be the most efficient photocatalyst due to its stability and favourable energetic for photocatalysis. Furthermore, the doping of carbon with anatase $\mathrm{TiO}_{2}$ also provides several advantages to enhance the visible light absorption of the photocatalyst. The research has deepened the author's understanding of the possible parameters and the characterisation techniques needed in the intricate design of this novel structure.

Thus this study postulates that by utilising a two-step approach it is possible to fabricate a nano-crystallised carbon composite titanium dioxide/bismuth nanostructure with controllable composition by manipulating the nanostructure during the doping process. Through the formation of this novel structure, it is postulated that it will not only increase the visible light absorption of the photocatalyst but provides additional surface area and the reactive sites for the trapping of photogenerated electron-hole pair. Most importantly the combination of these two processes allow parameters to be adjusted at various stages to achieve the desired morphology and characteristics. Furthermore, these finding presents tremendous potential for these complex nanostructure be applied in fields other than environmental remediation. 


\section{Methodology}

This chapter discusses the synthesis procedure for the one dimensional $\mathrm{TiO}_{2}$ nanostructures. The morphology and characteristics of the obtained one dimensional $\mathrm{TiO}_{2}$ nanostructures will be examined using a series of characterisation. Finally, a study on the photocatalytic properties of the composite $\mathrm{TiO}_{2}$ nanostructures will be conducted.

\subsection{Synthesis one-dimensional $\mathrm{TiO}_{2}$ nanostructures}

\subsubsection{Synthesis of $\mathrm{TiO}_{2}$ nanotubes}

Materials: Acetone $\left(\left(\mathrm{CH}_{3}\right) \mathrm{COCH}_{3}\right)$ of analytical grade and was used directly without further purification. Anhydrous monoethylene glycol $\left(\mathrm{HOCH}_{2} \mathrm{CH}_{2} \mathrm{OH}\right)$ and Ammonium fluoride $\left(\mathrm{NH}_{4} \mathrm{~F}\right)$ of reagent grade and were used directly without further purification.

First, the experiment involves the preparation of the anodization electrolyte, in which 0.3 $\mathrm{wt} \%$ of ammonium fluoride $\left(\mathrm{NH}_{4} \mathrm{~F}\right)$ was dissolved in a mixture of $3 \mathrm{wt} \%$ of deionised (DI) water and monoethylene glycol. A $2 \mathrm{~mL}$ of deionised (DI) water was added into the electrolyte solution to increase the rate of oxygen donation in the organic electrolyte. Before the electrochemical anodization of the Titanium (Ti) foil $(99.7 \%, 250 \mu \mathrm{m}$ thick, Goodfellow, Huntingdon England), it was first degreased by ultra-sonicating in acetone for 30 minutes. Thereafter, the degreased Ti foil was repeatedly rinsed in DI water before it was dried in a $\mathrm{N}_{2}$ stream. The electrochemical anodization of the high-purity Ti foil was conducted for 2 hours in a one-compartment two electrode electrochemical cell under a constant voltage of $60 \mathrm{~V}$, supplied by a DC power source (Agilent E3612A, Agilent Technologies, California, USA). The as-polished Ti foil served as the working electrode and Platinum foil $(99.99 \%, 1 \mathrm{~mm}$ thick, Goodfellow) served as counter electrode as shown in Figure 3.1. The anodized Ti samples were repeatedly rinsed with DI water and methanol before the tips were etched in a mild ultrasonic methanol bath for 1-2 mins to chemically dissolve nano-derbies off its surface. The resulting amorphous Ti film which was attached 
to the substrate was then left to dry in ambient environment. Subsequently, the freestanding amorphous $\mathrm{TiO}_{2}$ nanotube arrayed films were crystallised to the anatase phase by annealing it in air at $550^{\circ} \mathrm{C}$ in air for 2 hours at a temperature ramp of $1^{\circ} \mathrm{C}$ per minute.

\subsubsection{Synthesis of $\mathrm{TiO}_{2}$ nanofiber}

Materials: Ethanol $\left(\mathrm{CH}_{3} \mathrm{CH}_{2} \mathrm{OH}\right)$, Acetic acid $\left(\mathrm{CH}_{3} \mathrm{COOH}\right)$, of analytical grade and was used directly without further purification. Tetra n-Butyl Orthotitanate $\left(\mathrm{Ti}\left(\mathrm{OCH}_{2} \mathrm{CH}_{2} \mathrm{CH}_{2} \mathrm{CH}_{3}\right)_{4}\right)$ and Polyvinylpyrolidone (PVP, $\left.\mathrm{M}_{\mathrm{w}}=1,300,000\right)$ of reagent grade was used directly without further purification.

Table 3.1-List of Chemicals Required

\begin{tabular}{|c|c|c|c|}
\hline Chemicals & Composition & Quantity & Function \\
\hline $\begin{array}{c}\text { Anhydrous Ethanol } \\
\mathrm{C}_{2} \mathrm{H}_{5} \mathrm{OH}\end{array}$ & $\begin{array}{c}9_{\text {Ethanol }}: 1_{\text {Acetic acid }} \\
(V / N)\end{array}$ & $9 \mathrm{~mL}$ & Used as a solvent \\
\hline $\begin{array}{l}\text { Anhydrous Acetic Acid } \\
\qquad \mathrm{CH}_{3} \mathrm{COOH}\end{array}$ & $\begin{array}{c}9_{\text {Ethanol }}: 1_{\text {Acetic acid }} \\
(V / N)\end{array}$ & $1 \mathrm{~mL}$ & $\begin{array}{c}\text { Used as a stabiliser \& to } \\
\text { increase electrical } \\
\text { conductivity of the } \\
\text { precursor. }\end{array}$ \\
\hline $\begin{array}{c}\text { Poly(vinylpyrrolidone) } \\
\text { (PVP) }\end{array}$ & $\sim 7 \mathrm{wt} \%$ & $690-700 \mathrm{mg}$ & $\begin{array}{c}\text { Base polymer for } \\
\text { electrospinning }\end{array}$ \\
\hline $\begin{array}{c}\text { Tetra-n-butyl Orthotitanate } \\
\text { or Titanium Butoxide } \\
\text { (TBOT) } \\
\left.\left(\mathrm{C}_{4} \mathrm{H}_{9} \mathrm{O}\right)_{4} \mathrm{Ti} \text { or Ti(OBu}\right)_{4}\end{array}$ & $\sim 25 \mathrm{wt} \%$ & $2.5-2.7 \mathrm{~mL}$ & $\begin{array}{c}\text { Aloxide precursor for } \\
\text { fabrication of } \mathrm{TiO}_{2} \\
\text { nanofiber. }\end{array}$ \\
\hline
\end{tabular}

First, the experiment involved preparing the $\mathrm{TiO}_{2}$-precusor solution, in which $7 \mathrm{wt} \%$ of Polyvinylpyrrolidone was dissolved in the mixture of absolute ethanol and acetic acid solution with a volume ratio of $9: 1$. Subsequently, $25 \mathrm{wt} \%$ of Titanium Butoxide was added to the solution under continuous stirring for 30 mins to achieve a homogenous so-gel solution ready for electrospinning (Liu, Sun, Guo, \& Leckie, 2006). Table 3.1 summarises the materials needed to prepare a $10 \mathrm{~mL} \mathrm{TiO}_{2}$-precursor solution.

The solution was loaded into a $5 \mathrm{~mL}$ syringe equipped with a 'composite' stainless steel square tip needle with an internal diameter, $0.4 \mathrm{~mm}$. The needle was connected to a highvoltage supply that was capable of generating DC voltage of $30 \mathrm{kV}$. For the experiment, a voltage of $19 \mathrm{kV}$ was applied for the electrospinning. Using a syringe pump, the precursor 
solution was injected at a rate of $10 \mu \mathrm{L} / \mathrm{min}$ and a non-woven mat of PVP/Ti(OBu $)_{4}$ composite was collected on a grounded aluminium foil $18 \mathrm{~cm}$ away from the tip of the spinneret (Bai, Liu, \& Sun, 2012b). This electrospinning process was performed under room temperature at atmospheric conditions. The electrospun nanofibers were left to air for approximately 6 hours to allow hydrolysis to complete. Thereafter, the nanofibers were calcined at $550^{\circ} \mathrm{C}$ for 2 hours with a temperature ramp rate of $1{ }^{\circ} \mathrm{C} / \mathrm{min}$ to anneal the electrospun nanofiber and remove the remaining organics.

\subsection{Synthesis and band gap engineering of $\mathrm{TiO}_{2}$ nanofiber}

\subsubsection{Electrospinning of $\mathrm{TiO}_{2}$ nanofibers}

Materials: Ethanol $\left(\mathrm{CH}_{3} \mathrm{CH}_{2} \mathrm{OH}\right)$, Acetic acid $\left(\mathrm{CH}_{3} \mathrm{COOH}\right)$ Dimethylformadmide (DMF, $\left.\left(\mathrm{CH}_{3}\right)_{2} \mathrm{NCH}\right)$, were of analytical grade and were used directly without further purification. Tetra n-Butyl Orthotitanate $\left(\mathrm{Ti}\left(\mathrm{OCH}_{2} \mathrm{CH}_{2} \mathrm{CH}_{2} \mathrm{CH}_{3}\right)_{4}\right)$ and Polyvinylpyrolidone (PVP, $\mathrm{M}_{\mathrm{w}}$ $=1,300,000)$ used was of reagent grade and was used directly without further purification.

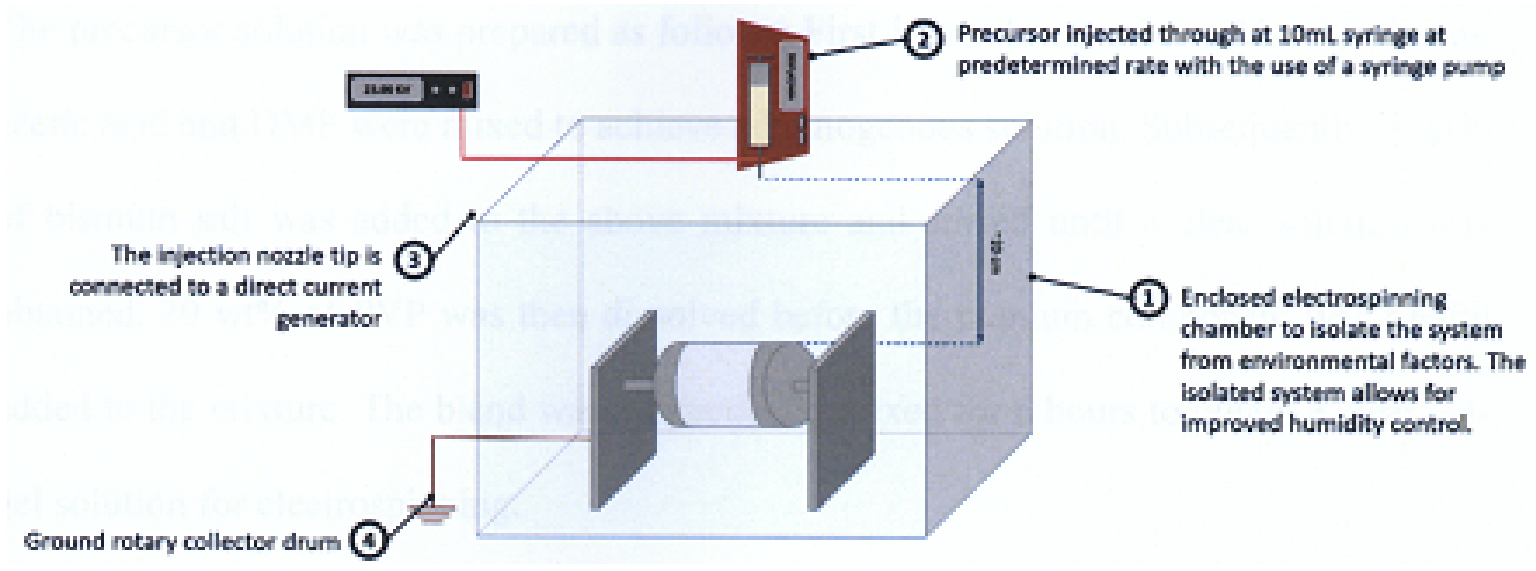

Figure 3.1 - Schematic Diagram of Electrospinning Chamber

The precursor solution was prepared as follows; first in a volume ratio of 11:3:1, ethanol, acetic acid and DMF were mixed to achieve a homogenous solution. Subsequently $\sim 20$ wt $\%$ of PVP was then dissolved before the titanium component was finally added to the mixture. The blend was magnetically mixed for 6 hours to obtain a clear sol-gel solution for electrospinning. The $\mathrm{TiO}_{2}$ nanofiber were electrospun using an electrospinning set up 
as shown in Figure 3.1. Facilitated using a syringe pump, the precursor solution was injected at a rate of $10 \mathrm{uL} / \mathrm{min}$ through a $10 \mathrm{~mL}$ composite stainless steel nozzle with an internal diameter of $1 \mathrm{~mm}$. The nozzle tip was subjected to an electrical potential of approximately $23 \mathrm{kV}(1.3 \mathrm{kV} / \mathrm{cm})$, and the electrospun fiber was collected on a rotary drum $16 \mathrm{~cm}$ away from the tip of the nozzle. The electrospun composite nanofiber was then left to hydrolyse in air for 6 hours before it was calcined at various temperature at a temperature ramp of $1^{\circ} \mathrm{C} / \mathrm{min}$.

\subsubsection{Synthesis of composite Bismuth Titanate/Titanium dioxide nanofiber} Materials: Ethanol $\left(\mathrm{CH}_{3} \mathrm{CH}_{2} \mathrm{OH}\right)$, Acetic acid $\left(\mathrm{CH}_{3} \mathrm{COOH}\right)$ Dimethylformadmide (DMF, $\left.\left(\mathrm{CH}_{3}\right)_{2} \mathrm{NCH}\right)$, Polyvinylpyrolidone (PVP, $\left.\mathrm{M}_{\mathrm{w}}=1,300,000\right)$ and Bismuth (III) Nitrate pentahydrate $\left(\mathrm{Bi}\left(\mathrm{NO}_{3}\right) \cdot 5 \mathrm{H}_{2} \mathrm{O}\right)$ were of analytical grade and were used directly without further purification. Tetra n-Butyl Orthotitanate $\left(\mathrm{Ti}\left(\mathrm{OCH}_{2} \mathrm{CH}_{2} \mathrm{CH}_{2} \mathrm{CH}_{3}\right)_{4}\right)$ used was of reagent grade.

The precursor solution was prepared as follows; First in a volume ratio of 11:3:1, ethanol, acetic acid and DMF were mixed to achieve a homogenous solution. Subsequently, $3 \mathrm{wt} \%$ of bismuth salt was added to the above mixture and stirred until a clear solution was obtained. $20 \mathrm{wt} \%$ of PVP was then dissolved before the titanium component was finally added to the mixture. The blend was magnetically mixed for 6 hours to obtain a clear solgel solution for electrospinning.

The $\mathrm{Bi}_{2} \mathrm{Ti}_{4} \mathrm{O}_{11} / \mathrm{TiO}_{2}$ composite nanofiber were electrospun using the same electrospinning setup as discussed in Section 3.2.1. 
3.2.3. Synthesis of nano-crystallised carbon Titanium dioxide-Bismuth composite nanofiber

Assuming that Sucrose $\left(\mathrm{C}_{12} \mathrm{H}_{22} \mathrm{O}_{11}\right)$ follows a thermal pyrolysis reaction as suggested in equation 5:

$$
\left.\mathrm{C}_{12} \mathrm{H}_{22} \mathrm{O}_{11} \rightarrow 12 \mathrm{C}+11 \mathrm{H}_{2}\right)
$$

A $0.2 \mathrm{M}$ Sucrose $\left(\mathrm{C}_{12} \mathrm{H}_{22} \mathrm{O}_{11}\right)$ stock solution was prepared by dissolving $6.85 \mathrm{~g}$ of Sucrose in $100 \mathrm{~mL}$ in deionised water (K. Wang et al., 2009). The mixture was left to stir for 2 hours to allow the solution to homogenise. Thereafter, the homogenous sucrose solution was mixed with approximately $0.15 \mathrm{~g}$ of $\mathrm{Bi}_{2} \mathrm{Ti}_{4} \mathrm{O}_{11} / \mathrm{TiO}_{2}$ composite nanofiber. This solution was dispersed by ultrasonication for 2 hours. The mixture was then filtered using a vacuum filtration system before the residue was left to concentrate till dryness in an oven at $50^{\circ} \mathrm{C}$ for 12 hours. The dried sucrose coated $\mathrm{Bi}_{2} \mathrm{Ti}_{4} \mathrm{O}_{11} / \mathrm{TiO}_{2}$ composite nanofiber were finally calcined at $700^{\circ} \mathrm{C}$ in an $\mathrm{N}_{2}$ environment for 2 hours with a temperature ramp of $5^{\circ} \mathrm{C} / \mathrm{min}$

\subsection{Photocatalytic Performance}

\subsubsection{Photocatalytic Oxidation}

Photocatalytic oxidation test was conducted with the use of an organic model dye pollutant, Acid Orange 7 (AO7) in the reactor vessel shown in Figure 3.2. A 20 ppm AO7 of the organic pollutant was first prepared at neutral $\mathrm{pH}$ before adding $0.5 \mathrm{~g} / \mathrm{L}$ (model pollutant) of $\mathrm{Bi}_{2} \mathrm{Ti}_{4} \mathrm{O}_{11} / \mathrm{TiO}_{2}$ composite nanofiber photocatalyst into the solution. This solution was magnetically stirred in the reactor for 120 mins to ensure homogeneity of the photocatalyst in the solution and establish an adsorption equilibrium between the organic pollutant and photocatalyst. Thereafter, the irradiation source a $360 \mathrm{~W}$ High pressure Sodium lamp (Riko, HNL-360A) was turned on and at pre-determined intervals of illumination, $2.0 \mathrm{~mL}$ of reaction solution was drawn and the decrease in concentration of the AO7 solution was measured using a spectrophotometer (UV-1800 Shimadzu $\mathbb{C}$ UV-Vis spectrophotometer). 


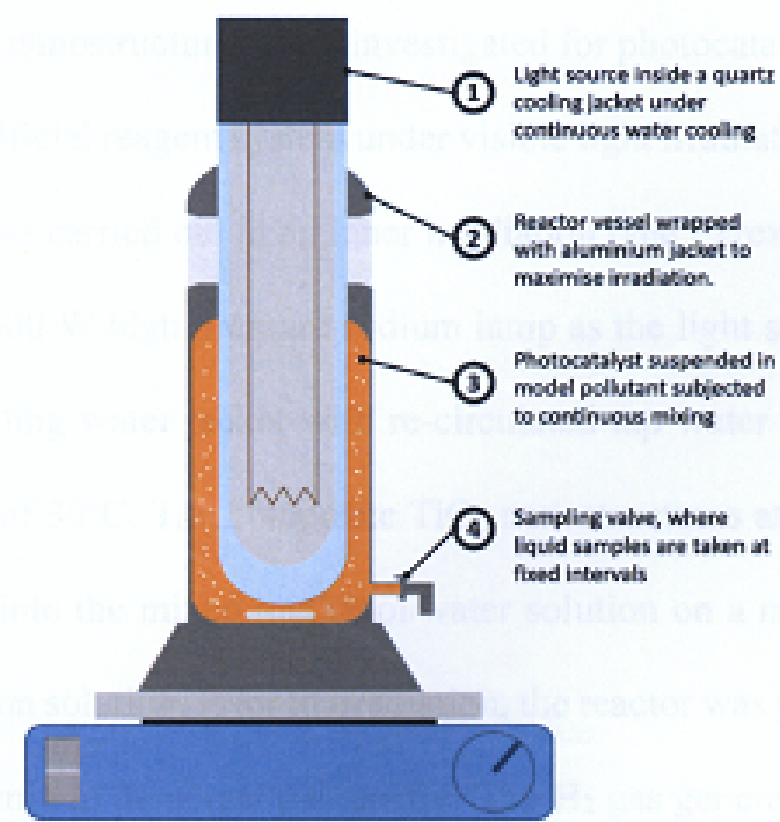

Figure 3.2 - Schematic diagram of Photocatalytic Oxidation Reactor

The designed photoreactor comprises of two components, the first being the outer reactor vessel which the $\mathrm{Bi}_{2} \mathrm{Ti}_{4} \mathrm{O}_{11} / \mathrm{TiO}_{2}$ composite nanofiber were suspended as photocatalyst. The second component, the inner quartz cooling jacket where different lamp sources were used to model irradiation energy. The cooling jacket was constantly cooled using a peristaltic pump to ensure that optimum operation temperature below $30^{\circ} \mathrm{C}$.

\subsubsection{Hydrogen $\left(\mathrm{H}_{2}\right)$ Generation}

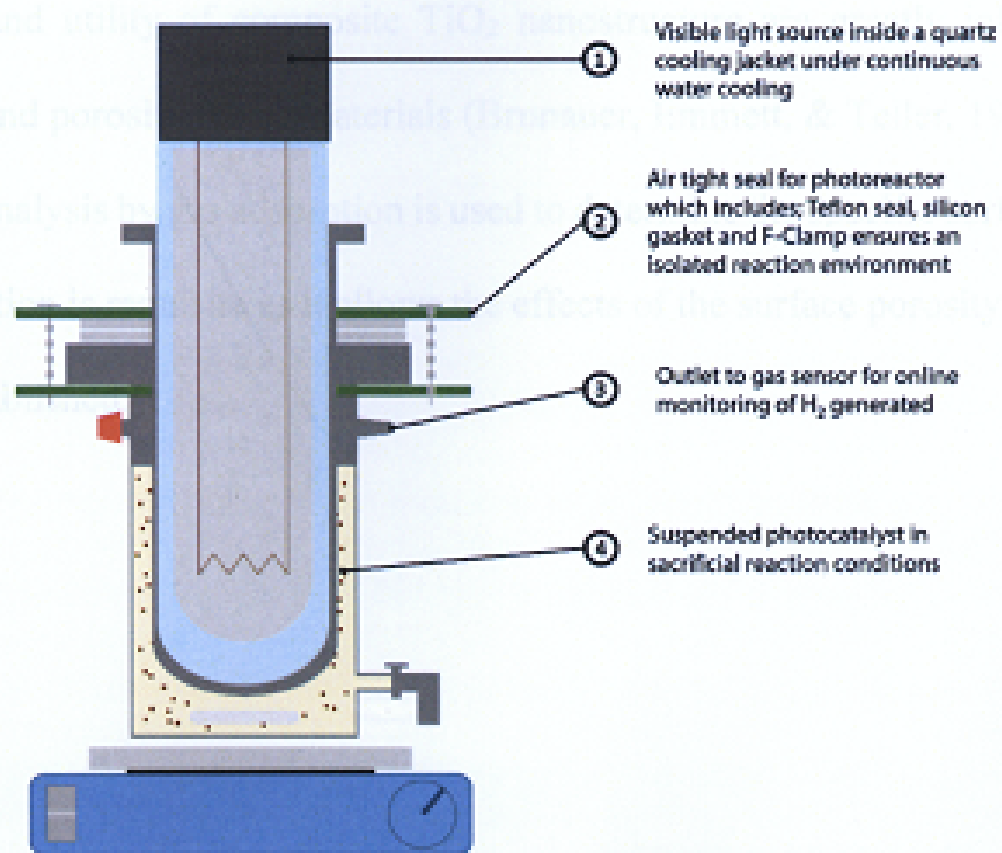

Figure 3.3 - Schematic diagram of $\mathrm{H}_{2}$ generation set up 
The composite $\mathrm{TiO}_{2}$ nanostructures were investigated for photocatalytic $\mathrm{H}_{2}$ generation in a methanol/water sacrificial reagent system under visible light irradiation. The photocatalytic $\mathrm{H}_{2}$ generation test was carried out in an inner irradiation type Pyrex reactor with a volume of $170 \mathrm{~mL}$ using a $400 \mathrm{~W}$ high pressure sodium lamp as the light source. The reactor was wrapped with a cooling water jacket with re-circulated tap water to maintain a constant reactor temperature of $30^{\circ} \mathrm{C}$. The composite $\mathrm{TiO}_{2}$ nanostructures at a concentration of 0.5 $\mathrm{g} / \mathrm{L}$ was suspended into the mixed methanol/water solution on a magnetic stirrer to form homogeneous reaction solution. Prior to irradiation, the reactor was purged thoroughly with nitrogen gas for $30 \mathrm{~min}$ to de-aerate the reactor. The $\mathrm{H}_{2}$ gas generated was detected using an online $\mathrm{H}_{2}$ gas sensor (BlueSens gas sensor $\mathrm{GmbH}$ ).

\subsection{Characterisation}

This section provides an understanding on the various morphology and characteristics tests that were carried out during the experiment. These analysis were important in determining the physical and chemical properties of the synthesised nanotubes.

\subsubsection{Brunauer-Emmett-Teller (BET) Surface Area Analysis}

The quality and utility of composite $\mathrm{TiO}_{2}$ nanostructure are greatly influenced by the surface area and porosity of the materials (Brunauer, Emmett, \& Teller, 1938). Thus, BET surface area analysis by gas adsorption is used to determine the specific surface area $\left(\mathrm{m}^{2} / \mathrm{g}\right)$. This examination is requisite as it allows the effects of the surface porosity and the particle size to be established. 


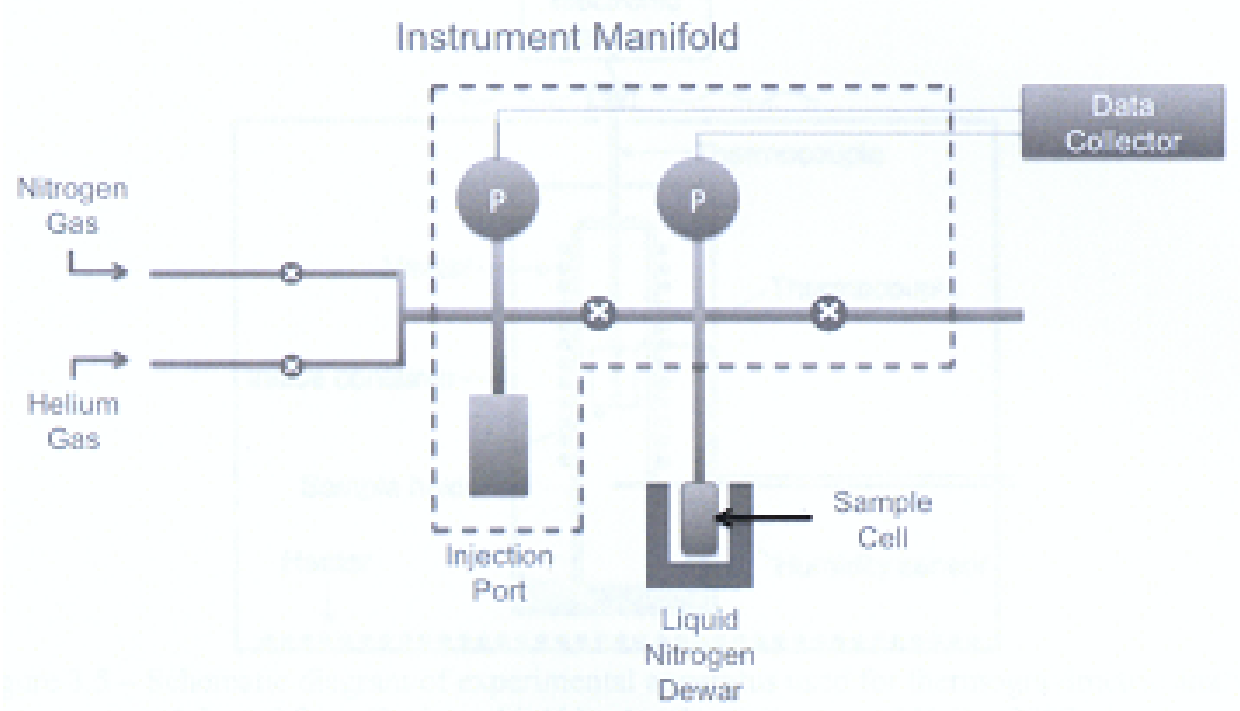

Figure 3.4 - Schematic diagram of BET instrument Adapted from Hwang \& Barron (2011)

The porous structure of the composite photocatalysts were characterized by a $\mathrm{N}_{2}$ adsorption/desorption isotherm using a QUADRASORB evo $^{\mathrm{TM}}$ Quantachrome $^{\mathscr{\Theta}}$ at liquid nitrogen temperature (77K) as shown in Figure 3.4. Before the measurement, $0.1 \mathrm{~g}$ sample was degassed under vacuum for 18 hours at $200^{\circ} \mathrm{C}$ to remove water and other contaminants before the surface area can be accurately measured. Both the pore volume and size distributions were derived from the desorption branches of the isotherms by the BarrettJoyner-Halenda (BJH) model and the Brunauer-Emmett-Teller (BET) equation was used to calculate the specific surface area from the adsorption data.

\subsubsection{Thermogravimetric Analysis}

Thermogravimetric analysis (Perkin Elmer TG4000) is a method of thermal analysis in which changes in physical and chemical properties of a material is measured as a function of increasing temperature from room temperature to $700^{\circ} \mathrm{C}$ under a constant heating rate of $5^{\circ} \mathrm{C} / \mathrm{min}$. During the annealing process, the mass loss due to decomposition, oxidation, or loss of volatiles (such as moisture) is measured by an electronic balance (Figure 3.5). The measured mass loss over time is recorded and provides information on the percentage of carbon present in the composite $\mathrm{TiO}_{2}$ nanostructure. 


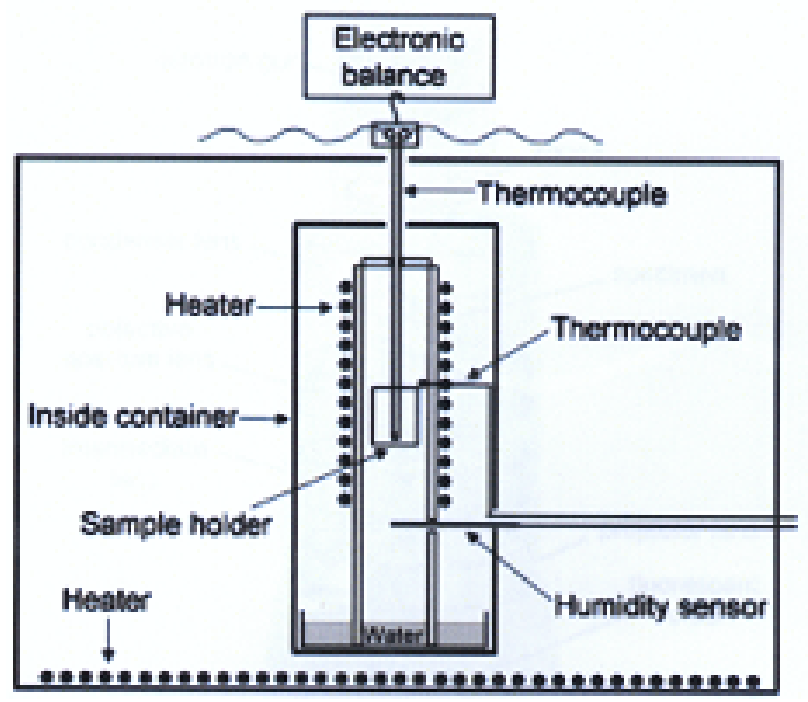

Figure 3.5 - Schematic diagram of experimental apparatus used for thermogravimetric analysis Adapted from Taninouchi, Uda, Awakura, Ikeda, and Haile (2007)

\subsubsection{Transmission Electron Microscopy Analysis (TEM)}

In order to study the surface morphology and crystallisation properties of the onedimensional nanostructures at a higher resolution, TEM was used. In a typical analysis, electrons emitted from the electron gun was focused into a thin beam by a condenser lens, which then strikes the thin crystalline sample and were dispersed (Leadley, 2010) on a copper grid. The unscattered electrons were latterly concentrated by the electromagnetic objective lens and were focused onto the fluorescent screen (Microscopes, 2016). The fluorescent screen displays images of the sample in varied darkness depending on their density and amount of electrons absorbed. 


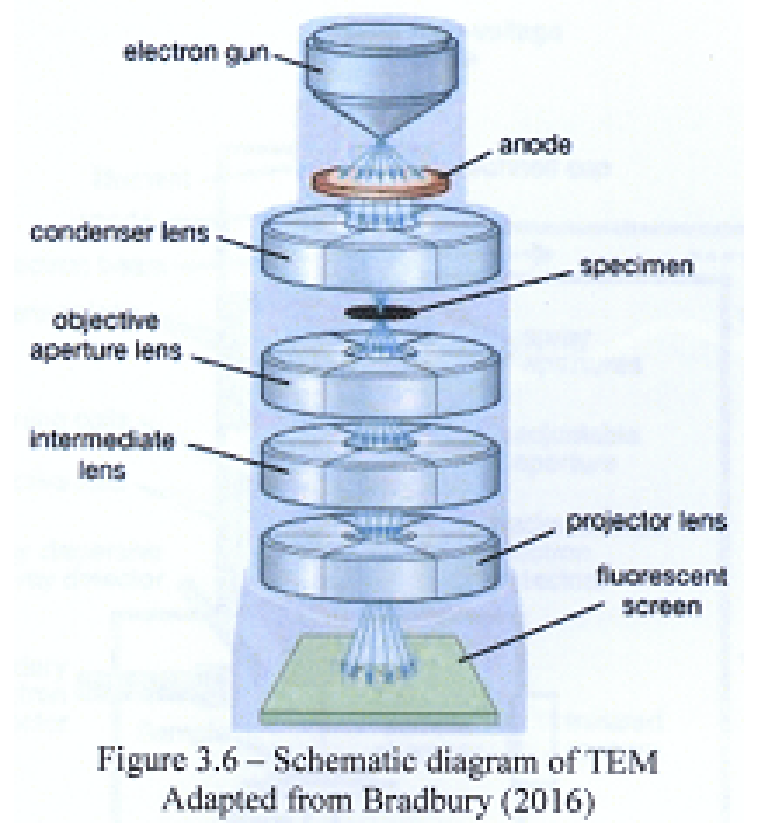

\subsubsection{Scanning Electron Microscopy}

The morphology change of the composite $\mathrm{TiO}_{2}$ nanostructure it is imperative that the samples are investigated using a scanning electron microscope. A scanning electron microscopy is an imaging technique that produces images of a specimen by illuminating it with electrons in high vacuum while detecting the electrons that are reflected from the sample surface or secondary electrons that are ejected from the sample.

Figure 3.7 illustrates how the electron beams were fired by an electron gun onto a series of magnetic lenses and apertures. The focused electron beams interact with the sample surface as it scanned across the sample generating various signals. The secondary or backscattered electrons are detected by a specialised detector before they are magnified to produce the resulting image of the sample's surface topography and structural morphology. 


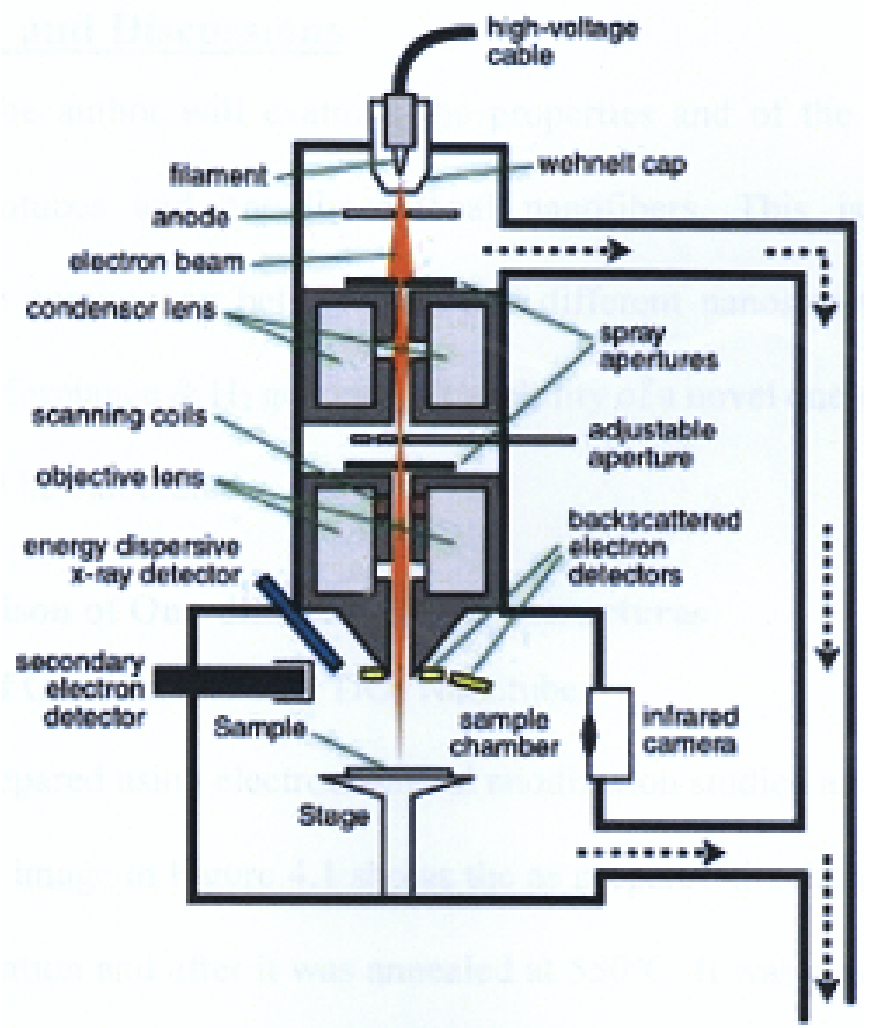

Figure 3.7 - Schematic diagram of a SEM Adapted from Wittke (2008)

\subsubsection{X-Ray Diffraction (XRD)}

XRD analysis was used to quantify the structure and characteristics of composite $\mathrm{TiO}_{2}$ nanostructures. The X-ray diffraction patterns were recorded on a Bruker D8 Advance Xray diffractometer (XRD) with monochromated high intensity $\mathrm{CuK} \alpha$ radiation $(\lambda=$ $1.5418 \AA$ ). A powdered sample of the one-dimensional $\mathrm{TiO}_{2}$ nanostructures was placed in a holder and illuminated with X-rays of a fixed wavelength. The intensity of the reflected radiations was recorded using a goniometer and analysed for the reflection angle to determine the inter-atomic spacing. Since each crystalline solid has its unique characteristic $\mathrm{X}$-ray pattern, the diffraction process thus allows for the fingerprinting characterisation, which is used for identification purposes. 


\section{Results and Discussions}

In this chapter, the author will examine the properties and of the synthesised onedimensional nanotubes and one-dimensional nanofibers. This is followed by a discussion on the comparison between the two different nanostructures. Lastly, the photocatalytic performance \& $\mathrm{H}_{2}$ generation capability of a novel one-dimensional $\mathrm{TiO}_{2}$ nanostructure will be elaborated.

\subsection{Comparison of One-dimensional nanostructures}

\subsubsection{Profile of One-Dimensional $\mathrm{TiO}_{2}$ Nanotubes}

The nanotubes prepared using electrochemical anodization studied and characterised as follows. A digital image in Figure 4.1 shows the as prepared titanium foil before, after 2 hours of anodization and after it was annealed at $550^{\circ} \mathrm{C}$. It was observed that during the course of anodization, there was a progressive change in of colour of the titanium foil from a metallic silver (Figure 4.1a) tone to yellowish green (Figure 4.1b). The change in colour was due to the growth of the $\mathrm{TiO}_{2}$ nanotubes on the surface of titanium foil which increases its absorption in the green region of the visible spectrum. In addition after the heat treatment at $550^{\circ} \mathrm{C}$, there was a further change in colour of the nanotubes array from dark green to yellowish green. This change in colour can be associated to the removal of residual organic and the oxidation of the $\mathrm{TiO}_{2}$ nanotubes during the calcination.

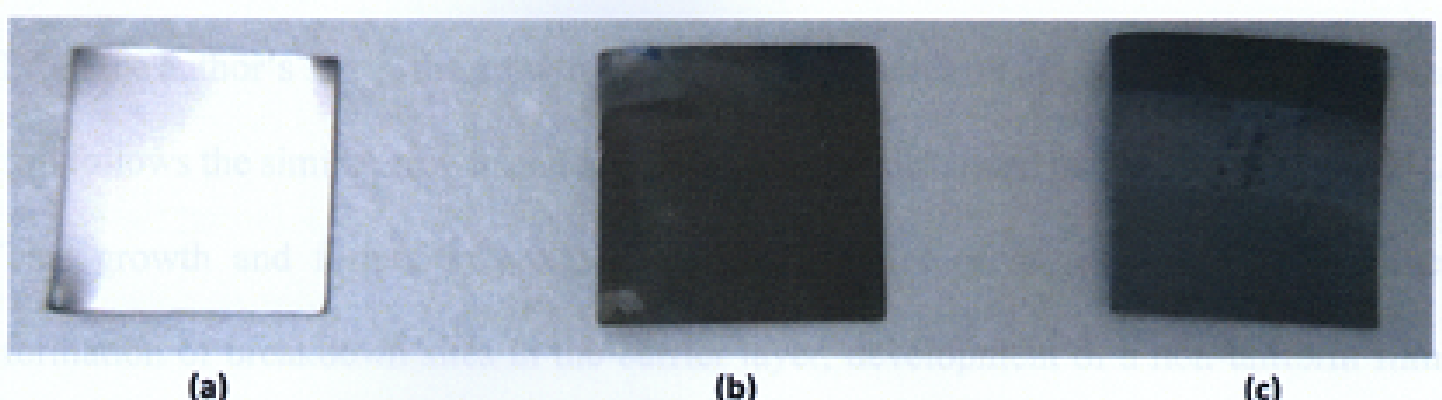

Figure 4.1 - Digital image of Titanium Foil (a) before anodization (b) after anodization (c) after anodization and calcination 


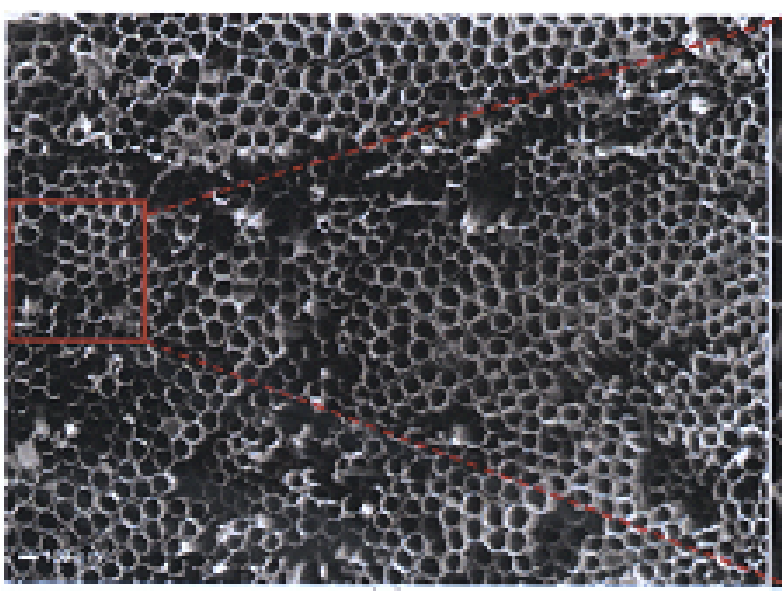

(a)

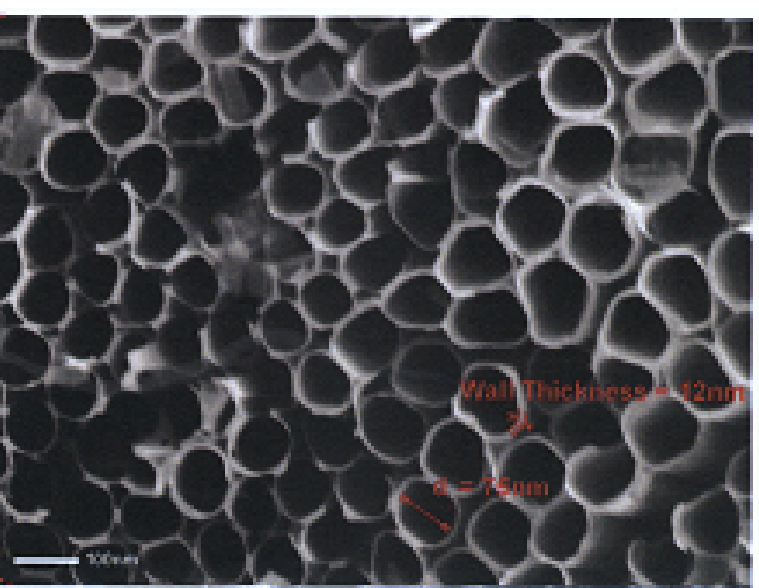

(b)

Figure 4.2 - (a) \& (b) FESEM Image of $\mathrm{TiO}_{2}$ nanotube at different magnification

The FESEM images of the calcined $\mathrm{TiO}_{2}$ nanotubes shown Figure 4.2 depicts the highly ordered nature of the nanotubes which have grown perpendicularly to the surface of the Titanium substrate. The nanotubes have an average inner diameter of $75 \mathrm{~nm}$ and a wall thickness of $11 \mathrm{~nm}$ (i.e. average outer diameter of $\sim 100 \mathrm{~nm}$ ) which illustrates the porous characteristic of the nanotubes. Furthermore, the nanotubes have excellent uniformity and are closely packed which provides a pathway for electron transport at the walls of the nanotubes. This high density of nanotubes in a small surface areas help prevent 'electron-hopping' (J. Wang \& Lin, 2008). Moreover, the vertical alignment of the nanotubes allow it to act as a "nano-reactor" for the oxidation-reduction reactions. This is due to the presence of the large interfacial surface areas for the photo-excited electrons to effectively dissociate, this suppresses the recombination of electrons with holes generated during by UV irradiation.

From the author's study, the growth of the $\mathrm{TiO}_{2}$ nanotubes on the surface of the titanium foil follows the similar growth and formation process discussed by Taveira et al. (2005). This growth and formation process involves a series of stages which include the formation of breakdown sites in the barrier layer, development of a non-uniform film morphology and eventual evolution of a highly regular tube-like structure. The competition between the reactions as discussed (Appendix - A). 
During the early stages of the anodization process, the oxide growth is controlled by field aided ion transport of $\left(\mathrm{O}^{2-}\right.$ and $\mathrm{Ti}^{4+}$ ions $)$. The oxidised metals species as shown in Equation 6 reacts with the $\mathrm{O}^{2-}$ ion found in $\mathrm{H}_{2} \mathrm{O}$ which results in the formation and growth of a compact oxide layer comprising of titanium dioxide and hydroxide as illustrated in Appendix A.

$$
\mathrm{Ti}+2 \mathrm{H}_{2} \mathrm{O} \rightarrow \mathrm{TiO}_{2}+4 \mathrm{H}^{+}+4 e^{-} \ldots(6)
$$

As the anodization progresses, the presence of the $\mathrm{F}^{-}$ions in the electrolyte solution leads to the formation of $\mathrm{TiF}_{6}{ }^{2-}$ metal complexes (Equation 7) which dissolves and breakdown the oxide layer on the surface.

$$
\mathrm{TiO}_{2}+6 \mathrm{~F}^{-} \rightarrow\left[\mathrm{TiF}_{6}\right]^{2-} \ldots(7)
$$

This inevitability prevents the precipitation of the oxide layer as the $\mathrm{Ti}^{4+}$ species arriving at the interface of the oxide and electrolyte can react and form $\mathrm{TiF}_{6}{ }^{2-}$ before it precipitates.

$$
T i^{4+}+6 F^{-} \rightarrow\left[T i F_{6}\right]^{2-} \ldots(8)
$$

This eventually leads to the development of breakdown sites which form groves that act as seeds in the growth of ordered tubular structures, these breakdown sites continue to propagate and grow beneath the compact layer thus increasing its active area. Simultaneously as the remnants barrier layer begin to dissolve, these irregular breakdown sites starts to propagate and become more pronounced forming a selforganised porous layer. This nanotubular layer becomes completely uncovered after 2 hours of anodization.

Amid the different stages of the formation of self-organised nanotubes, it was observed that the electrochemical conditions changes occurs at different stages of the anodization 
process. During the initial stage of anodization process, a current decay was observed. This decay in current can be attributed to the growth of the barrier oxide layer which gradually decreases the field strength and consequentially limit the growth of the barrier oxide layer. When the current decay reaches it limiting condition, an increase in current was observed. This increase in current was due to the propagation of the breakdown sites which initiates the growth of the nanotubes and enhances the active surface area. As the growth continues, the formation of well-defined nanotubular morphology causes interference and competition of available current attaining a steady state condition where the nanotubes equally share the available current and the current stabilises. Eventually, this leads to the formation of an array of highly order $\mathrm{TiO}_{2}$ nanotubes.

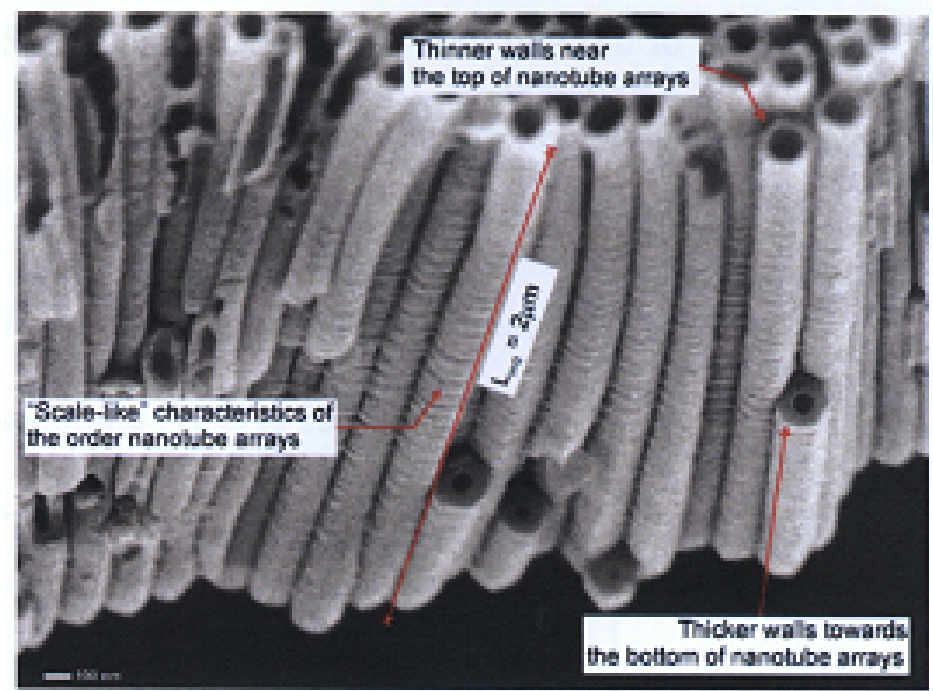

Figure 4.3 - FESEM image of the cross-section view of $\mathrm{TiO}_{2}$ nanotubes after 2 hour anodization

Illustrated in Figure 4.3, the length of the nanotubes ranges from $1.5 \mu \mathrm{m}$ to $2 \mu \mathrm{m}$ (Figure 4.3). This irregularity in their lengths was due to the uneven surface of the virgin titanium foil which results in different growth rates. Furthermore, the surface of the nanotubes appear rough and scale like, this characteristic which is most likely due to chemical dissolution of $\mathrm{TiO}_{2}$ occurring during throughout the anodization process. The "scale-like' morphology of the outer-walls may increase may enhance its photocatalytic properties through the provision of more surface active site. It was also found that the 
nanotubes have a "V-liked" morphology. At the tips, the nanotubes possess thinner walls and slowly become thicker as it moves down towards the bottom of the tube. Yasuda and Schmuki (2007), attributed this characteristic of the nanotubes was also associated to the dissolution effect occurring during anodization.

Figure 4.4 depicts the results of phases and states of $\mathrm{TiO}_{2}$ from the X-Ray Diffractometer (XRD) of the nanotubes. It illustrates the importance of calcinations on the formation of anatase phase $\mathrm{TiO}_{2}$ nanotubes. By comparing the XRD pattern of the uncalcined $\mathrm{TiO}_{2}$ nanotubes to the calcined nanotubes, the XRD pattern of uncalcined $\mathrm{TiO}_{2}$ nanotubes did not exhibit the characteristics peaks at $2 \theta=25.4^{\circ}$. This indicates an absence of the anatase nanocrystalline structure in the nanotubes. However, after calcining the nanotubes at $550^{\circ} \mathrm{C}$ the $\mathrm{XRD}$ patterns were indexed to anatase $\mathrm{TiO}_{2}$. From the XRD measurements, the major anatase orientation lies in the (101) plane with other planes such as (004), (200) and (105) only present in minor amount. Also from the XRD analysis, the estimated crystallite size calculated from Scherrer Equation (Appendix B) of the corresponding (101) is $26.79 \mathrm{~nm}$.

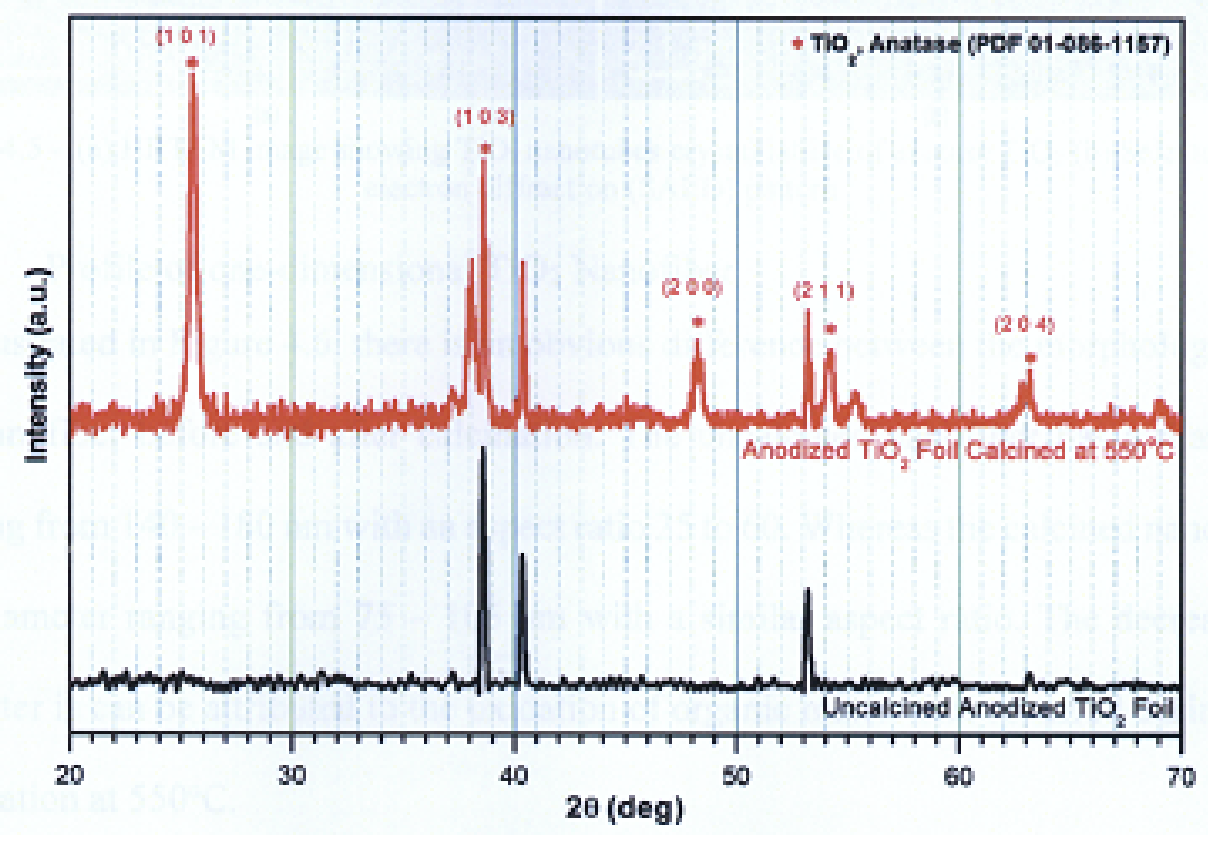

Figure 4.4 - XRD Pattern of anatase Phase $\mathrm{TiO}_{2}$ 
In addition, high resolution transmission electron microscopy image (TEM) in Figure 4.5 also substantially proves that the $\mathrm{TiO}_{2}$ can be indexed to anatase phase. Figure $4.5 \mathrm{a}$ clearly illustrate the lattice spacing of $0.325 \mathrm{~nm}$ which corresponds to the (101) plane of the anatase $\mathrm{TiO}_{2}$. Moreover, from the HRTEM image it was found that the over the entire length, the (101) plane is present along the walls which indicate a possible growth and subsequent crystallisation of single crystalline tubes. The selected area electron diffraction (SAED) pattern in Figure $4.5 \mathrm{~b}$ portrays a concentric spherical ring pattern for the anatase $\mathrm{TiO}_{2}$ further justifies the crystalline characteristics of the nanotubes and indicates its preferred growth of $\mathrm{TiO}_{2}$ in the (101) plane.

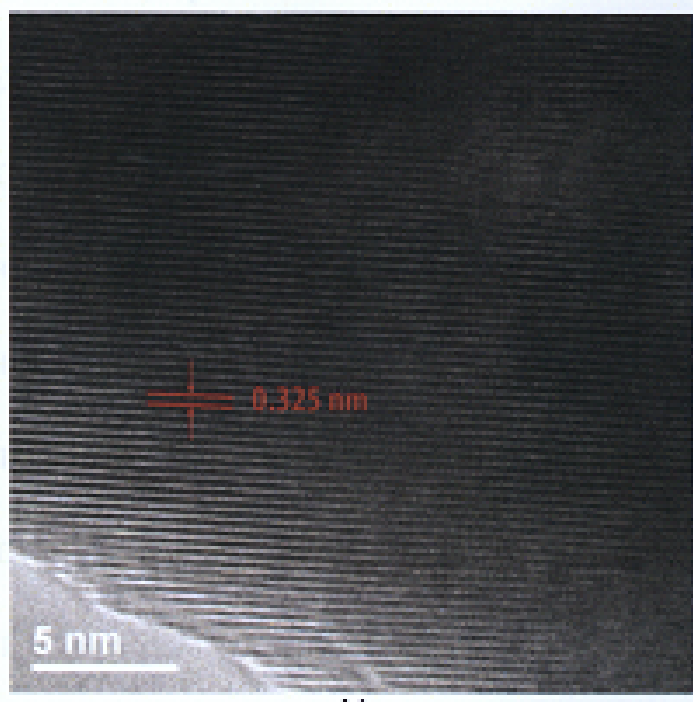

(a)

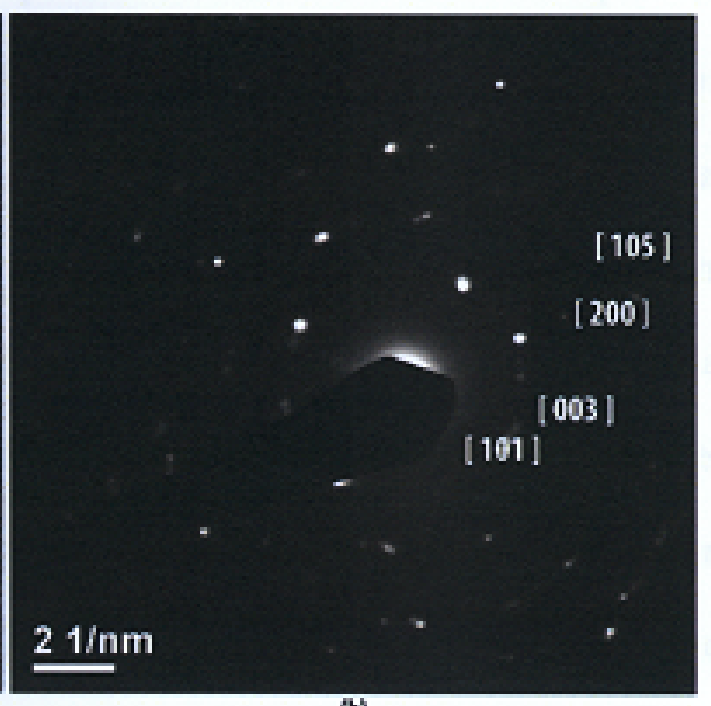

(b)

Figure 4.5 - (a) HRTEM image showing $\mathrm{TiO}_{2}$ nanotubes crystal lattice of anatase $\mathrm{TiO}_{2}$ (b) Selected area electron diffraction (SAED) pattern

\subsubsection{Profile of one-dimensional $\mathrm{TiO}_{2}$ Nanofiber}

As illustrated in Figure 4.6, there is an obvious difference between the morphologies of the nanofiber before and after calcination. The uncalcined nanofiber has a diameter ranging from $140-180 \mathrm{~nm}$ with an aspect ratio 25 to 60 . Whereas the calcined nanofiber has diameter ranging from $75-105 \mathrm{~nm}$ with a similar aspect ratio. The decrease in diameter is can be attributed to the oxidation of organic matter that occurred during the calcination at $550^{\circ} \mathrm{C}$. 


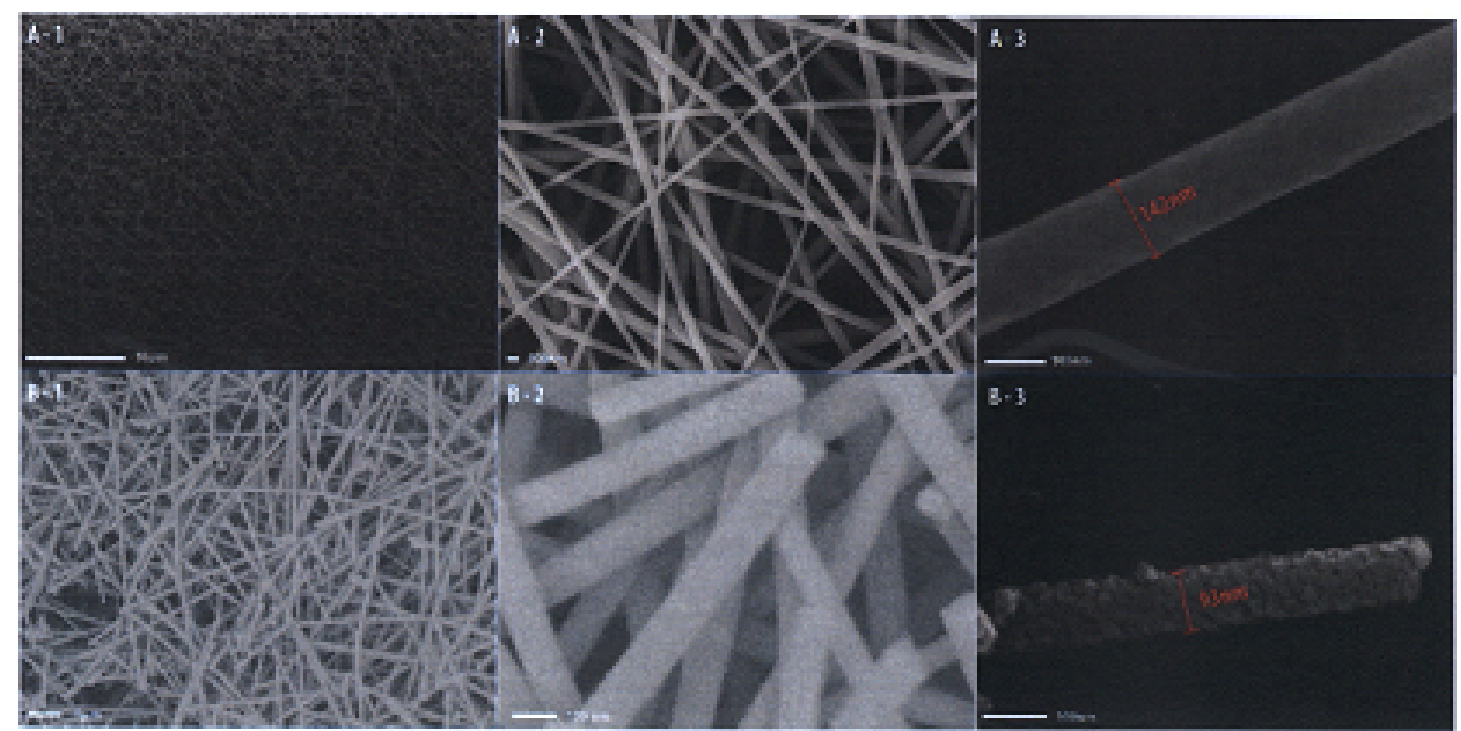

Figure 4.6 - FESEM images of uncalcined under different magnification (A-1 to A-3) and $\mathrm{TiO}_{2}$ nanofiber calcined at $550^{\circ} \mathrm{C}$ under different magnification (B-1 to B-3)

Moreover, upon calcination at elevated temperature of $550^{\circ} \mathrm{C}$ the surface morphology of the nanofiber evolved from a smooth and non-porous surface (Figure 4.6, A-3) into a rough and porous surface (Figure 4.6, B-3). The formation of a nonporous surface can be attributed to an increase in the surface-to-volume ratio. This suggests that the calcination process promotes crystalline growth, and also initiates union of granular crystals into larger crystals. The thermal treatment at elevated temperatures permitted for an enhanced degree of crystallisation which consequentially permitted for a more effective photodegradation of organic compounds as a result of the obsevered higher crystallinity (Khataee \& Kasiri, 2010). 


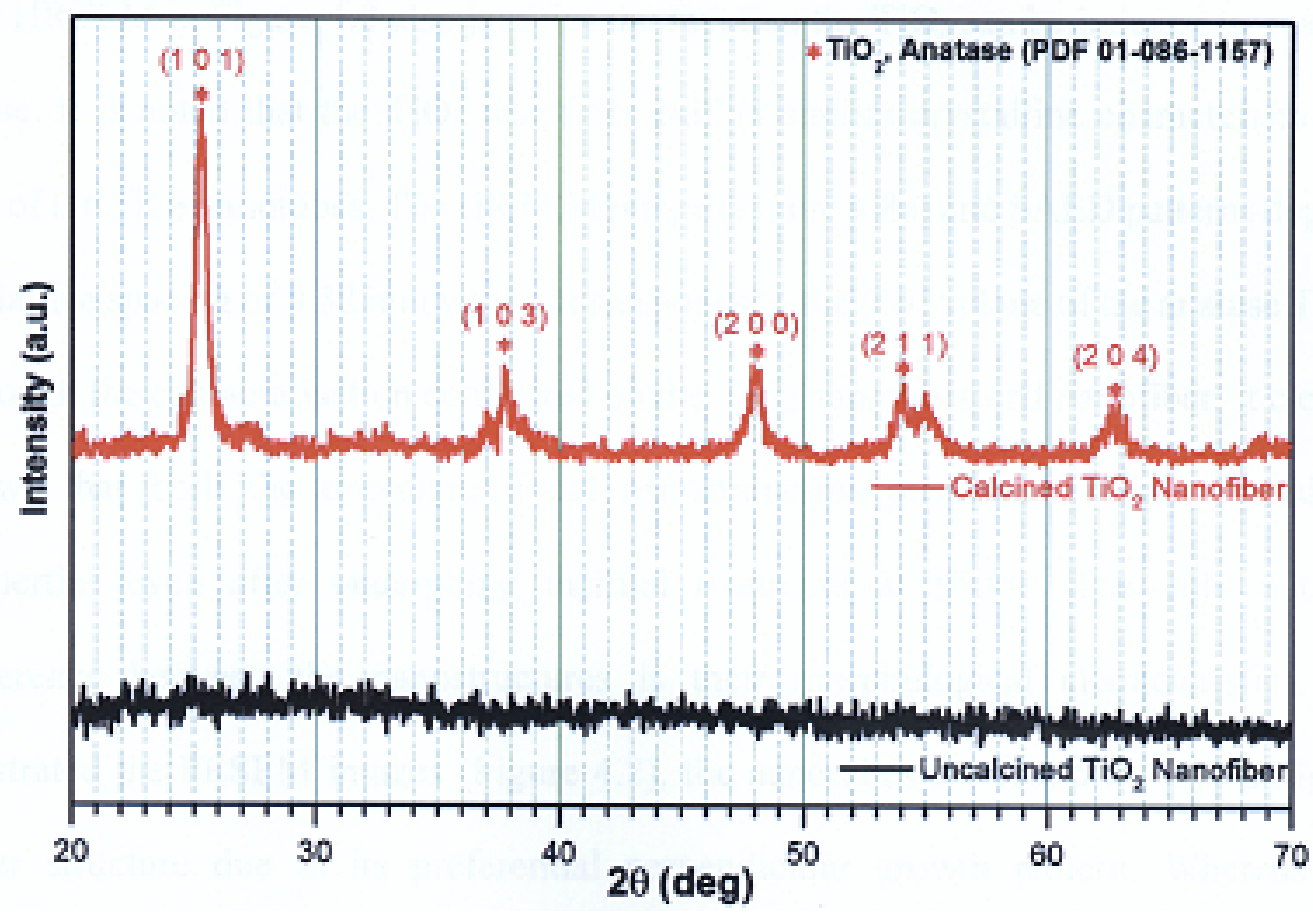

Figure 4.7 - XRD Diffraction pattern of uncalcined and calcined $\mathrm{TiO}_{2}$ nanofibers

Through the XRD analysis the calcined nanofiber underwent a phase transformation to the anatase phase. By comparing the diffraction patterns of the uncalcined and calcined nanofiber it further supports the need for thermal treatment to induce the phase transformation of the $\mathrm{TiO}_{2}$ crystal structure. The observed crystal size of the anatase $\mathrm{TiO}_{2}$ crystal was estimated to be at $17.03 \mathrm{~nm}$.

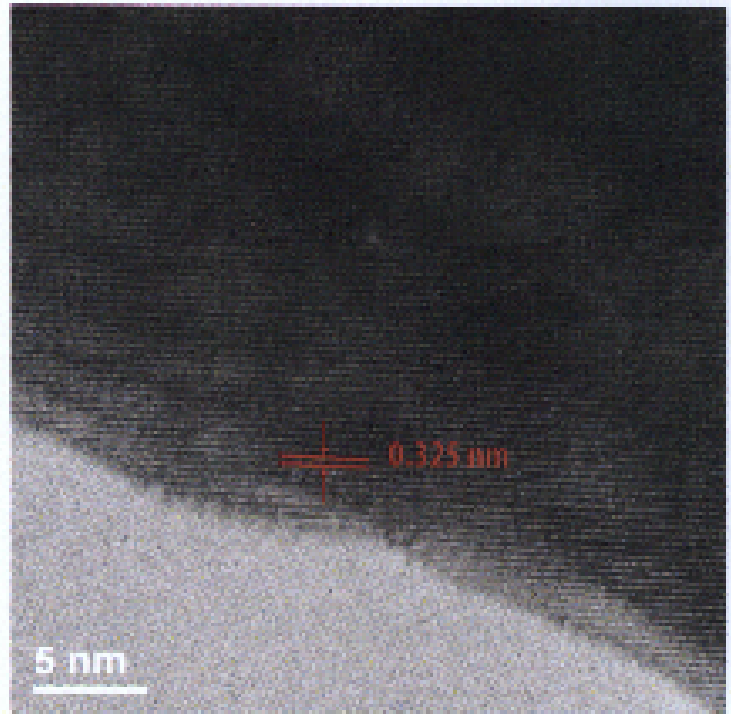

(a)

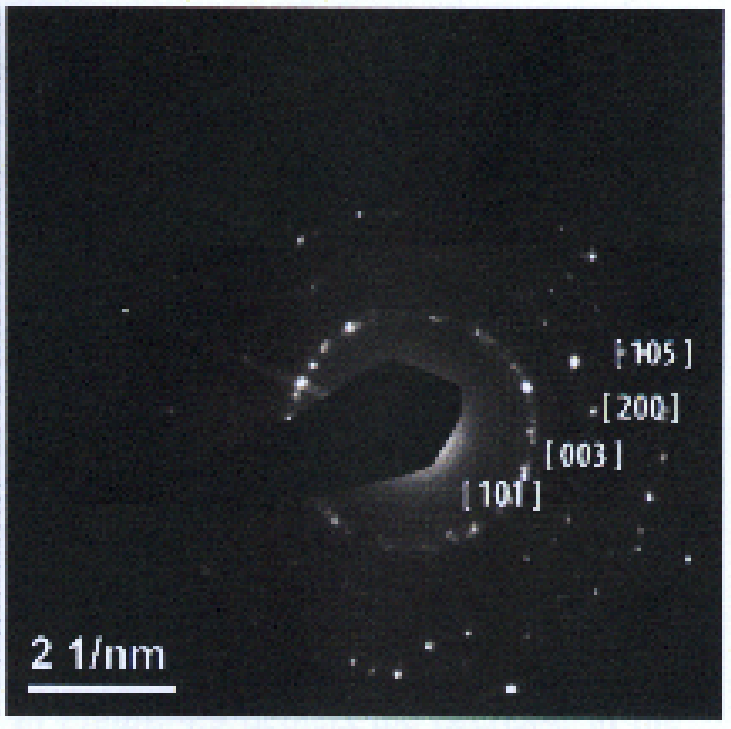

(b)

Figure 4.8 - (a) HRTEM image of $\mathrm{TiO}_{2}$ nanofiber indicating lattice of anatase $\mathrm{TiO}_{2}$ (b) Selected area electron diffraction (SAED) pattern 
The HRTEM in Figure 4.8 also justifies the fact that the $\mathrm{TiO}_{2}$ can be indexed to anatase phase. It is noted that the $\mathrm{TiO}_{2}$ nanofiber exhibit similar crystalline characteristics to that of the $\mathrm{TiO}_{2}$ nanotubes. The HRTEM image (Figure 4.8a) and SAED patterns depicts the lattice spacing of $0.325 \mathrm{~nm}$ which corresponds to the (101) plane of the anatase $\mathrm{TiO}_{2}$. Through the characterisation conducted on the $\mathrm{TiO}_{2}$ nanotubes and nanofiber, it clearly shows that both the one-dimensional nanostructures possesses similar crystalline properties even after undergoing thermal treatment at $550^{\circ} \mathrm{C}$. The only notable difference between the nanostructures is their morphological characteristics. As illustrated the FESEM images (Figure 4.2), the nanotubes are found to have a highly order structure due to its preferential perpendicular growth pattern. Whereas the nanofiber (Figure 4.6) were found to be random in its orientation and does not follow a specific formation pattern. Therefore, in order to determine the merits between the two different nanostructures their photocatalytic performance was evaluated. The results will be discussed in the following section.

\subsubsection{Review of Photocatalytic Performances}

Photocatalytic oxidation (PCO) tests was conducted to compare the photocatalytic performances of the synthesised one-dimensional $\mathrm{TiO}_{2}$ nanostructures. The photocatalytic activity of the one-dimensional $\mathrm{TiO}_{2}$ nanostructures was evaluated based on the degradation of acid orange 7 (AO7) under UV irradiation. AO7 is a water-soluble dye which is considered as a pervasive pollutants due to its potential to form cocontaminants for nitrates. It can be assumed that the rate at which AO7 degrades is proportional to its decolourisation rate at its characteristic wavelength (the wavelength at which the highest absorbance was observed in the blank sample $\lambda=480$ ) under UV irradiation. The experimental results shown in Figure 4.9 depicts the decrease in the normalised concentration of $\mathrm{AO} 7$ with time. 


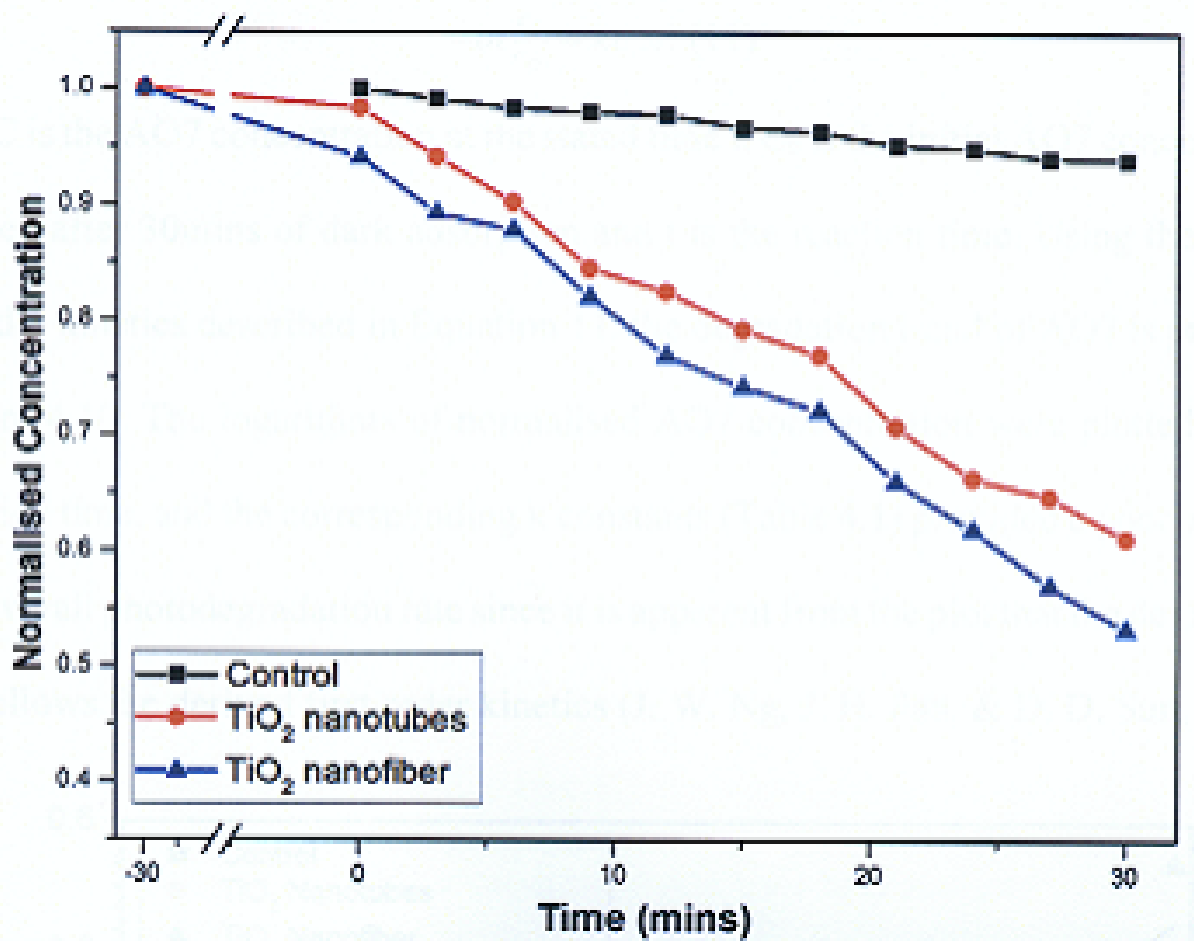

Figure 4.9 - Pseudo-First order degradation kinetics of one-dimensional $\mathrm{TiO}_{2}$ nanostructures

To model the photocatalytic degradation, Langmuir-Hinshelwood kinetics was applied (X. P. Wang \& Lim, 2010). As shown in Equation 9, the reaction rate (r) can be described as function of the degree of substrate coverage $(\theta)$ :

$$
r=k_{i} \theta=k_{i}\left(\frac{\kappa C}{1+K C}\right)
$$

where $\mathrm{C}$ is the concentration of $\mathrm{AO} 7, \mathrm{k}_{\mathrm{i}}$ is the intrinsic reaction rate constant, and $\mathrm{K}$ is the Langmuir adsorption equilibrium constant. As low AO7 concentration was used it can be readily presumed that $\mathrm{KC} \ll 1$. Hence, the reaction kinetics can be further simplified as indicated in Equation 10:

$$
r=-\frac{d C}{d t}=k K C=k C
$$

where $\mathrm{k}$ refers to the corresponding reaction rate kinetic constant. Assuming that the decolourisation $\mathrm{AO} 7$ follows a reaction pathway of a pseudo first-order reaction rate, the reaction kinetics can be further simplified in Equation 11. 


$$
-\ln \frac{c_{t}}{c_{o}}=k t
$$

where $\mathrm{C}$ is the $\mathrm{AO} 7$ concentration at the stated time $t, \mathrm{C}_{\mathrm{o}}$ is the initial $\mathrm{AO} 7$ concentration measured after $30 \mathrm{mins}$ of dark adsorption and $t$ is the reaction time. Using the pseudo first-order kinetics described in Equation 11, the degradation trend of $\mathrm{AO} 7$ is presented in Figure 4.10. The logarithms of normalised $\mathrm{AO} 7$ concentration were plotted against irradiation time, and the corresponding $\mathrm{k}$ constants (Table 4.1) provided a good measure of the overall photodegradation rate since it is apparent from the plot that the degradation trend follows the derived first order kinetics (J. W. Ng, J. H. Pan, \& D. D. Sun, 2011).

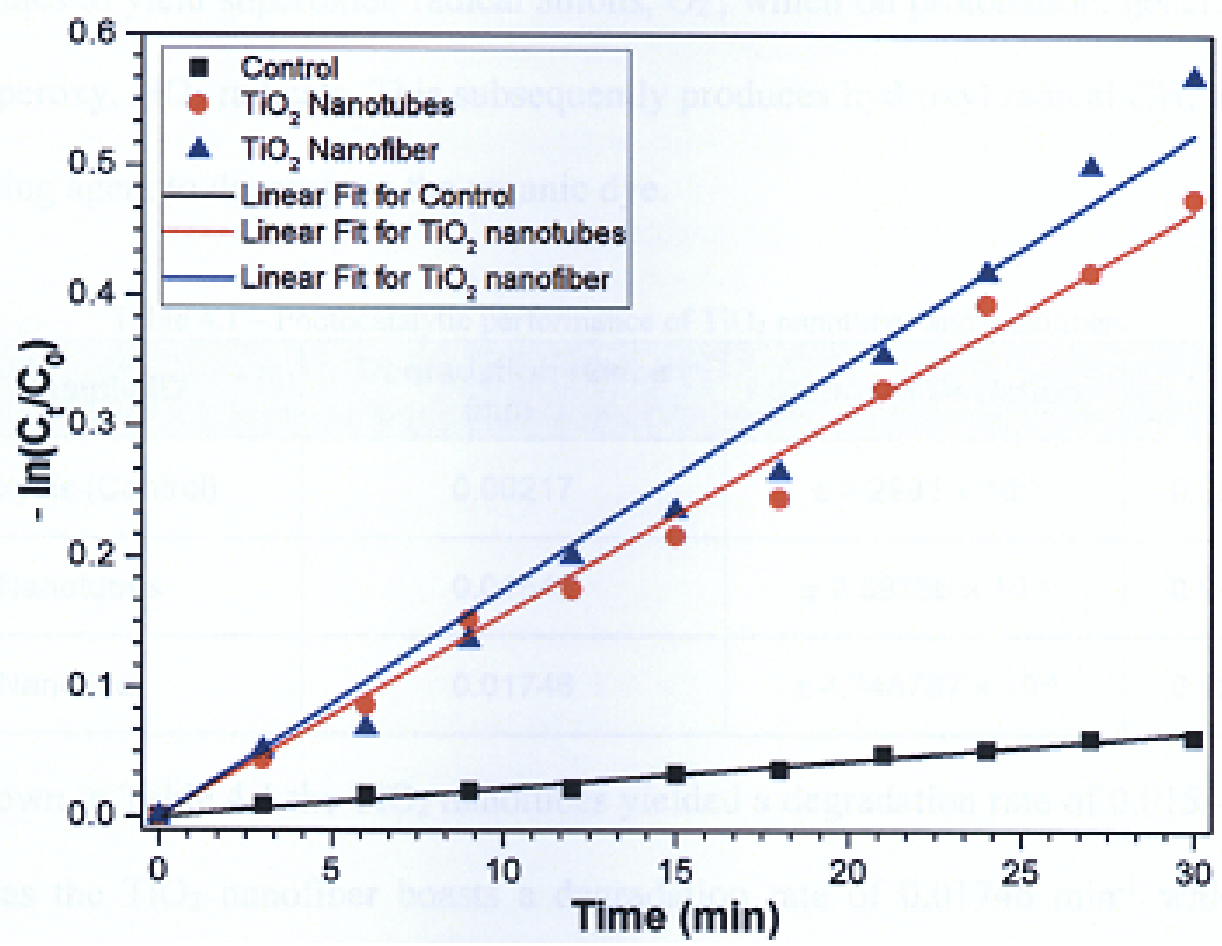

Figure 4.10-Plot of Normalised concentration against time comparing photocatalytic performance of different one-dimensional nanostructures

According to Figure 4.10 , it clearly illustrates the ability of the both one-dimensional $\mathrm{TiO}_{2}$ nanostructures to degrade the model organic pollutant. It is proposed that the onedimensional $\mathrm{TiO}_{2}$ nanostructure follows a similar degradation kinetics presented as follows (T. Cao, Li, Wang, Shao, \& Liu, 2011; X. M. Zhang, Huo, Hu, Wu, \& Chu, 2010): 


$$
\begin{gathered}
\mathrm{TiO}_{2}+h v \rightarrow \mathrm{TiO}_{2}\left(e_{C B}{ }^{-}+h_{V B}{ }^{+}\right) \\
h^{+}+\mathrm{OH}^{-} \rightarrow \mathrm{OH}^{\cdot \ldots}(13) \\
e^{-}+\mathrm{O}_{2} \rightarrow \mathrm{O}_{2}^{\cdot-} \ldots(14) \\
\mathrm{O}_{2}^{-}+\mathrm{H}_{2} \mathrm{O} \rightarrow \mathrm{HO}_{2} \cdot+\mathrm{OH}^{-} \ldots( \\
\mathrm{H}_{2} \mathrm{O}_{2} \rightarrow 2 \mathrm{OH} \cdot \ldots(16)
\end{gathered}
$$

Under UV irradiation $\mathrm{TiO}_{2}$ becomes excited, releasing electrons (e) from the valence band which immigrates to the conduction band (CB) of $\mathrm{TiO}_{2}$ leaving holes $\left(\mathrm{h}^{+}\right)$behind in the valence band. The electrons (e $\left.\mathrm{e}^{-}\right)$on the $\mathrm{CB}$ react with the dissolved oxygen molecules to yield superoxide radical anions, $\mathrm{O}_{2}{ }^{-}$, which on protonation, generates the hydroperoxy, $\mathrm{HO}_{2}$ radicals. This subsequently produces hydroxyl radical $\mathrm{OH}$, a strong oxidizing agent to decompose the organic dye.

Table 4.1 - Photocatalytic performance of $\mathrm{TiO}_{2}$ nanotubes and nanofibers

\begin{tabular}{|l|c|c|c|}
\hline Sample ID & $\begin{array}{c}\text { Dogradation rate, } \boldsymbol{k} \\
\left(\mathbf{m i n}^{-4}\right)\end{array}$ & Standard Deviation & $\mathbf{R}^{2}$ \\
\hline Photolysis (Control) & 0.00217 & $\pm 4.2991 \times 10^{-5}$ & 0.99544 \\
\hline $\mathrm{TiO}_{2}$ Nanotubes & 0.01548 & $\pm 2.59866 \times 10^{-4}$ & 0.99719 \\
\hline $\mathrm{TiO}_{2}$ Nanofiber & 0.01746 & $\pm 4.748767 \times 10^{-4}$ & 0.99266 \\
\hline
\end{tabular}

As shown in Table 4.1 the $\mathrm{TiO}_{2}$ nanotubes yielded a degradation rate of $0.01548 \mathrm{~min}^{-1}$ whereas the $\mathrm{TiO}_{2}$ nanofiber boasts a degradation rate of $0.01746 \mathrm{~min}^{-1}$ which was approximately $30 \%$ greater than that of the nanotubes. This difference in photocatalytic performance can be attributed to the dissimilar structural morphologies arising from the bundling of the nanotubes. This inevitably reduces the accessible surface area as it can be postulated that the organic pollutant $\mathrm{AO} 7$ does not enter the interstitial channels (the voids between the tubes in the bundles) of the nanotubular structure therefore decreasing the contact between the reaction environments (Schimmel et al., 2003). Further due to 
the structural properties of the $\mathrm{TiO}_{2}$ which are found in long fibers, it allows for better suppression to the recombination (Bai, Juay, et al., 2012).

Thus, despite the suggested enhance characteristics from the formation of the highly order structures it is revealed that from the photocatalytic oxidation tests that the relatively low accessible surface area resulted in the lower photocatalytic performance in the degradation of $\mathrm{AO} 7$ under UV irradiation. Moreover, Takanabe and Domen (2012) also supported the fact that the nanotubes which has a larger surface area resulted in the formation of different potential states due to the dangling bonds. These sites act as a recombination centre of the excited carriers thus leading to a decrease in the photocatalytic activity. Therefore, owing to these factors it is more feasible to select $\mathrm{TiO}_{2}$ nanofibers obtained through electrospinning as a basis for the subsequent bandgap engineering study as its morphology allows for more efficient flow of electrons and suppression to recombination. Moreover, experimental parameters of the electrospinning process can be easily modified at various stages of the process to obtain desired modifications.

\subsection{Optimisation of $\mathrm{TiO}_{2}$ Nanofibers for Band gap engineering}

As discussed Section 2.2.2 there are several factors influences the electrospinning process. During the author's attempt to synthesis a composite $\mathrm{TiO}_{2}$ nanofiber, it was found that the metal oxide salt, bismuth nitrate pentahydrate $\left(\mathrm{Bi}\left(\mathrm{NO}_{3}\right) \cdot 5 \mathrm{H}_{2} \mathrm{O}\right)$ did not readily dissolve in the formulation as previously shown in Table 3.1. Moreover, noted during the experimentation the solution promptly hydrolysed to form into a white precipitate after the addition of the bismuth salt. Therefore, this indicates the existing formulation is not compatible for the synthesis of the composite $\mathrm{TiO}_{2}$ nanofibers. Hence the composition of the precursor solution has to be adjusted to allow for the subsequent photocatalyst modifications of the $\mathrm{TiO}_{2}$ nanofiber. After several rounds of trial-and- 
error iteration and literature study, it is proposed that with the use of Dimethyformaide DMF (W. Wang et al., 2013) acting as an organic solvent it would be able to lower the evaporation rate and improve the solvent contact between the bismuth salt and the solution. This proposed adjustment made will aid in the synthesis process as it allowed for the formation of a stable precursor solution ready for electrospinning. The developed new composition of the precursor solution is shown in Table 4.2.

Table 4.2-Adjusted electrospinning precursor to accommodate the dissolution of bismuth salt

\begin{tabular}{|c|c|c|}
\hline Chemicals & Adjusted Ratio & Quantity \\
\hline $\begin{array}{l}\text { Anhydrous Ethanol } \\
\mathrm{C}_{2} \mathrm{H}_{5} \mathrm{OH}\end{array}$ & $11_{\text {Eth }}: 3_{A A}: 1_{D M F}$ & $11 \mathrm{~mL}$ \\
\hline $\begin{array}{l}\text { Anhydrous Acetic Acid } \\
\mathrm{CH}_{3} \mathrm{COOH}\end{array}$ & $11_{\text {Eth }}: 3_{A A}: 1_{D M F}$ & $3 \mathrm{~mL}$ \\
\hline $\begin{array}{l}\text { Dimethyformaide (DMF) } \\
\mathrm{C}_{3} \mathrm{H}_{7} \mathrm{NO}\end{array}$ & $11_{\mathrm{Eth}}: 3_{\mathrm{AA}}: 1_{\mathrm{DMF}}$ & $1 \mathrm{~mL}$ \\
\hline $\begin{array}{l}\text { Poly(vinylpyrrolidone) } \\
\text { (PVP) }\end{array}$ & $\sim 7$ wt $\%$ & $0.989 \mathrm{~g}$ \\
\hline $\begin{array}{l}\text { Titanium Butoxide (TBOT) } \\
\left(\mathrm{C}_{4} \mathrm{H}_{9} \mathrm{O}\right)_{4} \mathrm{Ti} \text { or } \mathrm{Ti}(\mathrm{OBu})_{4}\end{array}$ & $\sim 22$ wt \% & $3.2 \mathrm{~mL}$ \\
\hline $\begin{array}{l}\text { Bismuth Nitrate Pentahydrate } \\
\mathrm{Bi}\left(\mathrm{NO}_{3}\right)_{3} \cdot 5 \mathrm{H}_{2} \mathrm{O}\end{array}$ & $\sim 3 w t \%$ & $0.15 \mathrm{~g}$ \\
\hline
\end{tabular}

Therefore with the adjustment made to the precursor solution, it is imperative that the $\mathrm{TiO}_{2}$ nanofiber morphology and stability is evaluated in order to optimise its properties before for subsequent studies can be conducted. The high magnification FESEM image shown in Figure 4.11 shows the pure $\mathrm{TiO}_{2}$ nanofibers after calcination at various temperatures.

Table 4.3 - Description of nanofiber sample and its associated IDs

\begin{tabular}{|l|l|}
\hline Sample IDs & \multicolumn{1}{c|}{ Description } \\
\hline TNF450C & $\mathrm{TiO}_{2}$ nanofiber which was calcined at $\underline{450^{\circ} \mathrm{C}}$ \\
\hline TNF550C & $\mathrm{TiO}_{2}$ nanofiber which was calcined at $\underline{50^{\circ} \mathrm{C}}$ \\
\hline TNF650C & $\mathrm{TiO}_{2}$ nanofiber which was calcined at $\underline{650^{\circ} \mathrm{C}}$ \\
\hline TNF750C & $\mathrm{TiO}_{2}$ nanofiber which was calcined at $\underline{750^{\circ} \mathrm{C}}$ \\
\hline
\end{tabular}




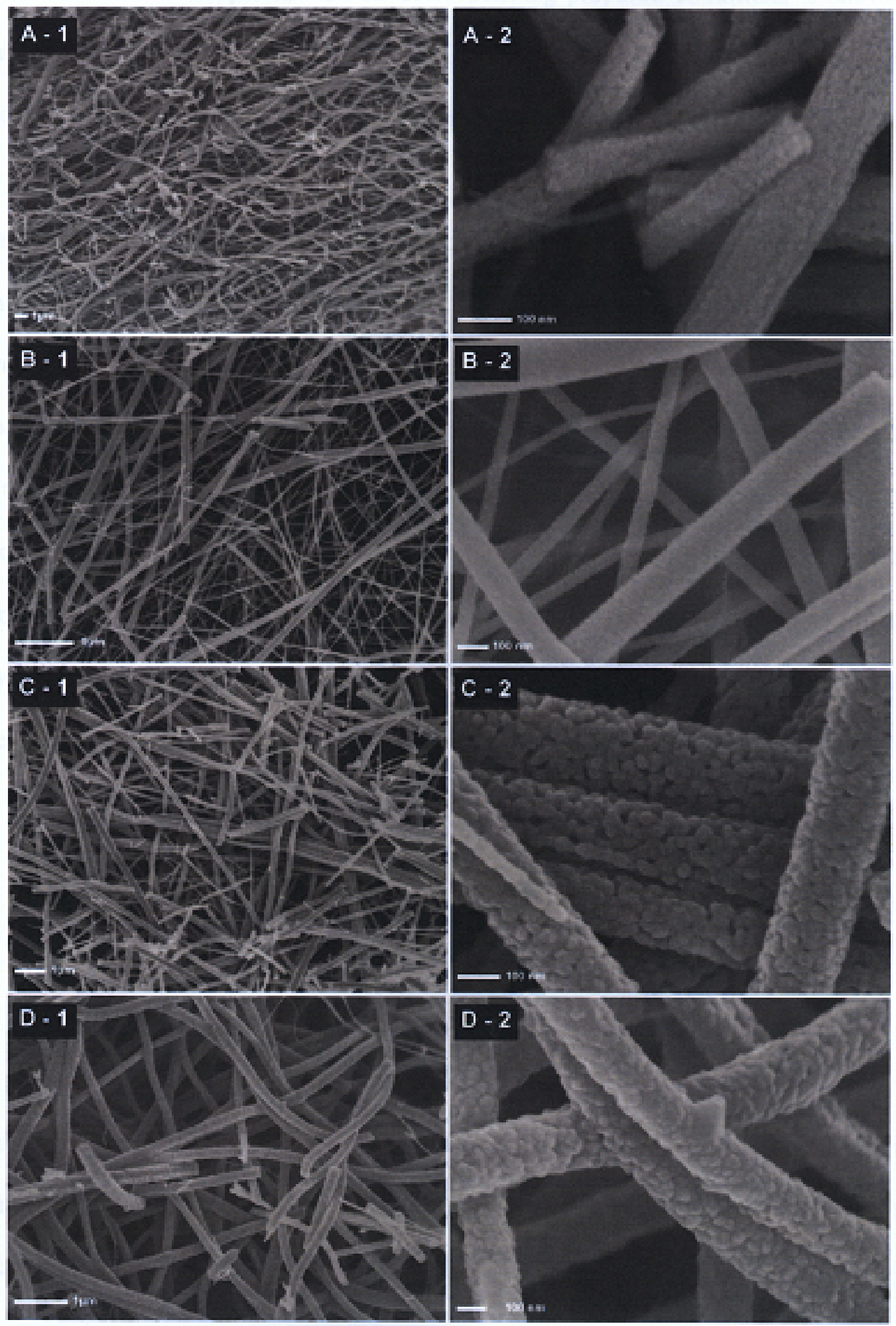

Figure 4.11 - FESEM images of $\mathrm{TiO}_{2} \mathrm{NFs}$ calcined at (a) $450^{\circ} \mathrm{C}$; (b) $550^{\circ} \mathrm{C}$; (c) $650^{\circ} \mathrm{C}$; (d) $750^{\circ} \mathrm{C}$

The images provides evidence of the stability of the precursor solution in the formation of the $\mathrm{TiO}_{2}$ nanofiber. The prepared nanofiber were calcined at different temperature to determine the optimum calcination temperature to maximise its photocatalytic 
performance. The sample ID and its corresponding prepared conditions is shown in Table 4.3. As illustrated in the FESEM images the evaporation and thermal decomposition of organic compounds coupled with the crystallisation of the $\mathrm{TiO}_{2}$ into its anatase phase resulted in the formation of the rough surface morphology for the $\mathrm{TiO}_{2}$ nanofiber. This phenomena was consistent despite the different calcination temperature. The formation of the rough and porous surface morphology and nanocrystalline structure of the anatase phase improves the surface properties than compare to smooth fibers which results in an improved photocatalytic efficiencies. Moreover as illustrated in the Table 4.4, as the thermal treatment temperature increases there was an observed decrease in the average fiber diameter. It is suggested that the decrease in diameter shows that with an increase in the thermal treatment temperature it lead to the growth in crystal size. The formation of larger anatase crystallites sizes would inevitable result in the decrease in the BET surface area.

Table 4.4-Diameter distribution of $\mathrm{TiO}_{2} \mathrm{NFs}$

\begin{tabular}{|l|c|c|}
\hline Sample & Diameter range $(\mathbf{n m})$ & $\begin{array}{c}\text { Average Fiber } \\
\text { Dlameter }(\mathbf{n m})\end{array}$ \\
\hline TNF450C & $90-210$ & 115 \\
\hline TNF550C & $82-180$ & 86 \\
\hline TNF650C & $77-186$ & 80 \\
\hline TNF750C & $61-147$ & 73 \\
\hline
\end{tabular}

This observed relation and its impact on the physiochemical characteristics of the $\mathrm{TiO}_{2}$ nanofiber will be further studied and the findings will be discussed in the following section. 
4.2.1. Physiochemical Properties of $\mathrm{TiO}_{2}$ nanofibers

Table 4.5-Physiochemical properties of $\mathrm{TiO}_{2}$ nanofiber calcined at various temperature

\begin{tabular}{|c|c|c|c|c|}
\hline Sample & $\begin{array}{c}\text { Surface } \\
\text { Area } \\
\left(\mathbf{m}^{\mathbf{2}} / \mathbf{g}\right)\end{array}$ & $\begin{array}{c}\text { Estimated pore } \\
\text { diameter } \\
(\mathbf{n m})\end{array}$ & $\begin{array}{c}\text { Full width at } \\
\text { half maximum } \\
\text { (deg) }\end{array}$ & $\begin{array}{c}\text { Anatase TiO } \\
\text { crystallite size } \\
\text { (nm) }\end{array}$ \\
\hline TNF450C & 39.986 & 3.635 & 0.70216 & 12.12 \\
\hline TNF550C & 28.327 & 3.634 & 0.49661 & 17.15 \\
\hline TNF650C & 17.756 & 3.273 & 0.26204 & 32.5 \\
\hline TNF750C & 10.536 & 2.144 & 0.20446 & 41.65 \\
\hline
\end{tabular}

Through the FESEM images it is evident that the nanofiber calcined at various temperature had different surface morphology, a detailed study on their physiochemical characteristics was conducted. The resultant findings are summarised in Table 4.5. The diffraction patterns of $\mathrm{TiO}_{2}$ nanofibers calcined at various temperatures are shown in Figure 4.12

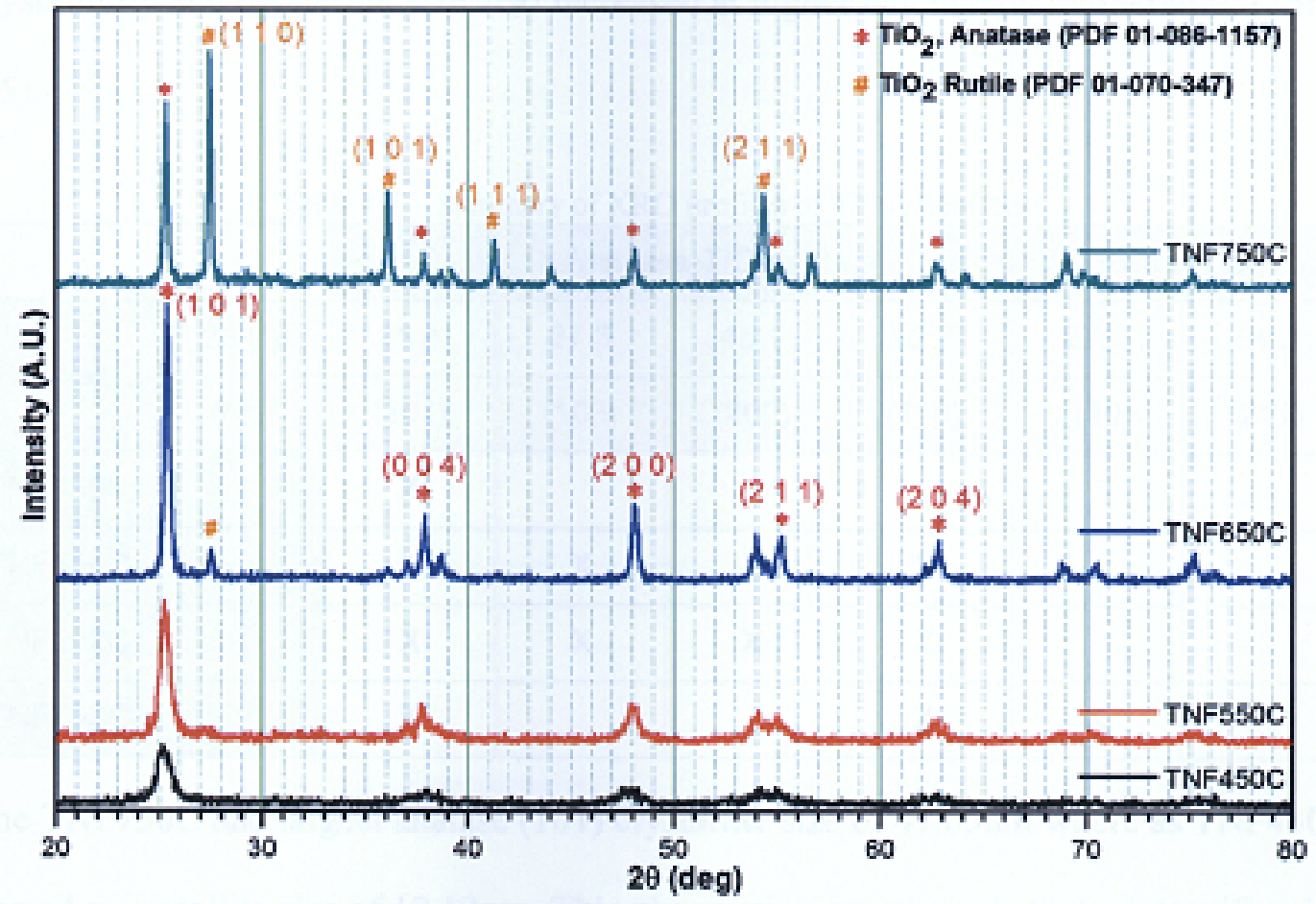

Figure 4.12 - Diffraction pattern $\mathrm{TiO}_{2}$ nanofibers

It is validated that the nanofibers are characterised to the anatase crystalline phase. Table 4.5 provides the summary of the XRD diffraction peaks for synthesised nanofibers. The detected anatase crystal phase with major diffraction peaks occurring at $25.4^{\circ}, 37.8^{\circ}$, 
$48.1^{\circ}$, and $62.7^{\circ}$ was observed for the TNF450C, TNF550C, TNF650C, TNF750C. Whereas the rutile peaks at $27.6^{\circ}$ and $54.3^{\circ}$ was only observed for the TNF750C. As discussed in the earlier section thermal treatment through the calcination process was required to induce the crystallisation and phase transformation of the $\mathrm{TiO}_{2}$ nanofibers. Upon calcination, $\mathrm{TiO}_{2}$ nanofibers that underwent heat treatment at $450^{\circ} \mathrm{C}$ (TNF450C), $550^{\circ} \mathrm{C}$ (TNF550C) and $650^{\circ} \mathrm{C}$ (TNF650C) displays characteristic of anatase $\mathrm{TiO}_{2}$, while $\mathrm{TiO}_{2}$ nanofiber calcined at $750^{\circ} \mathrm{C}$ (TNF750C) displays characteristic of both anatase rutile $\mathrm{TiO}_{2}$. This indicates that the phase transition from anatase to rutile occurred above $650^{\circ} \mathrm{C}$. Although residual anatase phase is still observed to be present in TNF750C, the rutile content was found to increase with respect to the calcination temperature at the cost of anatase crystals. Furthermore, revealed from the diffraction patterns the crystallinity and crystallite size also increased at higher calcination temperature (Table 4.5).

Table 4.6 - Summary of XRD profiles of $\mathrm{TiO}_{2}$ nanofibers

\begin{tabular}{|c|c|c|c|c|c|c|c|}
\hline & & \multicolumn{4}{|c|}{ Anatase- $\mathrm{TIO}_{2}$} & \multicolumn{2}{|c|}{ Rutile-TIO 2} \\
\hline \multirow{2}{*}{ Sample } & $2 \theta\left(^{\circ}\right)$ & 25.4 & 37.8 & 48.1 & 62.7 & 27.6 & 54.3 \\
\hline & (hkl) & (101) & (103) & (200) & $(116)$ & (110) & (211) \\
\hline TNF 450C & & $\mathbf{X}$ & & & & & \\
\hline TNF550C & $=$ & $\mathbf{x}$ & $\mathbf{X}$ & $\mathbf{X}$ & $\mathbf{X}$ & & \\
\hline TNF650C & & $\mathbf{x}$ & $\mathbf{X}$ & $\mathbf{X}$ & $\mathbf{X}$ & & \\
\hline TNF750C & & $x$ & & & $X$ & $x$ & $X$ \\
\hline
\end{tabular}

The TNF750C had largest anatase (101) crystallite size of $41.65 \mathrm{~nm}$ where as TNF450C owned a crystallite size of $12.12 \mathrm{~nm}$. This observation corresponds to the intensification of the anatase diffraction peaks at higher calcination temperature and the progressive narrowing of the width of the anatase peaks. These changes observed in the diffraction patterns are attributed to the growth of the $\mathrm{TiO}_{2}$ crystal as the calcination temperature 
increases (S. S. Lee, Bai, Liu, \& Sun, 2013). Essentially, these results prove that high temperature treatment induces aggregation of small crystals through the crystal growth process thereby causing the curtailment of the surface area and diminution of fiber diameter.

From the BET analysis, it was observed that the hypothesised correlation between the increase in calcination temperature and the decrease in BET surface area is consistent. The observed BET surface area decreased with an increase in calcination temperature; TNF450C $-39.986 \mathrm{~m}^{2} / \mathrm{g}>$ TNF550C $-28.327 \mathrm{~m}^{2} / \mathrm{g}>$ TNF $650 \mathrm{C}-17.1756 \mathrm{~m}^{2} / \mathrm{g}>$ TNF750C $-10.536 \mathrm{~m}^{2} / \mathrm{g}$. As such, it can be concluded that the smaller crystallites allowed the formation of a larger BET surface area as evident from the FESEM images and XRD analysis.

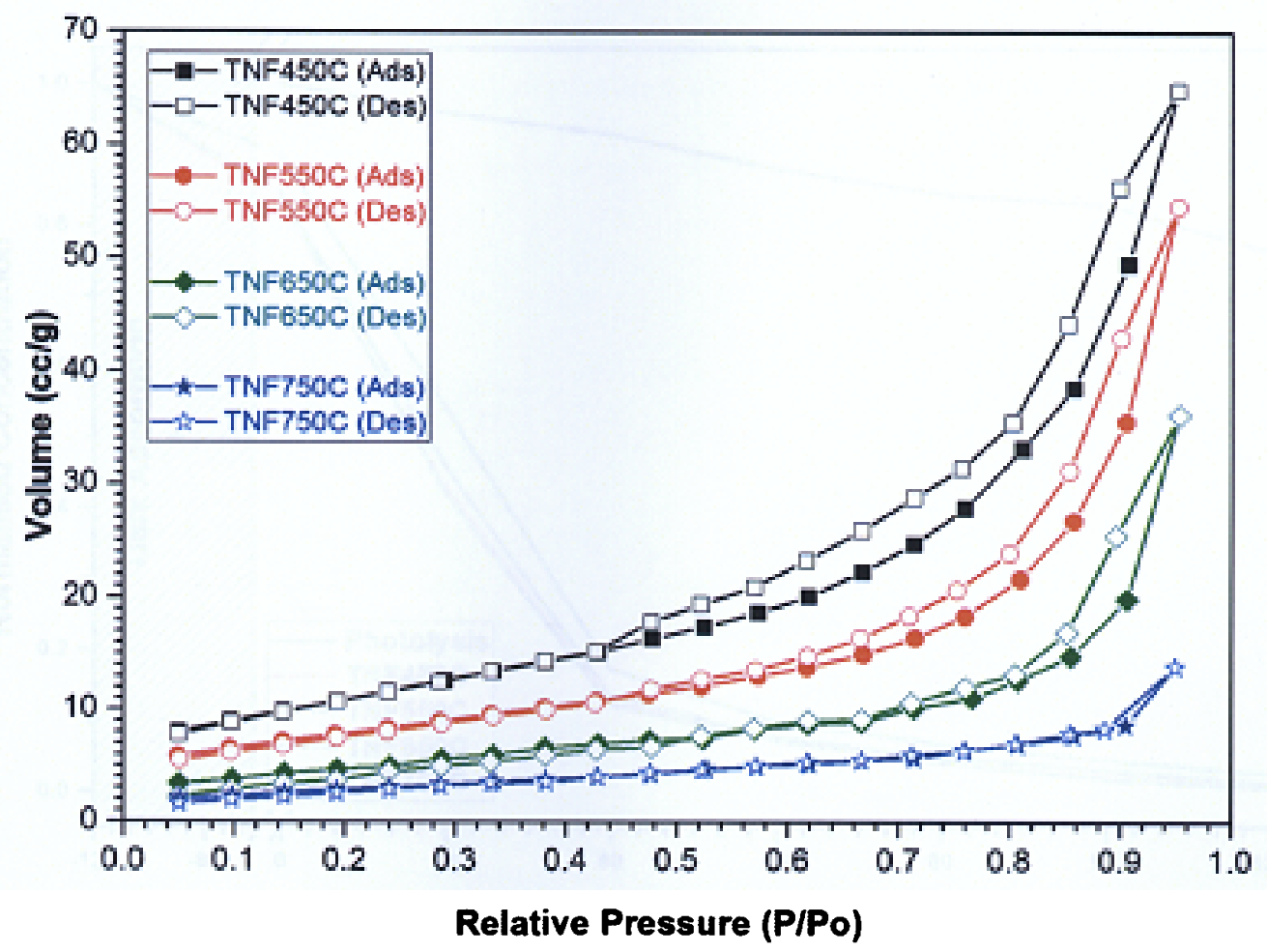

Figure 4.13 - Adsorption/Desorption isotherms of $\mathrm{TiO}_{2}$ nanofibers calcined at various temperatures Moreover, from the adsorption/desorption isotherms shown in Figure 4.13 the nanofiber calcined between $450^{\circ} \mathrm{C}$ and $750^{\circ} \mathrm{C}$ are attributed with a Type IV Brunauer-Emmett- 
Teller (BET) isotherm. This indicates the existence of mesoporosity (Table 4.7) in the nanofibers. The modelled BJH pore size (Appendix C) further affirms the mesoporosity of the nanofibers with the nanofiber having an estimate pore size between 2.7 to $3.6 \mathrm{~nm}$

Table 4.7- Characteristics of pores structure

\begin{tabular}{|c|c|}
\hline Types of pores & Pore diameter, $\mathbf{d}_{\mathbf{p}}(\mathbf{n m})$ \\
\hline Micropores & $<2$ \\
\hline Mesopores & 2 to 50 \\
\hline Macropores & $>50$ \\
\hline
\end{tabular}

Adapted from Trunschke (2013)

\subsubsection{Photocatalytic activity}

To evaluate the performance of the $\mathrm{TiO}_{2}$ nanofiber calcined at various temperature, photocatalytic oxidation test was conducted under UV irradiation. Figure 4.14 shows the normalised degradation curve of Acid Orange 7 (AO7) under UV irradiation.

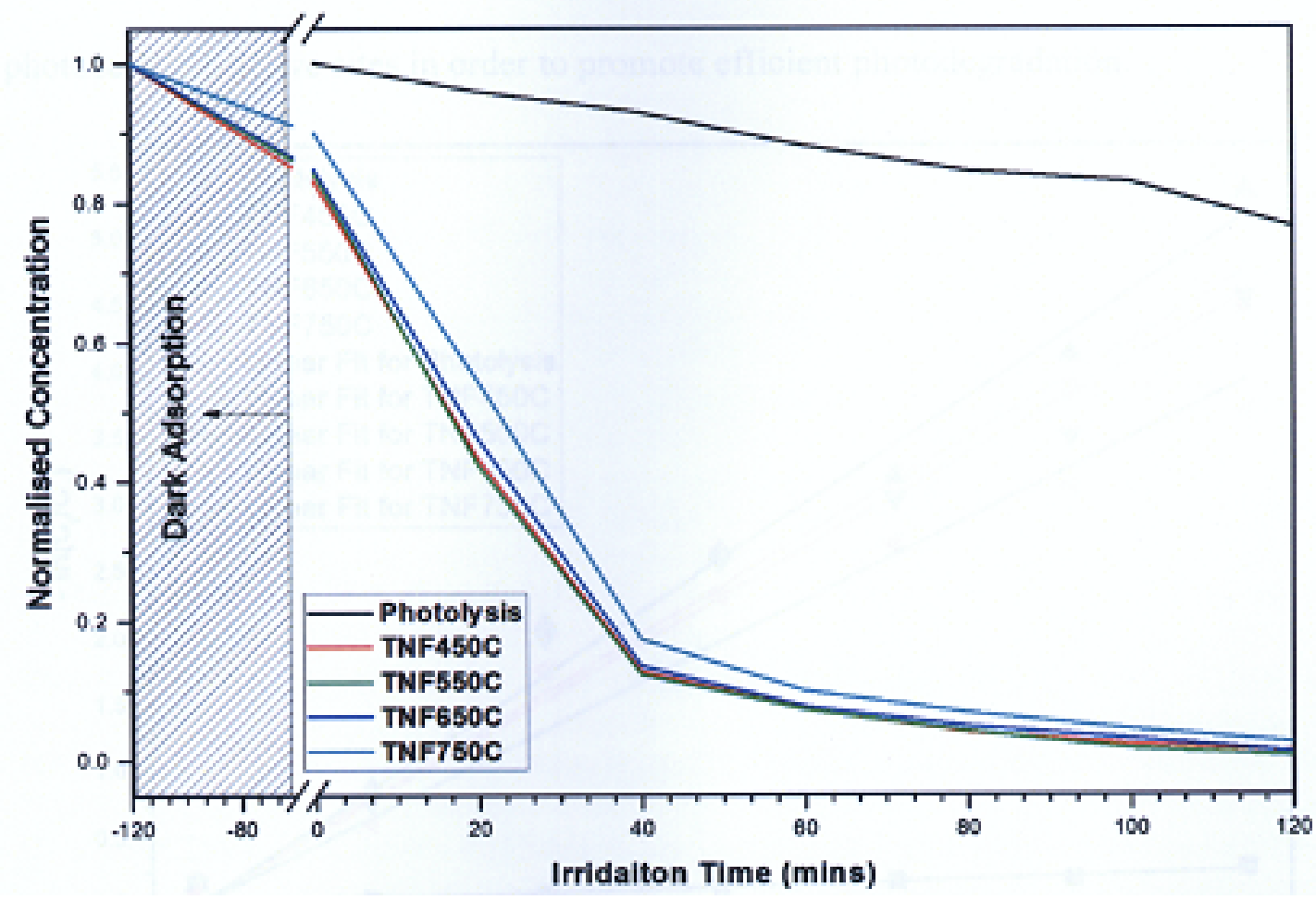

Figure 4.14 - Plot of Normalised concentration against time of $\mathrm{TiO}_{2}$ nanofiber calcined at various temperatures

The results indicate that the synthesised nanofiber with the adjusted formulation maintained its capability to degrade AO7 under UV irradiation. The degradation kinetics 
discussed in Section 4.1.3 was applied to determine the pseudo-first order degradation rate of the nanofiber calcined at various temperatures. The pseudo-first order rate constants of the degradation reaction procured from Figure 4.15 are $0.03952 \mathrm{~min}^{-1}$, $0.04307 \mathrm{~min}^{-1}, 0.03818 \mathrm{~min}^{-1}, 0.03274 \mathrm{~min}^{-1}$ corresponding to TNF450C, TNF550C, TNF650C and TNF750C respectively (Table 4.8).

It is well established that surface properties of the photocatalyst has a significant influence on the degradation of organic molecules. The TNF750C which has the lowest BET surface area of $10.536 \mathrm{~m}^{2} / \mathrm{g}(\mathrm{TNF} 450 \mathrm{C}>\mathrm{TNF} 550 \mathrm{C}>\mathrm{TNF} 650 \mathrm{C}>\mathrm{TNF} 750 \mathrm{C})$, consequentially indicates a lack of active sites for the photogeneration of electron-hole pairs. Moreover, this decreases the interaction between the photocatalyst and the environment due to the inferior surface-to-volume ratio of the TNF750C. Therefore, these findings indicate that the surface area properties are beneficial in increasing photocatalytic active sites in order to promote efficient photodegradation.

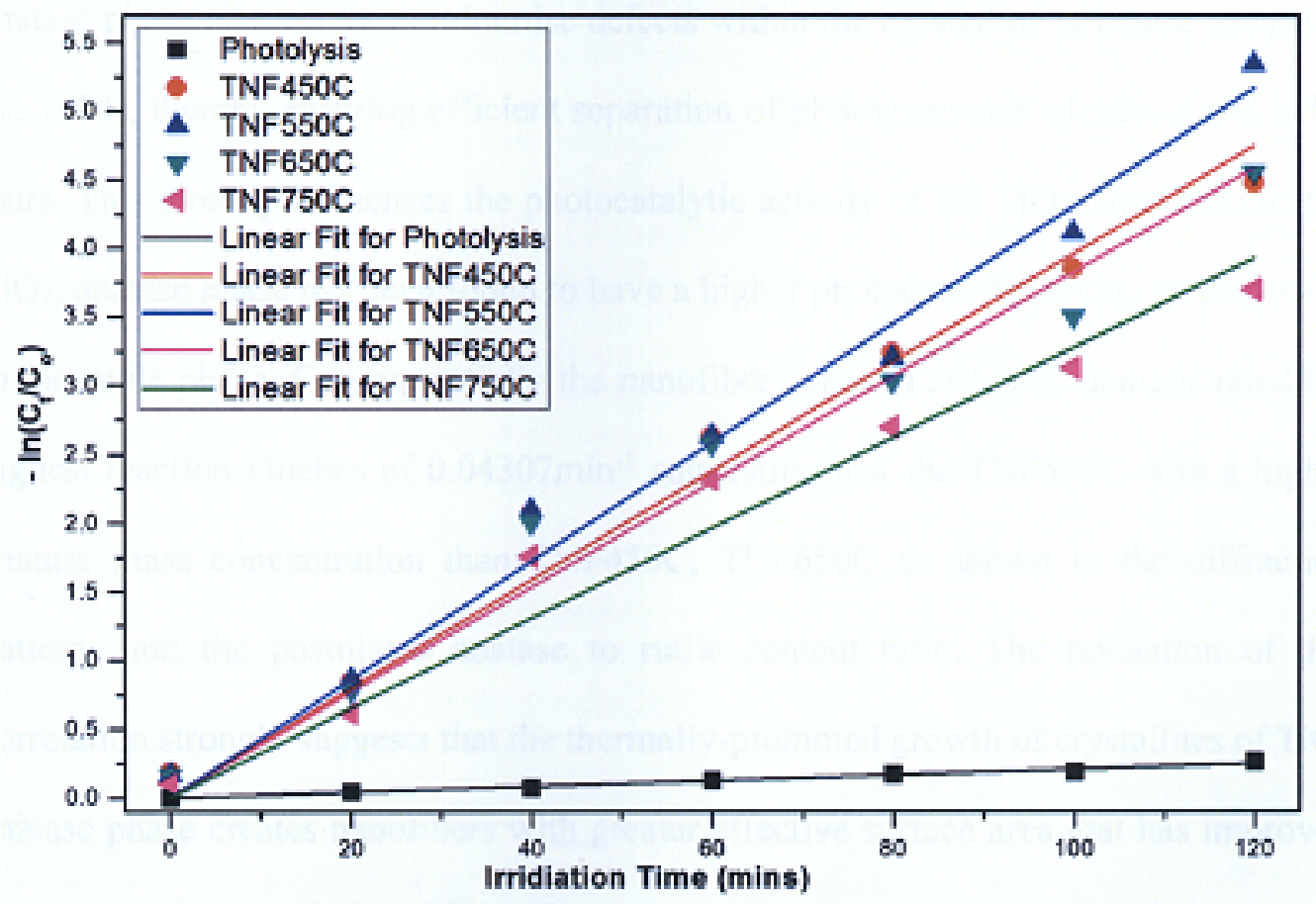

Figure 4.15 - Plot of logarithm of first order degradation rate of $\mathrm{TiO}_{2}$ nanofiber calcined under various temperature 
However, comparing the degradation kinetics and the BET surface area of the TNF450C $\left(0.03952 \mathrm{~min}^{-1}, 39.986 \mathrm{~m}^{2} / \mathrm{g}\right)$ and TNF550C $\left(0.04307,28.327 \mathrm{~m}^{2} / \mathrm{g}\right)$ it can be concluded that the crystalline properties of the nanofibers greatly influences the photocatalytic ability of the photocatalyst. The results indicated in Table 4.8 shows that the $\mathrm{TiO}_{2}$ nanofiber with a greater anatase crystalline properties possess a higher photocatalytic activity under UV irradiation.

Table 4.8 - Modelled Pseudo-first order degradation rate of $\mathrm{TiO}_{2}$ nanofibers

\begin{tabular}{|c|c|c|c|}
\hline Sample ID & $\begin{array}{c}\text { Degradation rate, } \boldsymbol{k} \\
\left(\mathbf{m i n}^{-1}\right)\end{array}$ & $\begin{array}{c}\text { Standard } \\
\text { Doviation }\end{array}$ & $\mathbf{R}^{2}$ \\
\hline Photolysis & 0.00209 & $\pm 6.343544 \times 10^{-5}$ & 0.99434 \\
\hline TNF450C & 0.03952 & \pm 0.00139 & 0.99214 \\
\hline TNF550C & 0.04307 & \pm 0.00117 & 0.99484 \\
\hline TNF650C & 0.03818 & \pm 0.001428 & 0.99179 \\
\hline TNF750C & 0.03274 & \pm 0.00138 & 0.98942 \\
\hline
\end{tabular}

As such the TNF450C, TNF550C and TNF650C had average higher degradation rate of $25 \%$ greater than the TNF750C. It is proposed that the high crystalline properties of the anatase phase is essential to minimise defects within the crystalline structure (Göpel et al., 1984), thereby ensuring efficient separation of photogenerated electrons and holes pairs. This directly influences the photocatalytic activity of the $\mathrm{TiO}_{2}$ nanofibers as the $\mathrm{TiO}_{2}$, anatase phase has been found to have a higher photocatalytic ability as compared to the rutile phase. Consequentially the nanofiber calcined at $550^{\circ} \mathrm{C}$ demonstrated the highest reaction kinetics of $0.04307 \mathrm{~min}^{-1}$ suggesting that the TNF550C with a higher anatase mass concentration than TNF450C, TNF650C as shown in the diffraction patterns and the postulated anatase to rutile content ratio. The revelation of this correlation strongly suggests that the thermally-promoted growth of crystallites of $\mathrm{TiO}_{2}$ anatase phase creates nanofibers with greater effective surface area that has improved photocatalytic degradation ability of organic pollutants. 


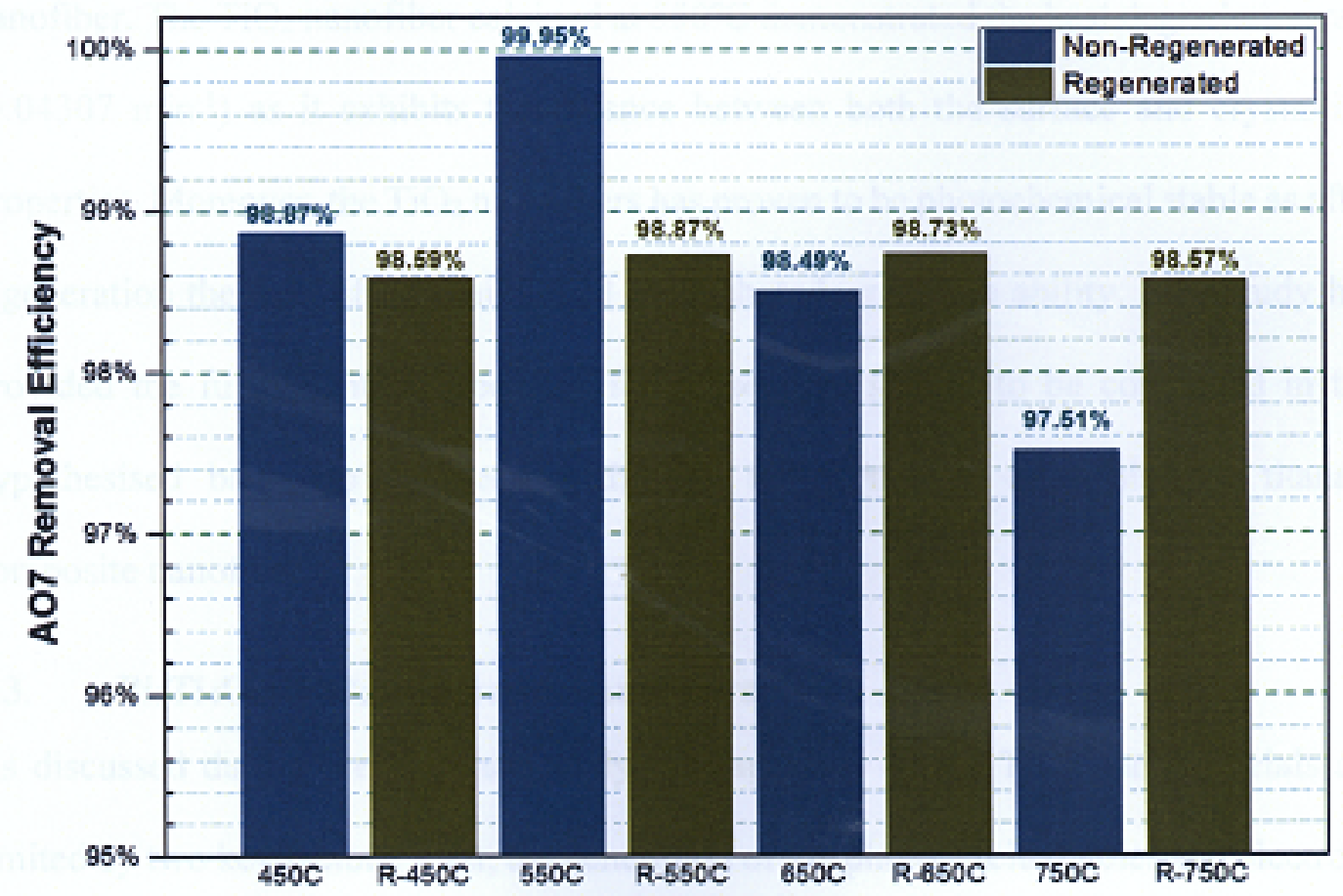

Figure 4.16 - Photochemical stability of $\mathrm{TiO}_{2} \mathrm{NFs}$

To evaluate the photochemical stability of various $\mathrm{TiO}_{2}$ nanofibers, the nanofibers were reclaimed and regenerated at $450^{\circ} \mathrm{C}$ to oxidise and remove the residual organics after the initial photocatalytic oxidation tests. From the experimental results illustrated in Figure 4.16 it indicates that regenerated nanofibers maintained their photocatalytic performance with the average decrease in $1 \%$ of removal efficiency considered as negligible. Thereby demonstrating the outstanding mechanical and photochemical stability of the prepared nanofibers.

\subsubsection{Summary}

In sum, this section has revealed that with the adjusted precursor formulation it permitted the synthesis of electrospun $\mathrm{TiO}_{2}$ nanofibers. Furthermore, revealed from the various studies conducted the calcination temperature has a significant impact on the photocatalytic degradation ability of organic pollutants (S. Yang et al., 2010). The BET surface area and the crystalline properties which changes with the increase in calcination temperature collectively influences the photocatalytic performances of the $\mathrm{TiO}_{2}$ 
nanofiber. The $\mathrm{TiO}_{2}$ nanofiber calcined at $550^{\circ} \mathrm{C}$ demonstrated the best degradation rate $\left(0.04307 \mathrm{~min}^{-1}\right)$ as it exhibits the balance between both the surface and crystalline properties. Moreover, the $\mathrm{TiO}_{2}$ nanofibers has proven to be photochemical stable as after regeneration the nanofibers maintained their photodegradation ability. This study has provided the fundamentals necessary for subsequent studies to be conducted in the hypothesised band-gap engineering through the formation of a bismuth titanate composite nanofiber.

\section{3. $\mathrm{Bi}_{2} \mathrm{Ti}_{4} \mathrm{O}_{11} / \mathrm{TiO}_{2}$ Composite nanofibers}

As discussed during the literature study the capability of the $\mathrm{TiO}_{2}$ nanomaterials are limited by two key factors. First, the generation of the photo-excited holes and electrons can only be achieved by UV irradiation $(\lambda<380 \mathrm{~nm})$ which renders the use of solar irradiation inefficient due to wide band gap of $\mathrm{TiO}_{2}(3.2 \mathrm{eV}$ anatase) (Devi \& Kavitha, 2013). Second, the lifetime of the photo-excited electrons and holes have limited mobility (Santato et al., 2001) due to the recombination of electron-hole pair (Ansari \& Cho, 2016).

In order to address these limitations, it is hypothesised that through the formation of a composite bismuth nanofiber it is possible to suppress the recombination of photogenerated electrons-holes and simultaneously decrease the band-gap allowing to absorb a larger spectrum of irradiation. The proposed composite bismuth titanate/titanium dioxide nanofiber prepared through this novel approach will be reviewed in the following sections.

\subsubsection{Physiochemical Properties}

The crystal structure of the composite nanofiber were investigated by XRD analysis (Figure 4.17). The diffraction patterns of the nanofiber calcined at various temperature revealed the successful formation of a composite nanostructure with both $\mathrm{Bi}_{2} \mathrm{Ti}_{4} \mathrm{O}_{11}$ and 
$\mathrm{TiO}_{2}$ crystalline structures. As observed the $\mathrm{Bi}_{2} \mathrm{Ti}_{4} \mathrm{O}_{11}$ diffraction were not prominent due to the low concentration of Bismuth precursor and convolution of the diffraction patterns of $\mathrm{TiO}_{2}$ anatase phase and the $\mathrm{Bi}_{2} \mathrm{Ti}_{4} \mathrm{O}_{11}$ phase (J. Hou, Wang, Jiao, \& Zhu, 2011). Moreover from the increase in peak intensity of the $\mathrm{Bi}_{2} \mathrm{Ti}_{4} \mathrm{O}_{11}$ species at higher temperatures, it can be suggested that a higher degree of crystallisation is required to enhance the detection of the $\mathrm{Bi}_{2} \mathrm{Ti}_{4} \mathrm{O}_{11}$ species. The $\mathrm{TiO}_{2}$ crystallinity and crystallite size also increased as calcination temperature increased. It was observed that the strength of the anatase diffraction peaks intensified at higher calcination temperature coupled with a progressive narrowing of the width of the anatase peaks which was attributed to the growth of the $\mathrm{TiO}_{2}$ crystal as the calcination temperature increases (S. S. Lee et al., 2013). This is further corroborated by the calculation of crystallite sizes of the anatase (lll $\left.\begin{array}{lll}1 & 0 & 1\end{array}\right)$ plane diffraction peak using the Scherrer equation as depicted in Table 4.8. In addition, from the nature of the XRD patterns it shows that the presence of the $\mathrm{Bi}_{2} \mathrm{Ti}_{4} \mathrm{O}_{11}$ did not affect the phase transformation of the $\mathrm{TiO}_{2}$, thus implying that the $\mathrm{Bi}$ precursor did not substitute $\mathrm{Ti}$ to enter the $\mathrm{TiO}_{2}$ lattice but was formed through a heterojunction which assimilates the $\mathrm{Bi}_{2} \mathrm{Ti}_{4} \mathrm{O}_{11}$ crystal phase and $\mathrm{TiO}_{2}$ crystal phase. 


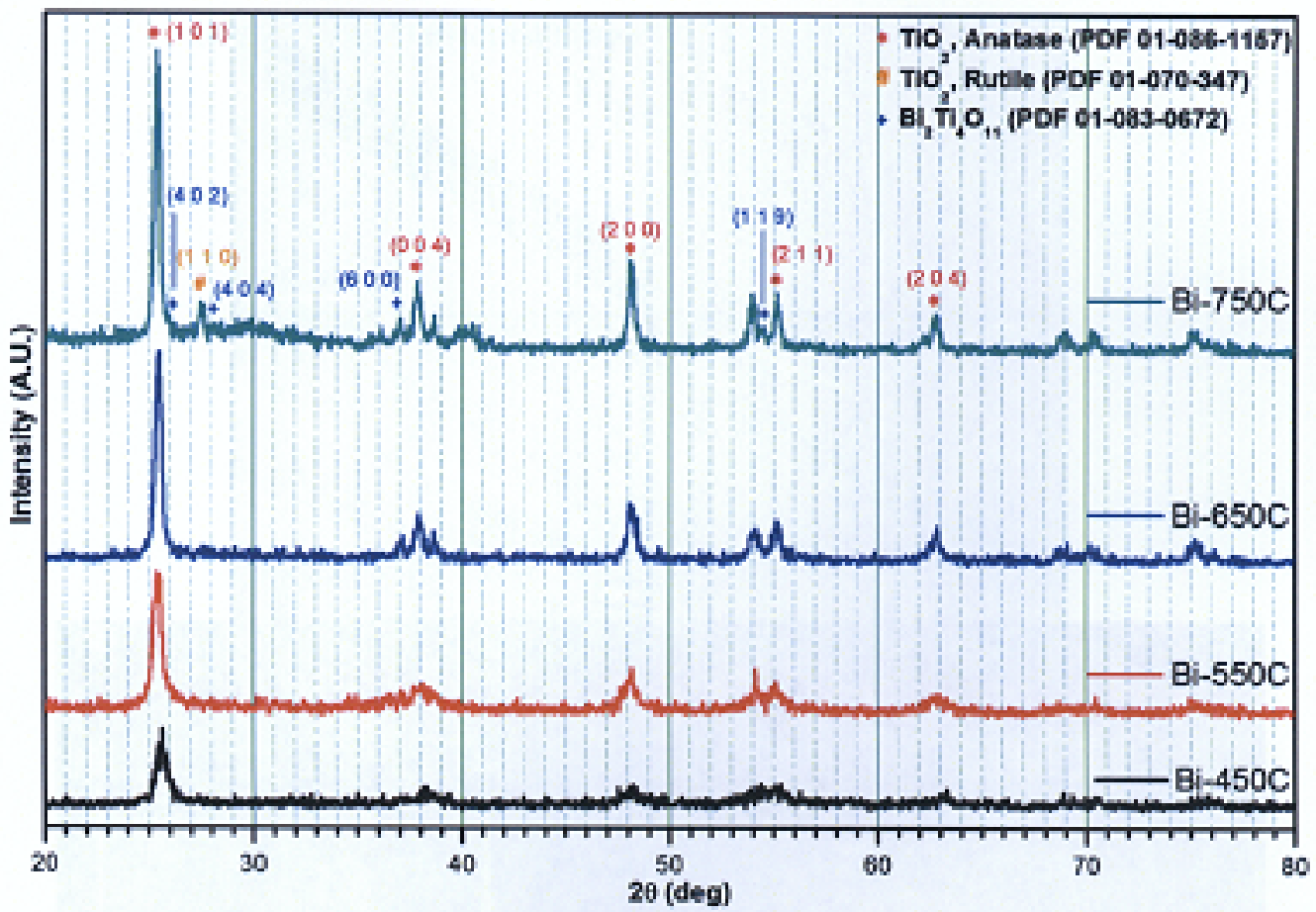

Figure 4.17 - XRD diffraction patterns of $\mathrm{Bi}_{2} \mathrm{Ti}_{4} \mathrm{O}_{11} / \mathrm{TiO}_{2}$ composited nanofiber which was calcined at various temperatures

From the XRD analysis as illustrated in Figure 4.17, it further substantiate the stability of the anatase phase between temperatures $450^{\circ} \mathrm{C}$ and $750^{\circ} \mathrm{C}$ as no further phase transformation from the anatase to rutile phase was observed. However, it is possible that amorphous crystals may still crystallise into the anatase phase. EDX analysis was conducted to determine the possible elements found in the composite nanofibers. EDX spectrum as shown in Figure 4.18(b) indicates the presence of the 3 elements; $\mathrm{Ti}, \mathrm{Bi}$ and O. As illustrated in the elemental mapping in Figure 4.18(a), Bi species was highly dispersed within composite nanofiber thus implying the homogeneous nature of the electrospinning sol-gel. Moreover, the EDX analysis also showed that the weight ratio of the Bismuth component was approximated at $3.34 \mathrm{wt} \%$ which corresponds to the amount of Bismuth precursor added to the sol-gel. This finding supports the fact of weak diffraction peaks for the $\mathrm{Bi}_{2} \mathrm{Ti}_{4} \mathrm{O}_{11}$ species as a consequence of the low concentrations and well dispersed nature of the Bi precursor $(\mathrm{Xu}, \mathrm{Ng}, \mathrm{Du}, \mathrm{Liu}, \&$ Sun, 2011). 


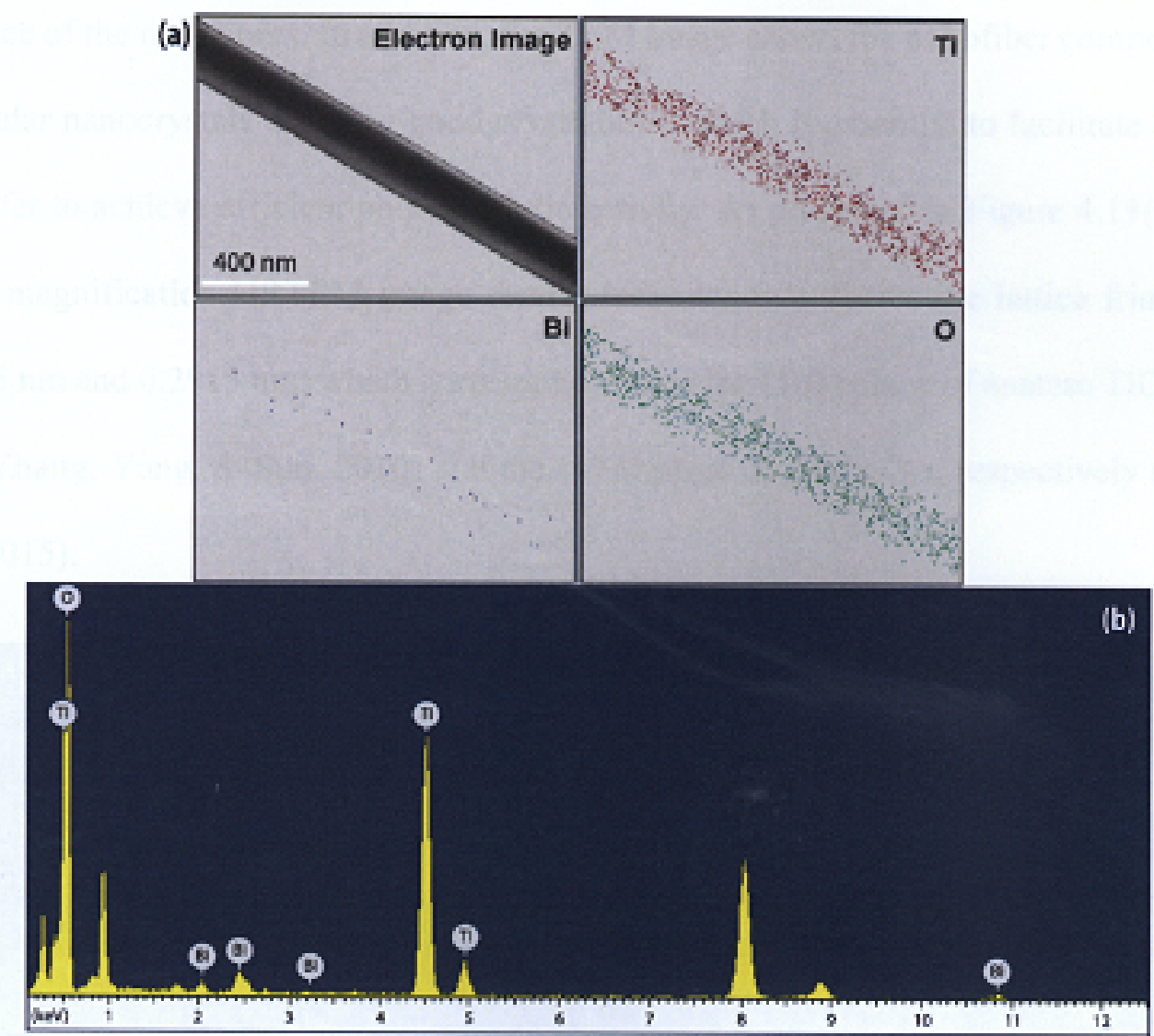

Figure 4.18 - (a) Elemental Mapping of the selected area for Ti element, Bi Element and $\mathrm{O}$ element (b) EDX spectrum of electron image shown in (a)

The FESEM image of the synthesised composite nanofiber is shown in Figure 4.19(a). Evidently, the composite nanofiber have diameters ranging from 70 to $100 \mathrm{~nm}$ with an aspect ratio from 25 to 55 . Under higher magnification, the nanofiber appeared to be smooth before the sintering, however after undergoing calcination, the surface of the nanofiber became rougher and the diameter was reduced. This indicates that the calcination process has led to the oxidation of organic materials and polymer binder used in the precursor (Bai, Juay, et al., 2012) hence the formation of a coarse and porous surface of the nanofiber. This characteristic of the nanofiber provides more active site for adsorption as well as enhance light absorption and utilisation for photocatalysis. The TEM image illustrated in Figure 4.19(c) exemplifies the detailed porous microstructure which was also observed in Figure 4.19(b). As proposed the porous structure is conducive for photocatalysis as it provides channels for the reactants to sorb onto the 
surface of the nanofibers. In addition, the TEM image shows the nanofiber comprises of granular nanocrystals denoting good crystallinity which is essential to facilitate charge transfer to achieve efficient photocatalytic activity. As presented in Figure 4.19(d), the high magnification HRTEM image clearly indicates two distinctive lattice fringes of $0.325 \mathrm{~nm}$ and $0.2953 \mathrm{~nm}$; which correspond well to the (101) plane of anatase $\mathrm{TiO}_{2}(\mathrm{Ng}$, $\mathrm{Xu}$, Zhang, Yang, \& Sun, 2010) and the (171) plane of $\mathrm{Bi}_{2} \mathrm{Ti}_{4} \mathrm{O}_{11}$, respectively (Shi et al., 2015).

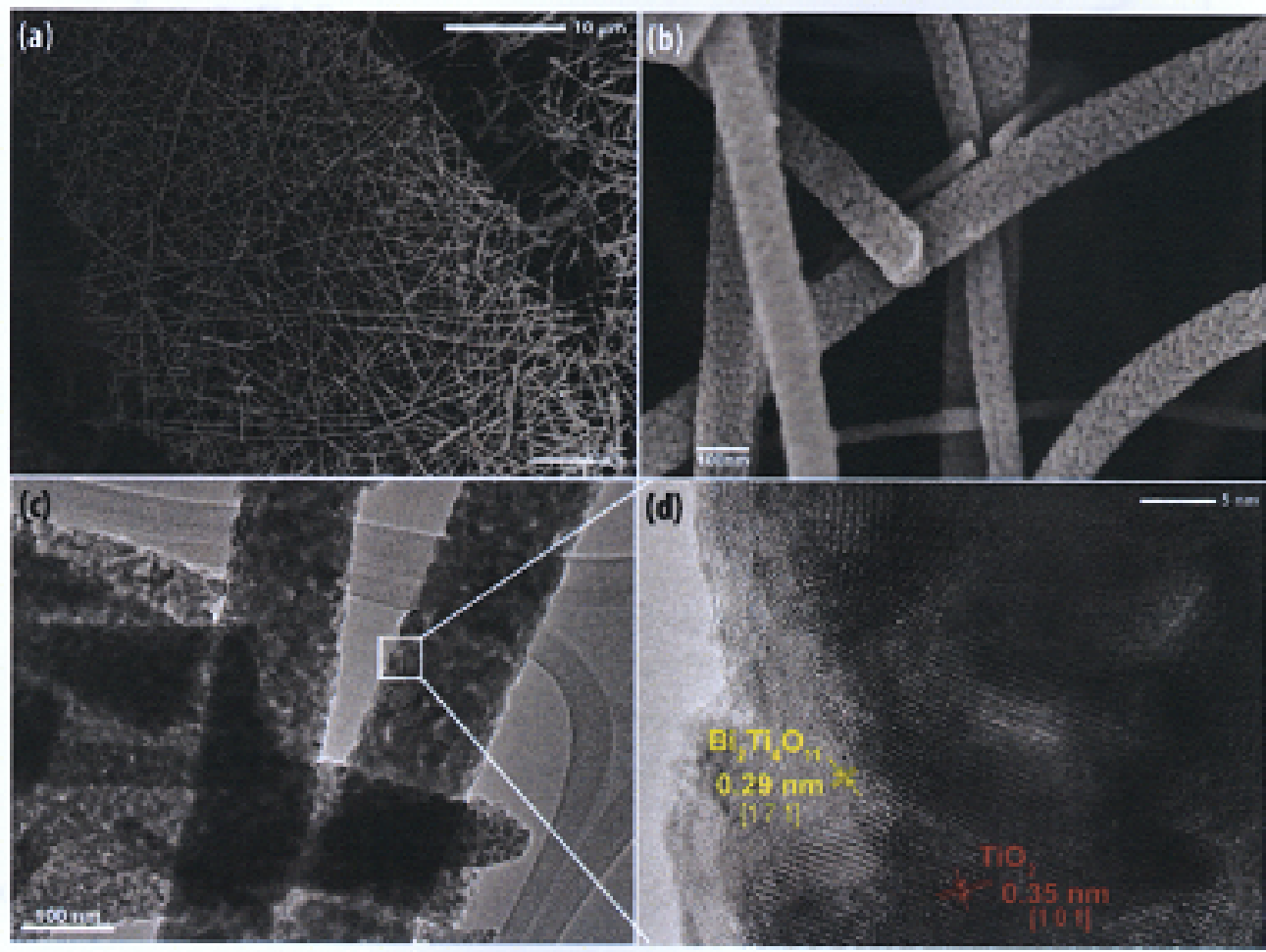

Figure 4.19 - (a) Low magnification FESEM of $\mathrm{Bi}_{2} \mathrm{Ti}_{4} \mathrm{O}_{11} / \mathrm{TiO}_{2}$ (Bi-550C) composite nanofiber after calcination $550^{\circ} \mathrm{C}$ (b) High magnification of FESEM image of $\mathrm{Bi}-550 \mathrm{C}$ (c) TEM image of Bi-550C (d) HRTEM image of $\mathrm{Bi}-550 \mathrm{C}$ showing corresponding lattice of $\mathrm{TiO}_{2}$ and $\mathrm{Bi}_{2} \mathrm{Ti}_{4} \mathrm{O}_{11}$

In order to study porosity of the prepared composite nanofibers, Brunauer-EmmettTeller nitrogen sorption measurements were carried out. When calcination temperature increased from $450^{\circ} \mathrm{C}$ to $750^{\circ} \mathrm{C}$, surface area decreased from $57.56 \mathrm{~m}^{2} / \mathrm{g}$ to $6.39 \mathrm{~m}^{2} / \mathrm{g}$ (Table 4.9). Evidently, the decrease in BET specific surface area was consistent with the growth of the anatase $\mathrm{TiO}_{2}$ crystallite at higher temperatures. Moreover, from the $\mathrm{N}_{2}$ adsorption and desorption isotherms (Figure 4.20), the composite nanofiber comprise of 
mesopores. Through the analysis, it was observed that, Bi-450C, Bi-550C, Bi-650C demonstrated a greater adsorbate-adsorbent and adsorbate-adsorbate interactions (P. D. Yang, Zhao, Margolese, Chmelka, \& Stucky, 1998) thus implying the occurrence of capillary condensation within mesopores. Meanwhile, the Bi-750C isotherms showed weak interactions of the adsorbate-adsorbent arising from the crystal growth that resulted in the aggregation at higher calcination temperature.

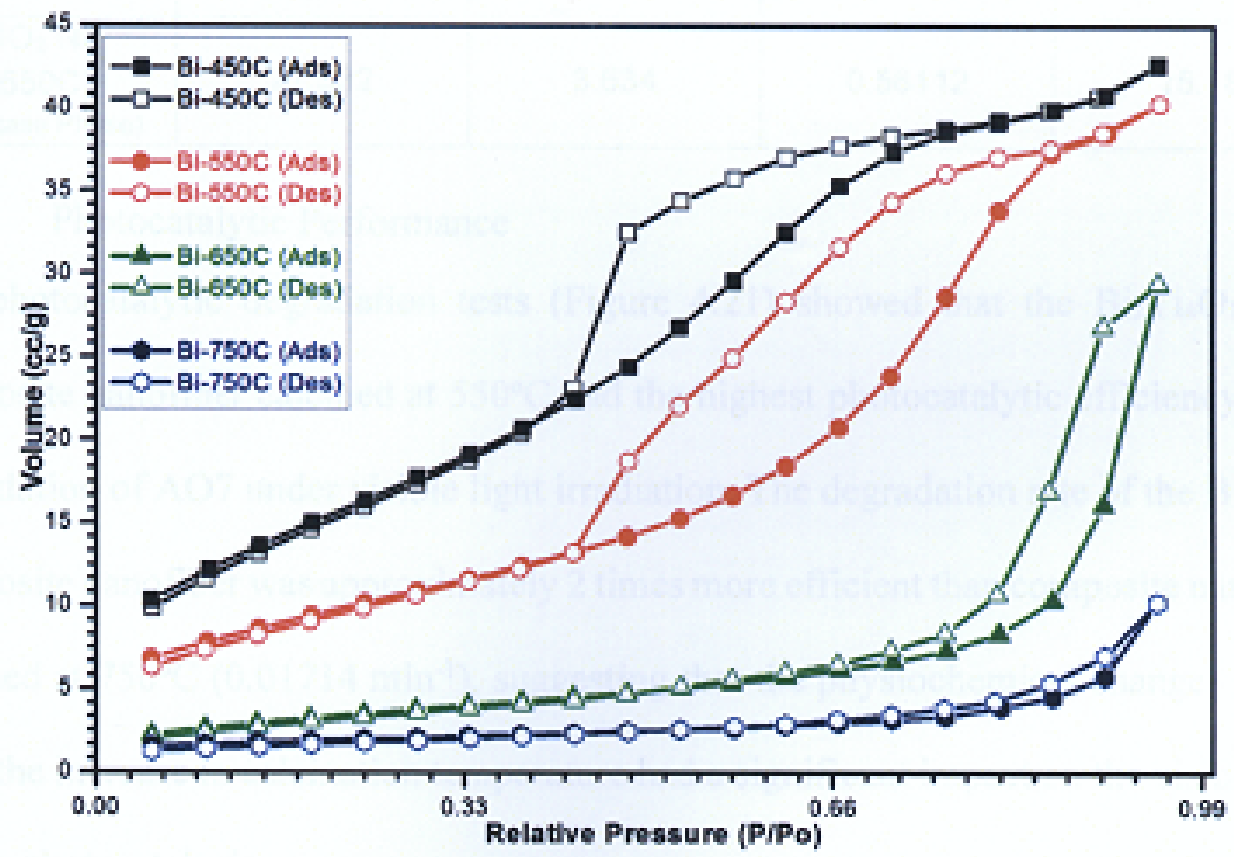

Figure 4.20 - Nitrogen adsorption/desorption isotherms for calcined $\mathrm{Bi}_{2} \mathrm{Ti}_{4} \mathrm{O}_{11} / \mathrm{TiO}_{2}$ composite nanofibers

Additionally, from the BET analysis it can be noted that the formation of the composite nanofiber increased the surface area of the nanofiber, with the composite nanofiber showing a $25 \%$ improvement in the surface area as compared to the pure $\mathrm{TiO}_{2}$ nanofiber. This implies that the formation of the composite structure has increased the active sites available for photocatalysis. 
Table 4.9 - Physiochemical characteristics of synthesised $\mathrm{Bi}_{2} \mathrm{Ti}_{4} \mathrm{O}_{11} / \mathrm{TiO}_{2}$ composite nanofiber

\begin{tabular}{|c|c|c|c|c|}
\hline Sample ID & $\begin{array}{c}\text { BET Specific } \\
\text { Surface Area } \\
\left(\mathrm{m}^{2} / \mathrm{g}\right)\end{array}$ & $\begin{array}{c}\text { Estimated pore } \\
\text { diameter (mm) } \\
\text { Estimated with } \\
\text { BJH }\end{array}$ & $\begin{array}{l}\text { Full width at } \\
\text { half maximum } \\
\text { (deg) }\end{array}$ & $\begin{array}{l}\text { Anatase } \mathrm{Tl}_{2} \\
\text { Crystallite Size } \\
(\mathrm{nm})\end{array}$ \\
\hline $\mathrm{Bi}-450 \mathrm{C}$ & 57.56 & 3.632 & 0.67360 & 12.64 \\
\hline $\mathrm{Bi}-550 \mathrm{C}$ & 34.96 & 3.639 & 0.54656 & 15.57 \\
\hline $\mathrm{Bi}-650 \mathrm{C}$ & 12.29 & 3.034 & 0.38360 & 22.19 \\
\hline $\mathrm{Bi}-750 \mathrm{C}$ & 6.39 & 2.661 & 0.34123 & 24.94 \\
\hline $\begin{array}{c}\mathrm{TiO}_{2} \mathrm{NF} \\
(550 \mathrm{C}) \\
\text { (Anatase Phase) }\end{array}$ & 27.582 & 3.634 & 0.56112 & 15.18 \\
\hline
\end{tabular}

\subsubsection{Photocatalytic Performance}

The photocatalytic degradation tests (Figure 4.21) showed that the $\mathrm{Bi}_{2} \mathrm{Ti}_{4} \mathrm{O}_{11} / \mathrm{TiO}_{2}$ composite nanofiber calcined at $550^{\circ} \mathrm{C}$ had the highest photocatalytic efficiency in the degradation of $\mathrm{AO} 7$ under visible light irradiation. The degradation rate of the $\mathrm{Bi}-550 \mathrm{C}$ composite nanofiber was approximately 2 times more efficient than composite nanofiber calcined at $750^{\circ} \mathrm{C}\left(0.01714 \mathrm{~min}^{-1}\right)$, suggesting that the physiochemical changes arising from the increase in calcination temperature had a significant impact on the visible light driven photocatalysis.

The nanofiber calcined at $750^{\circ} \mathrm{C}$ has a BET specific surface area of $6.39 \mathrm{~m}^{2} / \mathrm{g}$ which was significantly lower than the nanofiber calcined at $550^{\circ} \mathrm{C}\left(34.96 \mathrm{~m}^{2} / \mathrm{g}\right)$. This suggests that the higher calcination temperature might have led to the collapse of the microporous structure which exists at lower temperatures (Madhugiri, Sun, Smirniotis, Ferraris, \& Balkus, 2004) thus resulting in a poorer mass transport between the model pollutant and the composite nanofiber as it becomes more difficult for the pollutant to enter the pore channel of the composite nanofiber. Consequentially this resulted in a lower photocatalytic efficiency due to the decrease in the active sites available for reactions arising from the lower BET specific surface area. 

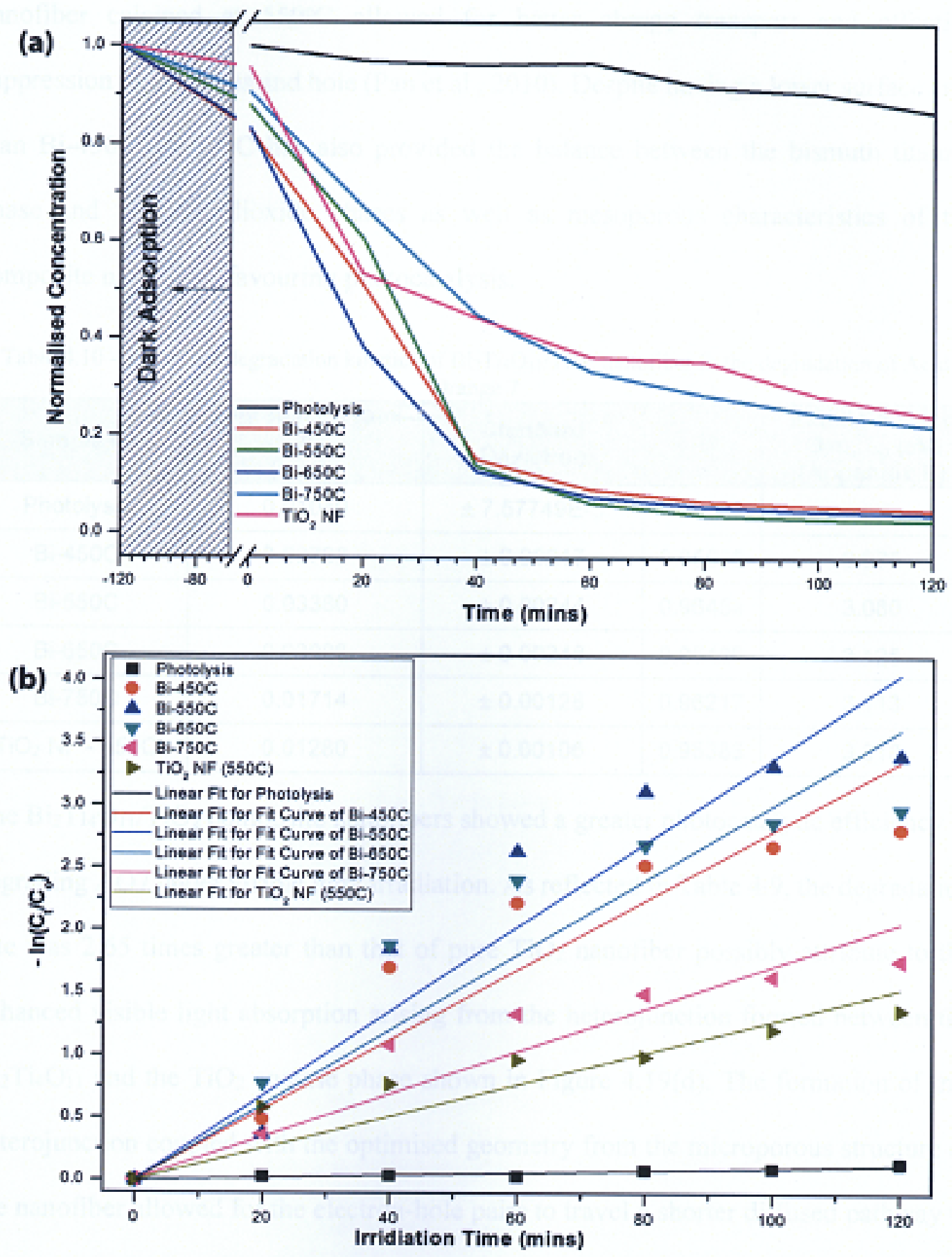

Figure 4.21 - (a) Normalised concentration showing the degradation of $\mathrm{AO} 7$ with reaction time for the various photocatalysts (b) Modelled pseudo-first order degradation kinetics for the various photocatalysts

Furthermore, comparing the photocatalytic efficiencies (Table 4.10) of the Bi-450C, Bi$550 \mathrm{C}$ and $\mathrm{Bi}-650 \mathrm{C}$, the $\mathrm{Bi}-550 \mathrm{C}$ had a photocatalytic efficiency of the $21 \%$ greater than $\mathrm{Bi}-450 \mathrm{C}$ and $12 \%$ greater than that of the $\mathrm{Bi}-650 \mathrm{C}$ respectively. This indicates that the higher crystallinity of the both the $\mathrm{Bi}_{2} \mathrm{Ti}_{4} \mathrm{O}_{11}$ and anatase $\mathrm{TiO}_{2}$ phase of the composite 
nanofiber calcined at $550^{\circ} \mathrm{C}$ allowed for better charge transport and effective suppression of electrons and hole (Pan et al., 2010). Despite having a lower surface area than $\mathrm{Bi}-450 \mathrm{C}, \mathrm{Bi}-550 \mathrm{C}$ has also provided the balance between the bismuth titanate phase and titanium dioxide phases as well as mesoporous characteristics of the composite nanofiber, favouring photocatalysis.

Table 4.10 - Modelled degradation kinetics of $\mathrm{Bi}_{2} \mathrm{Ti}_{4} \mathrm{O}_{11} / \mathrm{TiO}_{2}$ nanofiber in the degradation of Acid

\begin{tabular}{|c|c|c|c|c|}
\hline \multicolumn{5}{|c|}{ Orange 7} \\
\hline Sample ID & $\begin{array}{c}\text { Degradation rate, } \\
k \\
\left(\min ^{-1}\right)\end{array}$ & $\begin{array}{l}\text { Standard } \\
\text { Daviation }\end{array}$ & $\mathrm{R}^{2}$ & $\begin{array}{l}\text { Estimate Band } \\
\text { Gap, E, (oV) } \\
\text { (Appendix D) }\end{array}$ \\
\hline Photolysis & 0.01040 & $\pm 7.57749 \mathrm{E}-5$ & 0.96393 & - \\
\hline $\mathrm{Bi}-450 \mathrm{C}$ & 0.02798 & \pm 0.00217 & 0.95938 & 3.075 \\
\hline $\mathrm{Bi}-550 \mathrm{C}$ & 0.03380 & \pm 0.00244 & 0.96454 & 3.080 \\
\hline $\mathrm{Bi}-650 \mathrm{C}$ & 0.03008 & \pm 0.00248 & 0.95426 & 3.125 \\
\hline $\mathrm{Bi}-750 \mathrm{C}$ & 0.01714 & \pm 0.00128 & 0.96217 & 3.113 \\
\hline $\mathrm{TiO}_{2} \mathrm{NF}-550 \mathrm{C}$ & 0.01280 & \pm 0.00106 & 0.95383 & 3.318 \\
\hline
\end{tabular}

The $\mathrm{Bi}_{2} \mathrm{Ti}_{4} \mathrm{O}_{11} / \mathrm{TiO}_{2}$ composite nanofibers showed a greater photocatalytic efficiency in degrading AO7 under visible light irradiation. As reflected in Table 4.9, the degradation rate was 2.65 times greater than that of pure $\mathrm{TiO}_{2}$ nanofiber possibly attribute to the enhanced visible light absorption arising from the heterojunction formed between the $\mathrm{Bi}_{2} \mathrm{Ti}_{4} \mathrm{O}_{11}$ and the $\mathrm{TiO}_{2}$ anatase phase shown in Figure 4.19(d). The formation of this heterojunction coupled with the optimised geometry from the microporous structure of the nanofiber allowed for the electron-hole pairs to travel a shorter diffused pathway to reach the active surface sites of the photocatalyst therefore permitting for a more effective suppression of the electron-hole recombination (T. Cao, Li, Wang, Shao, et al., 2011). Moreover, as shown in Table 4.10, the diffuse reflectance analysis revealed that the composite nanofibers possessed a lower estimated optical band gap (3.075 to 3.113 $\mathrm{eV})$ than that of the pure $\mathrm{TiO}_{2}$ nanofiber $(3.318 \mathrm{eV})$. The lower band gap due to the 
presence of the $\mathrm{Bi}_{2} \mathrm{Ti}_{4} \mathrm{O}_{11}$ (J. K. Zhou, Zou, Ray, \& Zhao, 2007) can be interpreted as an improved light absorption capacity in the visible-light region.

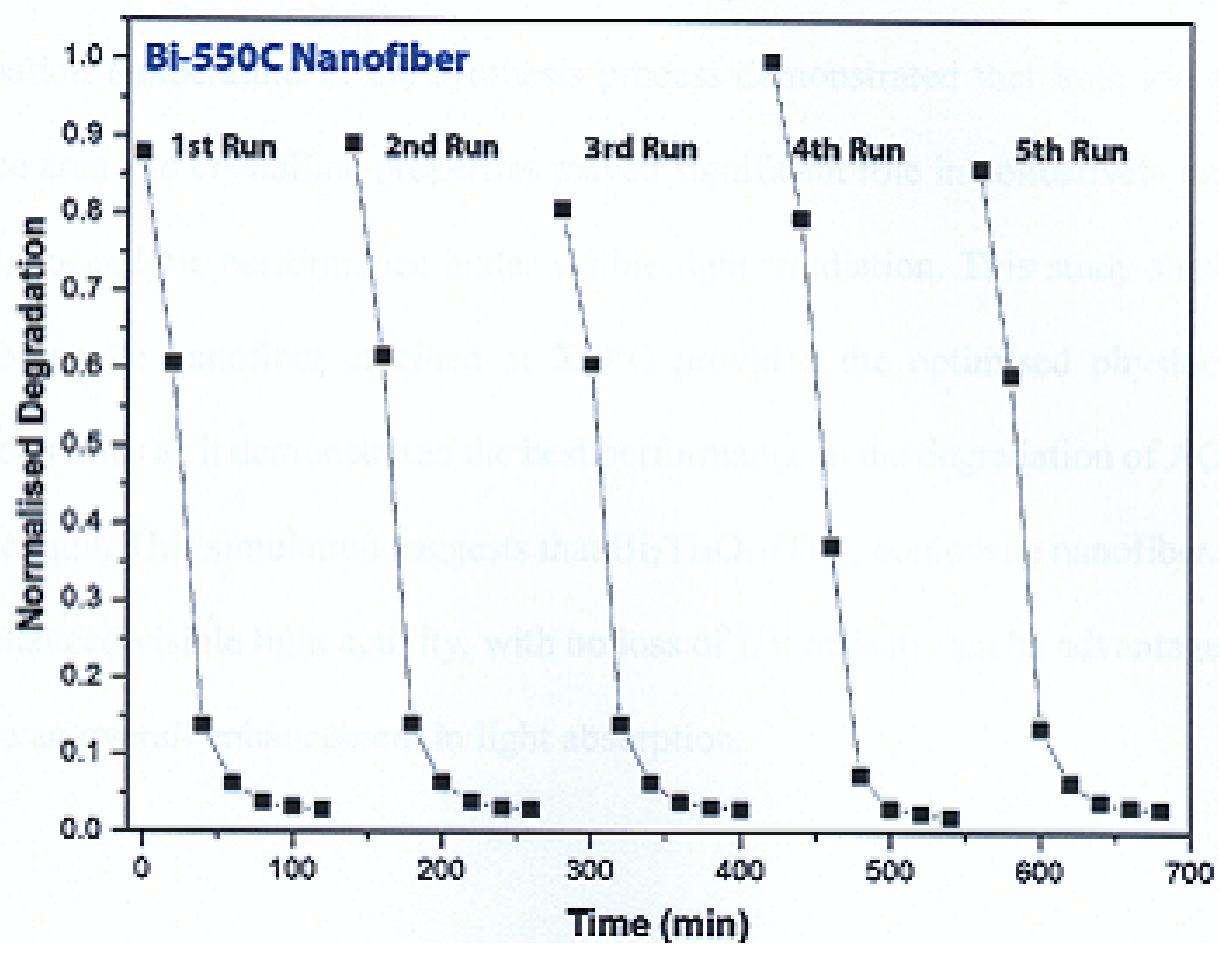

Figure 4.22 - Photocatalytic stability of the composite nanofiber calcined at $550^{\circ} \mathrm{C}$

To investigate the stability of the $\mathrm{Bi}_{2} \mathrm{Ti}_{4} \mathrm{O}_{11} / \mathrm{TiO}_{2}$ composite nanofiber photocatalysis under visible light irradiation, the same samples were repeatedly used after separation via membrane filtration, and the results are shown in Figure 4.22. No observed significant changes was observed to the photocatalytic activity after five cycles as its degradation potential remained virtually unchanged. This indicates good structural stability under visible light irradiation for the photocatalytic decomposition of organic pollutants.

\subsubsection{Summary}

This study demonstrated that it is possible to synthesis an enhanced visible light driven composite nanofiber photocatalysts with a composite system comprising of $\mathrm{Bi}_{2} \mathrm{Ti}_{4} \mathrm{O}_{11}$ (lll $\left.\begin{array}{ll}1 & 1\end{array}\right)$ phase and anatase $\mathrm{TiO}_{2}\left(\begin{array}{lll}1 & 0 & 1\end{array}\right)$ phase. The improved visible light photoactivity is attributed to the shift of the adsorption edge to a longer wavelength through the 
heterojunction formed between the $\mathrm{Bi}_{2} \mathrm{Ti}_{4} \mathrm{O}_{11}$ and the $\mathrm{TiO}_{2}$ phase. The experimental results revealed that $\mathrm{Bi}_{2} \mathrm{Ti}_{4} \mathrm{O}_{11} / \mathrm{TiO}_{2}$ composite nanofiber showed better photocatalytic performance than pure $\mathrm{TiO}_{2}$ under visible light irradiation. Employing different calcination temperature in the synthesis process demonstrated that both the effective surface area and crystalline properties played significant role in collectively enhancing the photocatalytic performance under visible light irradiation. This study showed that the composite nanofiber calcined at $550^{\circ} \mathrm{C}$ provided the optimised physiochemical characteristics as it demonstrated the best performance in the degradation of AO7 under visible light. This simulation suggests that $\mathrm{Bi}_{2} \mathrm{Ti}_{4} \mathrm{O}_{11} / \mathrm{TiO}_{2}$ composite nanofiber allowed for enhanced visible light activity, with no loss of UV activity can be advantageous and lead to an overall enhancement in light absorption. 


\subsection{Comparison of Hydrogen production potential}

To further evaluate the photocatalytic ability of the $\mathrm{Bi}_{2} \mathrm{Ti}_{4} \mathrm{O}_{11} / \mathrm{TiO}_{2}$ nanofiber, photocatalytic $\mathrm{H}_{2}$ generation test was conducted under visible light irradiation employing an alternate irradiation source in a water/methanol sacrificial regent system with lamp's photoluminescence predominantly in the visible light spectrum.

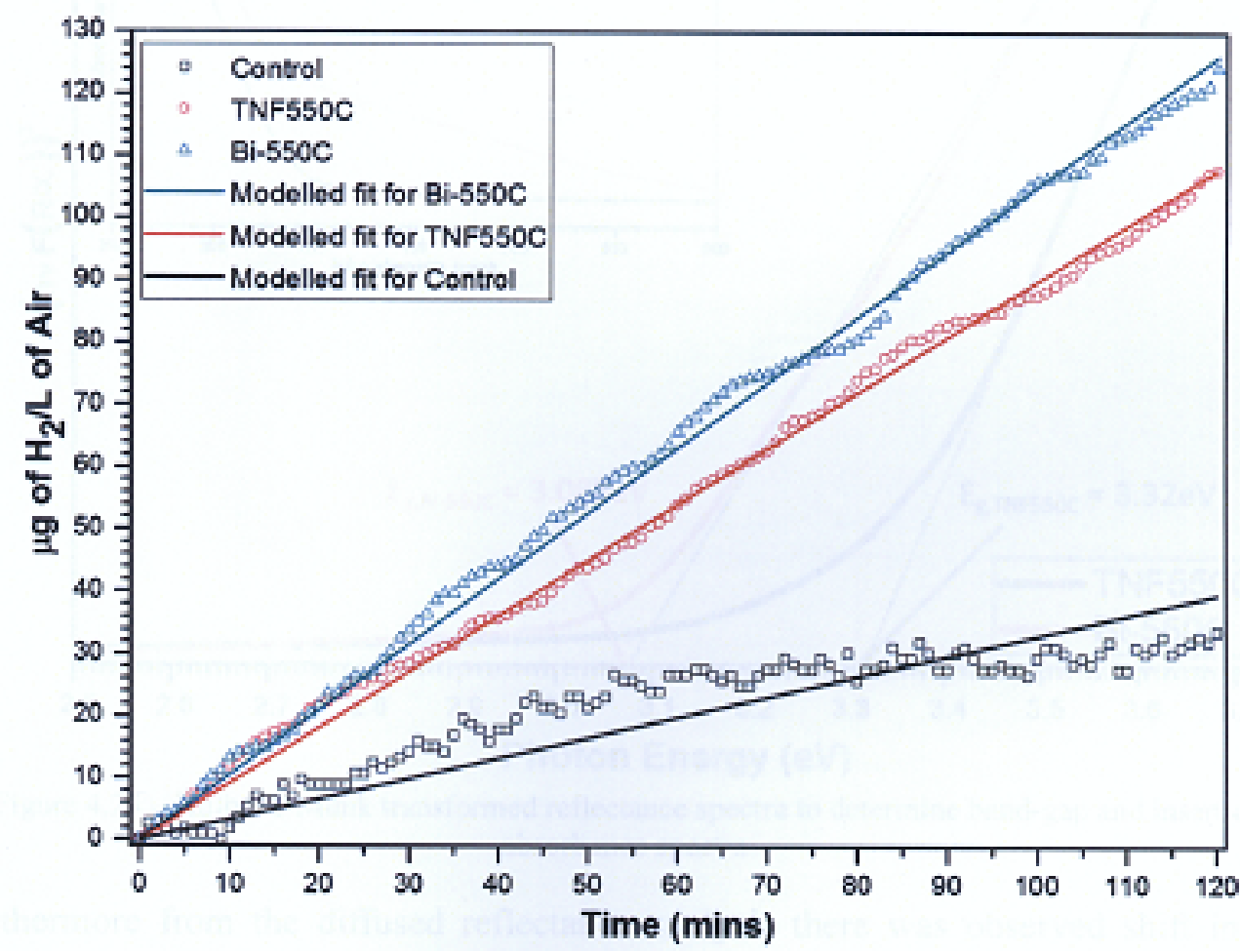

Figure $4.23-\mathrm{H}_{2}$ evolution comparison of the TNF550C and Bi-550C

The ability of the TNF550C and Bi-550C photocatalyst to generate $\mathrm{H}_{2}$ was compared on the basis that these two nanofibers exhibited the best photocatalytic degradation kinetics for $\mathrm{AO} 7$ amongst the nanofibers calcined at various temperature. Clearly from Figure 4.23 the $\mathrm{Bi}_{2} \mathrm{Ti}_{4} \mathrm{O}_{11} / \mathrm{TiO}_{2}$ composite nanofiber showed stability and reactivity even after 2 hours of irradiation. The improved $\mathrm{H}_{2}$ generation rate of $17.5 \%$ can be ascribed to the formation of the heterojunction in the Bi-550C. Moreover, coupled with the optimised geometry from the microporous structure of the nanofiber allowed for the electron-hole pairs to travel a shorter diffused pathway to reach the active surface sites 
of the photocatalyst therefore allowing for a more effective suppression of the electronhole recombination

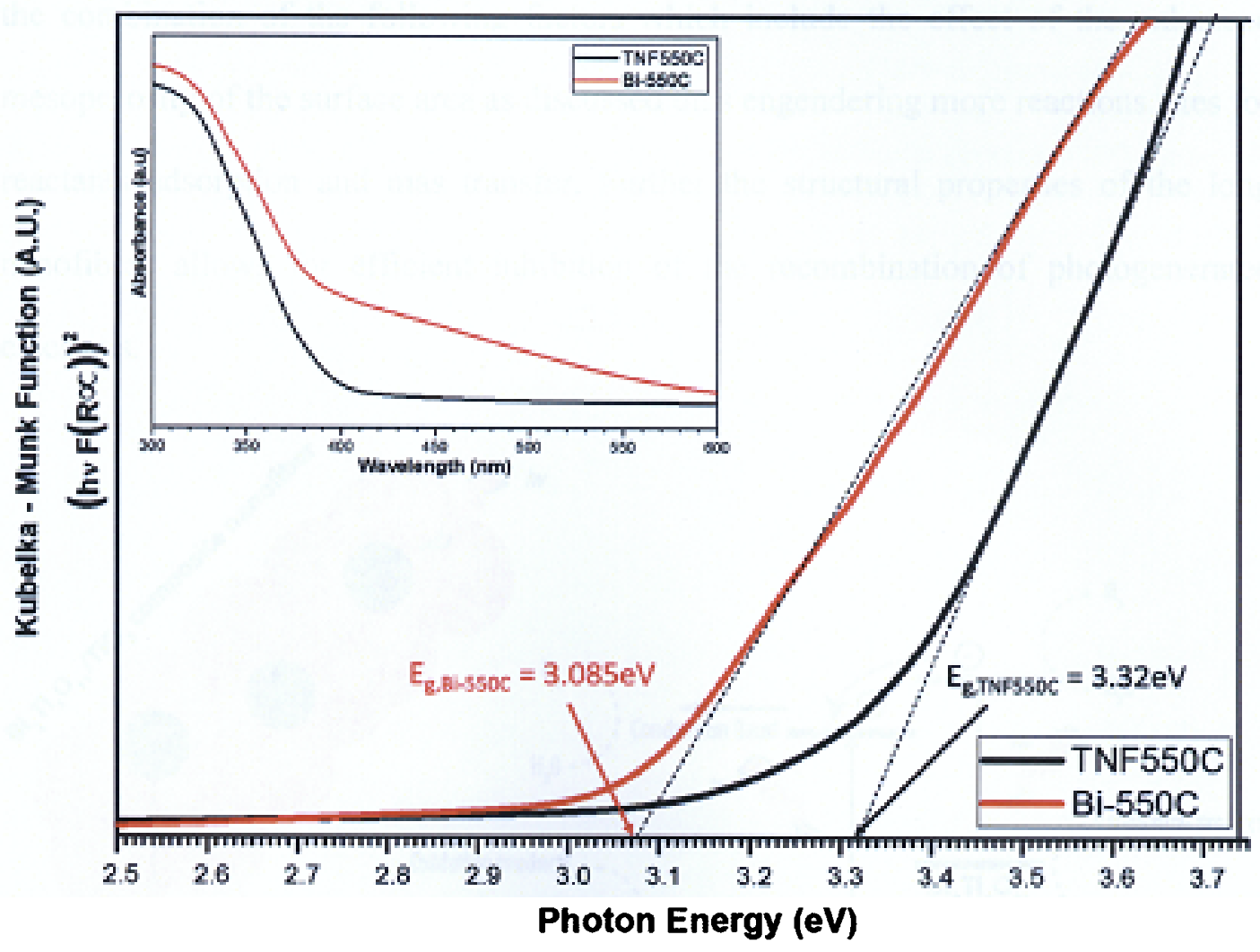

Figure 4.24 - Kulbeka-Munk transformed reflectance spectra to determine band-gap and insert of absorbance spectra

Furthermore from the diffused reflectance analysis there was observed shift in the absorbance to a wider spectrum. The estimate band-gap of the Bi550C was $3.085 \mathrm{eV}(\lambda$ $\approx 401 \mathrm{~nm})$ whereas the TNF550C has an estimated optical band gap of $3.32 \mathrm{eV}(\lambda \approx$ $373 \mathrm{~nm})$. This indicates that the $\mathrm{Bi}_{2} \mathrm{Ti}_{4} \mathrm{O}_{11} / \mathrm{TiO}_{2}$ composite nanofiber not only showed enhance crystalline and surface properties, the formation of the heterojunction further promotes the effective light utilisation by enabling the absorbance of a larger spectrum of irradiation Therefore, through the modification of the electronic structure and optical properties of the $\mathrm{TiO}_{2}$ nanofibers which resulted in the red-shift of the spectrum allowed for better $\mathrm{H}_{2}$ generation capability under visible light irradiation. 
4.4.1. Comparison of Energy band gap between $\mathrm{TiO}_{2}$ Nanofiber and $\mathrm{Bi}_{2} \mathrm{Ti}_{4} \mathrm{O}_{11} / \mathrm{TiO}_{2}$ Composite nanofibers

The efficient $\mathrm{H}_{2}$ generation of the $\mathrm{Bi}_{2} \mathrm{Ti}_{4} \mathrm{O}_{11} / \mathrm{TiO}_{2}$ composite nanofibers is attributed to the combination of the following factors which include the effect of the enhanced mesoporosity of the surface area as discussed thus engendering more reactions sites for reactants adsorption and mas transfer. Further the structural properties of the long nanofibers allows for efficient inhibition of the recombination of photogenerated electrons.

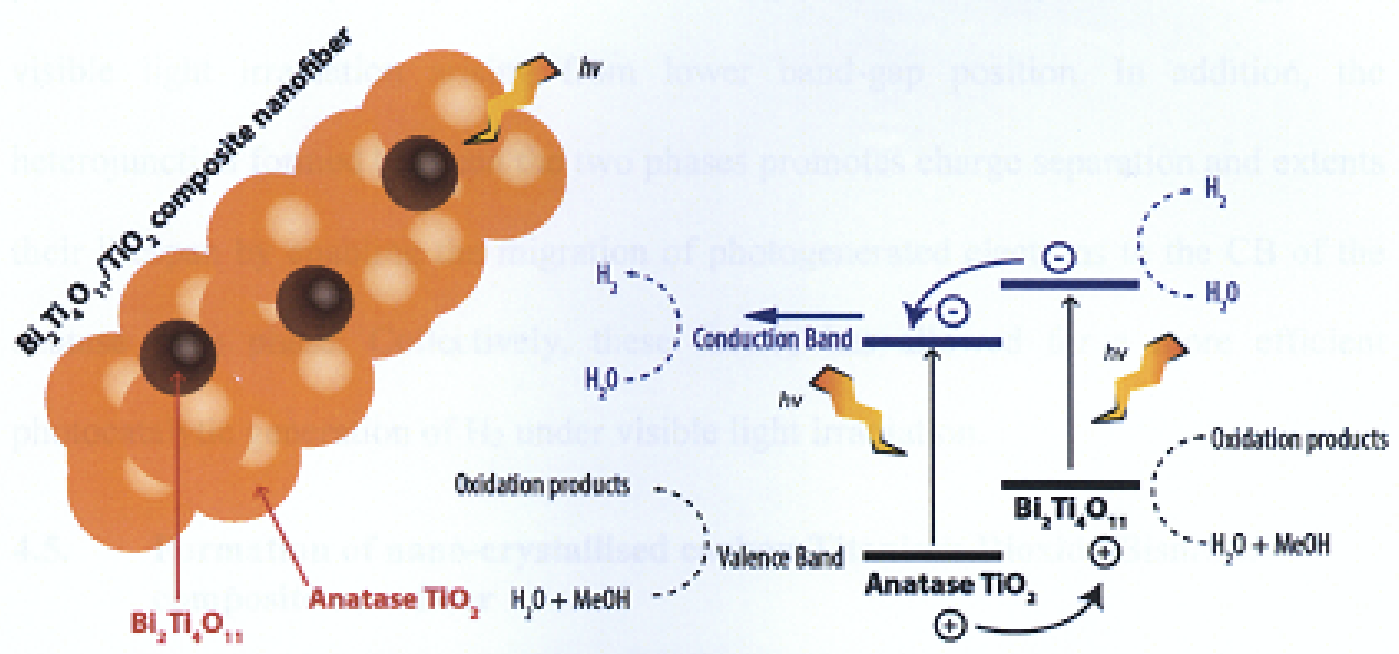

Figure 4.25 - Schematic diagram of the photogenerated electrons and holes in the $\mathrm{Bi}_{2} \mathrm{Ti}_{4} \mathrm{O}_{11} / \mathrm{TiO}_{2}$ composite nanofibers

A schematic diagram shown in Figure 4.25 is proposed based on the experimental data, HRTEM images and the XRD results in the previous sections to explain the probable electrons transfer between the phases in the $\mathrm{Bi}_{2} \mathrm{Ti}_{4} \mathrm{O}_{11} / \mathrm{TiO}_{2}$ composite nanofibers. Based on the $\mathrm{H}_{2}$ generation performance under visible light irradiation, it is proposed that the $\mathrm{Bi}_{2} \mathrm{Ti}_{4} \mathrm{O}_{11}$ phase $(3.085 \mathrm{eV})$ lies above that of the anatase $\mathrm{TiO}_{2}(3.32 \mathrm{eV})$. Due to the formation of the heterojunction between the $\mathrm{Bi}_{2} \mathrm{Ti}_{4} \mathrm{O}_{11}$ phase and the anatase $\mathrm{TiO}_{2}$ phase it allowed for a favourable separation of electrons and holes due to the effects of in the inner electric field (C. H. Cao, Xiao, Chen, \& Cao, 2015). 
As shown in Figure 4.25, upon the harvesting of photon energy from the simulated solar irradiation it leads to the excitation of electrons which travels from the valence band (VB) to the conduction band (CB) leaving holes in the VB of the $\mathrm{Bi}_{2} \mathrm{Ti}_{4} \mathrm{O}_{11}$ phase. Here due to the heterojunction formed between the phases, the electrons from the $\mathrm{CB}$ of the $\mathrm{Bi}_{2} \mathrm{Ti}_{4} \mathrm{O}_{11}$ could transfer to the $\mathrm{CB}$ of the anatase $\mathrm{TiO}_{2}$. As these photoexcited electrons and holes separate and migrate to the surface of the photocatalyst, it reacts with the aqueous phase generating reducing and oxidising agents to produce $\mathrm{H}_{2}$. Therefore, the presence $\mathrm{Bi}_{2} \mathrm{Ti}_{4} \mathrm{O}_{11}$ phase provides the advantage to absorb the photonic energy from visible light irradiation arising from lower band-gap position. In addition, the heterojunction formed between the two phases promotes charge separation and extents their lifespan by enabling the migration of photogenerated electrons to the CB of the anatase $\mathrm{TiO}_{2}$ phase. Collectively, these factors has allowed for a more efficient photocatalytic generation of $\mathrm{H}_{2}$ under visible light irradiation.

\subsection{Formation of nano-crystallised carbon Titanium Dioxide/Bismuth composite nanofiber}

The application of titanium dioxide as heterogeneous photocatalyst for environmental remediation has led to its significant interest. However with a band gap of $3.2 \mathrm{eV}$ which limits its photoreactivity in the UV region of the solar spectrum has resulted in exploration of methods to absorb visible light (Yun et al., 2008). Therefore to further augment the properties of the $\mathrm{Bi}_{2} \mathrm{Ti}_{4} \mathrm{O}_{11} / \mathrm{TiO}_{2}$ composite nanofibers it is proposed with the formation of a nano-crystallised carbon layer it will further enrich its visible light absorption ability and photocatalytic properties. This phenomena will be future elaborated in the following sections. 


\subsubsection{Properties of carbon-doped $\mathrm{Bi}_{2} \mathrm{Ti}_{4} \mathrm{O}_{11} / \mathrm{TiO}_{2}$ composite nanofiber}
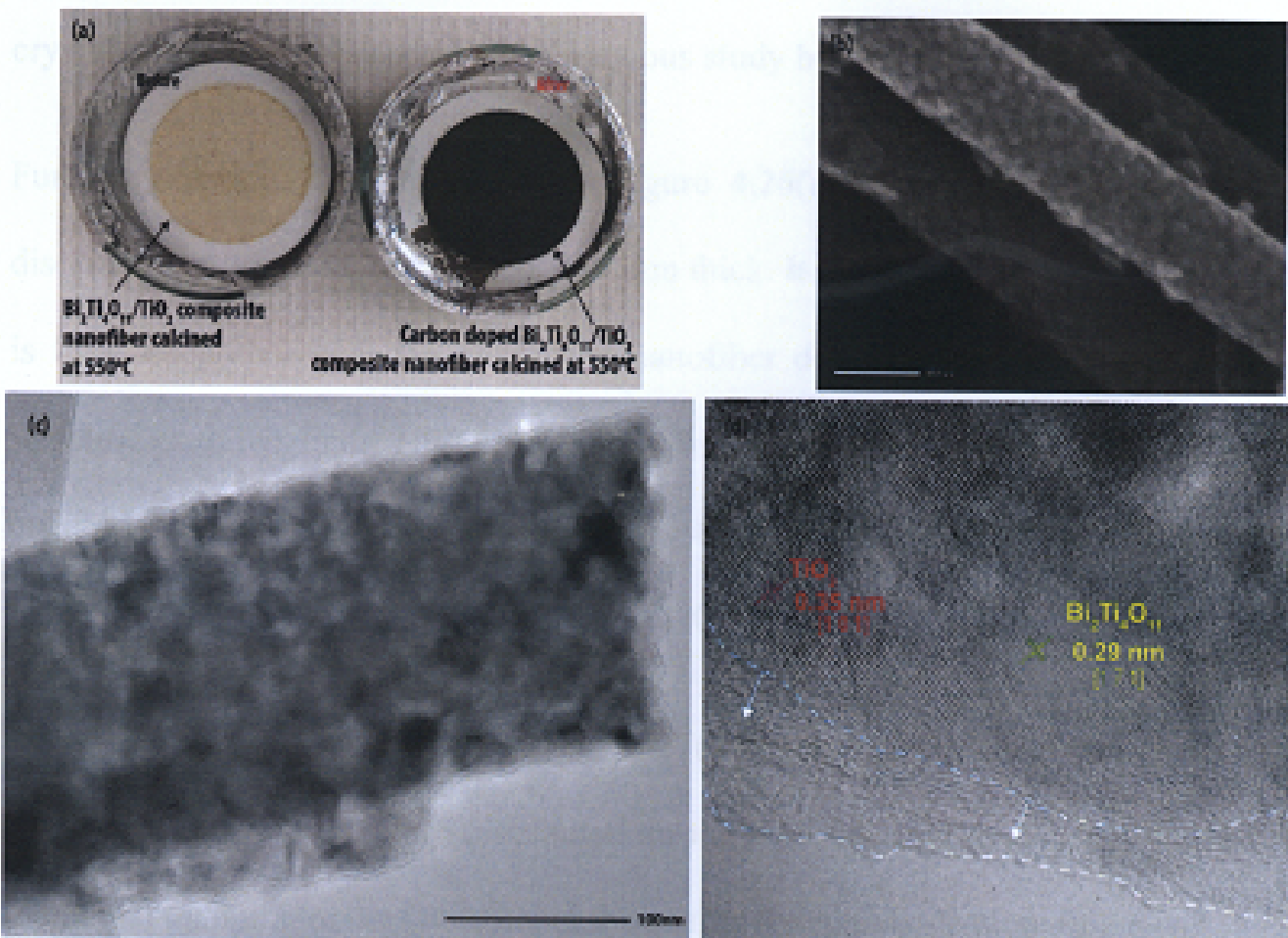

Figure 4.26-(a) Digital photo comparing the Bi550C nanofiber and the $\mathrm{C}-\mathrm{Bi} 550 \mathrm{C}$ nanofiber. (b) FESEM image of the C-Bi550C nanofiber (c) TEM image of the C-Bi550C nanofiber with disordered outer fringe layer (d) HRTEM images of $\mathrm{TiO}_{2}$ nanocrystals, $\mathrm{Bi}_{2} \mathrm{Ti}_{4} \mathrm{O}_{11}$ nanocrystals and the outer layer of the earbon dopant layer

The digital image in Figure 4.26(a) depicts the carbon doped $\mathrm{Bi}_{2} \mathrm{Ti}_{4} \mathrm{O}_{11} / \mathrm{TiO}_{2}$ composite nanofiber (calcined at $550^{\circ} \mathrm{C}$ ) before undergoing going the proposed doping process of concentration and carbonisation of sucrose at $700^{\circ} \mathrm{C}$. The FESEM image in Figure 4.26(b) demonstrates the stability of the composite nanofiber as it maintained its surface morphology despite undergoing sintering at elevated temperature. In addition, from the TEM image in Figure 4.26(c) illustrates the formation of a disordered lattice (Chen et al., 2010) along the fringe of the composite nanofiber. The formation of the disordered lattice is due to the substitution of Oxygen (O) elements with Carbon (C) elements in the $\mathrm{TiO}_{2}$ lattice. Therefore, it is proposed that the growth of the nano-crystallised carbon layer on the $\mathrm{Bi}_{2} \mathrm{Ti}_{4} \mathrm{O}_{11} / \mathrm{TiO}_{2}$ composite nanofiber gives rise to a continuum of energy states or overlapping of the band edges through the up-shift of the valence band edge. This allows for improved number and energy of photons harvested on the surface of the 
$\mathrm{C}-\mathrm{Bi550C}$ arising from the broadening of the spectrum. This inclusion of the $\mathrm{C}$ in the crystal lattice is consistent with the previous study by (Barborini et al., 2005).

Furthermore, the HRTEM image in Figure 4.26(d) illustrates the thickness of the disordered lattice layer to between 2 to $5 \mathrm{~nm}$ thick. It observed that the disordered lattice is fully integrated with the composite nanofiber due to the continuity of the lattice structure as shown in the HRTEM images. Additionally, due to the thinness of the nanocrystallised carbon layer it is strongly suggested that the C-dopant would not inhibit the photocatalytic properties of the $\mathrm{Bi}_{2} \mathrm{Ti}_{4} \mathrm{O}_{11} / \mathrm{TiO}_{2}$ composite nanofiber.

The elemental mapping shown in Figure 4.27(a) revealed that the carbon content present in the C-Bi550C was evenly distributed throughout its surface. The evenly distributed elemental mapping of the $\mathrm{C}$-elements shows that the ultrasonication process allowed for a homogenous dispersion and adsorption of the external carbon dopant into the parent $\mathrm{Bi}_{2} \mathrm{Ti}_{4} \mathrm{O}_{11} / \mathrm{TiO}_{2}$ composite nanofiber. Moreover, the elemental mapping of the evenly dispersed C-elements confirms that the substitution of O-elements in the lattices of composite nanofiber (Khan et al., 2002). This proves that the carbon has effectively doped into the composite nanofiber and not just covering the surface. The EDS spectrum in Figure 4.27(b) shows the elements $\mathrm{Ti}, \mathrm{O}, \mathrm{Bi}, \mathrm{C}$ and $\mathrm{Cu}$ were detected from the analysis. The $\mathrm{Cu}$ peaks is attributed to the copper gird which was used during the analysis. The spectrum indicated that the formation of this nano-crystallised carbon layer did not inhibit the detection of the low contents of Bi-elements in the $\mathrm{Bi}_{2} \mathrm{Ti}_{4} \mathrm{O}_{11} / \mathrm{TiO}_{2}$ composite nanofiber. This further supports the fact that the thin nature of the nano-crystallised carbon layer does not impede the existing photocatalytic properties of composite nanofiber. Additionally the presence of this nano-crystallised carbon increases the conductivity of the photogenerated electrons the surface on the 
nanofibers which results in an improved photocatalytic performance (Bai, Liu, \& Sun, 2012a).

(a)
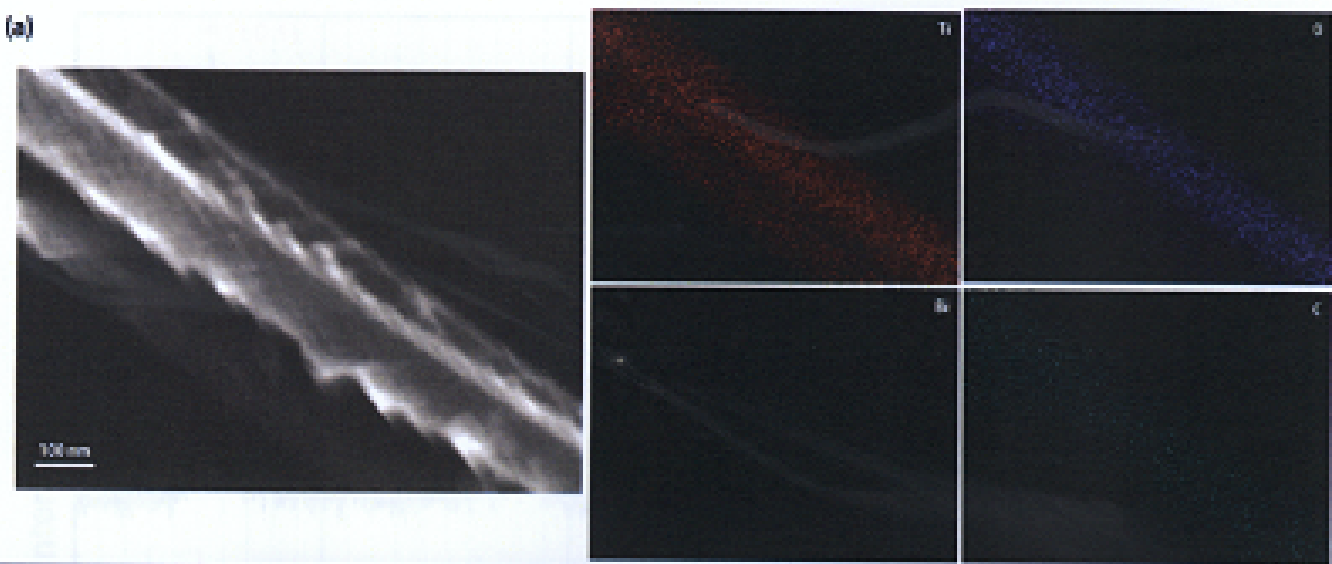

\section{(b) 9}
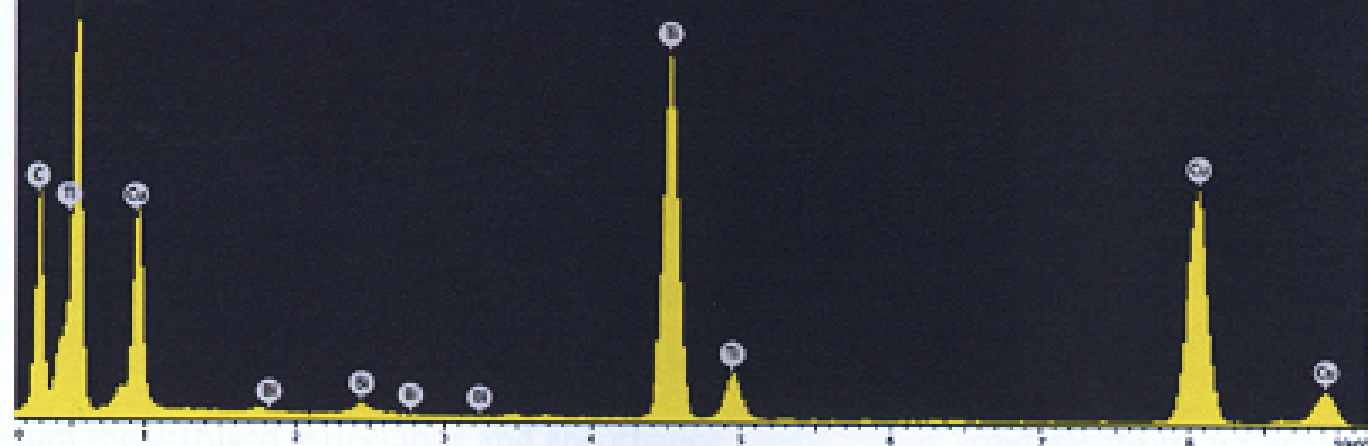

Figure 4.27 - (a) Elemental mapping of Carbon doped Bi-550C (C-Bi550C) nanofiber (b)

Corresponding EDS spectrum of Carbon doped Bi-550C nanofiber

Through the comparison of the XRD diffraction in Figure 4.28 the Bi-550C and C-550C

it is noted that the diffraction patterns have analogous characteristics. As the thermal treatment under $\mathrm{N}_{2}$ conditions induced little change in the crystalline properties, this implies that the carbon dopant allowed the conservation of the anatase crystalline phase despite an increase in treatment temperature. Furthermore the presence of the $\mathrm{Bi}_{2} \mathrm{Ti}_{4} \mathrm{O}_{11}$ still remained detectable as illustrated in the XRD patterns thus supporting the findings illustrated by M. Inagaki et al. (2005) which revealed that the formation of this nanocrystallised carbon layer on the surface allowed for the suppression of phase transformation from anatase to rutile permitting higher thermal loading capacity. The 
inhibition of the formation of rutile crystals thereby preserves the photocatalytic properties of the anatase $\mathrm{TiO}_{2}$ photocatalyst.

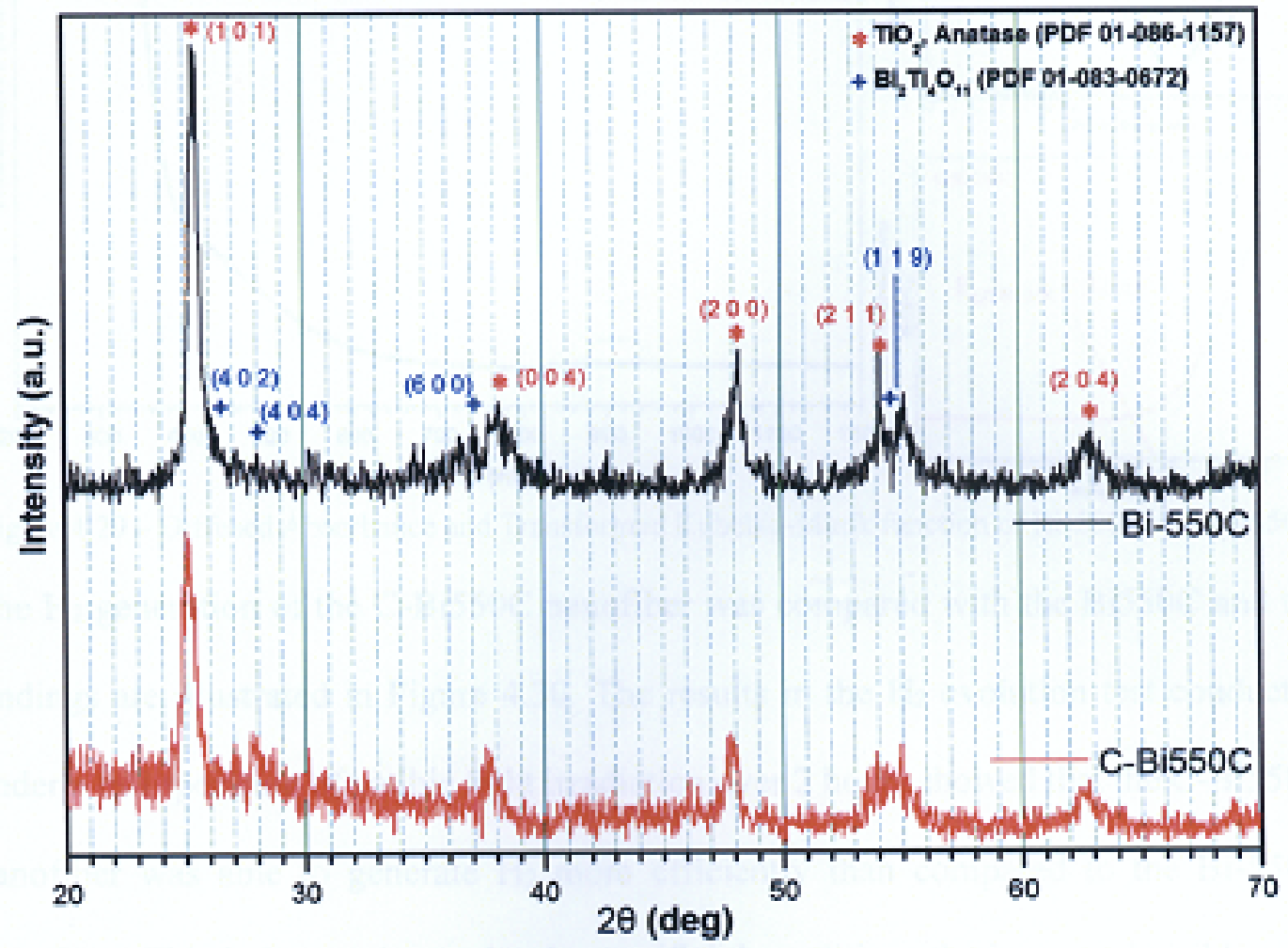

Figure 4.28 - Diffraction pattern of $\mathrm{Bi}-550 \mathrm{C}$ and C-Bi550C nanofiber

From the diffused reflectance and absorbance spectroscopy solid spectrometer analysis illustrated in Figure 4.29 the band gap of the Bi-550C is approximately $3.08 \mathrm{eV}$ which is lower than anatase $\mathrm{TiO}_{2}$ nanofiber $(3.3 \mathrm{eV})$ indicating the ability the ability to absorb irradiation in the visible light region. For the C-Bi550C the onset of optical absorption of was lowered to about $2.55 \mathrm{eV}(\sim 490 \mathrm{~nm})$. This abrupt change in both the reflectance and absorbance spectra suggest that the optical band gap of the C-Bi550C was narrowed therefore allowing for a more enhance absorption of irradiation. 

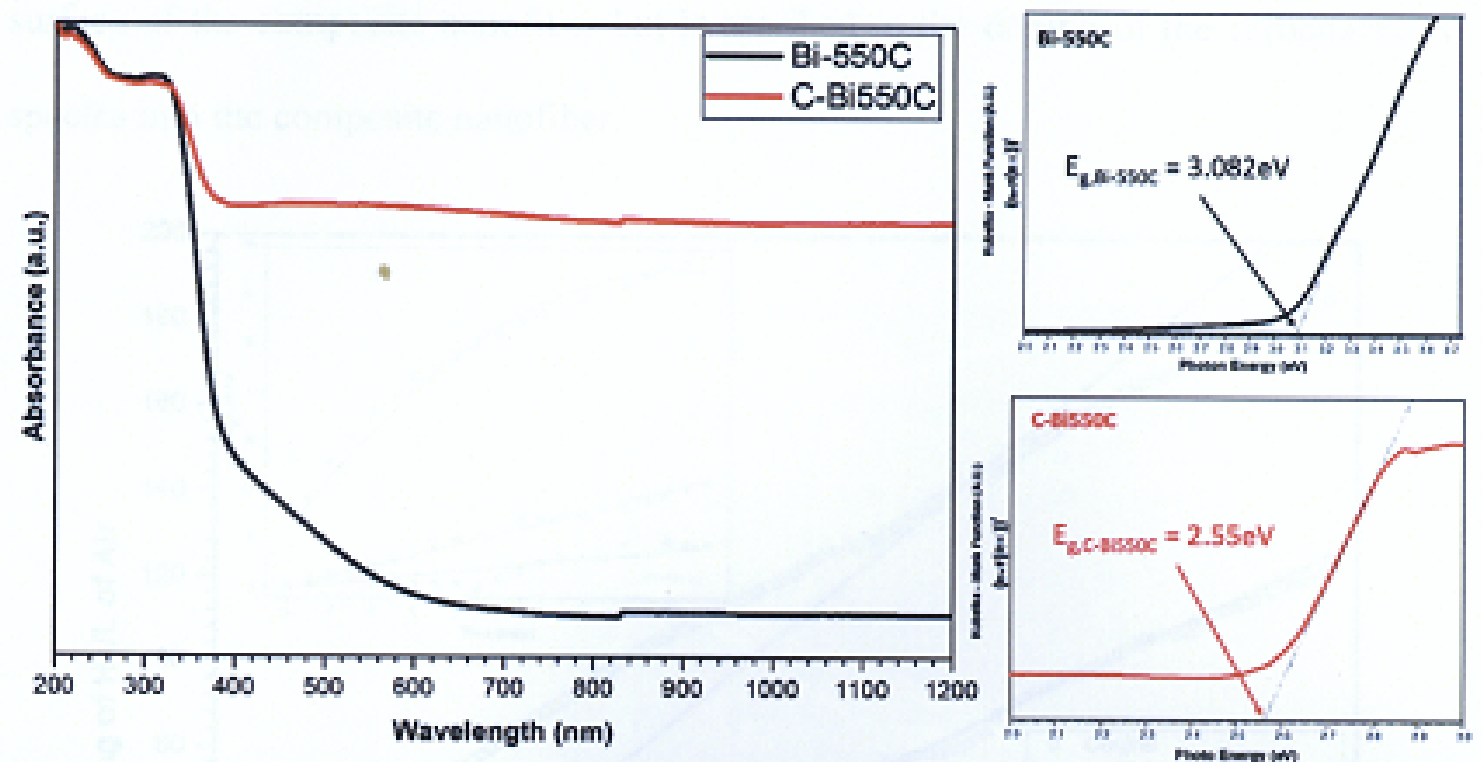

Figure 4.29 - Diffused Absorbance and Transformed Kubelka-Munk function of Bi-550C and Bi-550C

The $\mathrm{H}_{2}$ generation of the $\mathrm{C}-\mathrm{Bi} 550 \mathrm{C}$ nanofiber was compared with the $\mathrm{Bi} 550 \mathrm{C}$ and the findings are illustrated in Figure 4.30. The results in the $\mathrm{H}_{2}$ evolution test conducted under a full spectrum of visible light irradiation over 2 hours showed that the C-Bi550C nanofiber was able to generate $\mathrm{H}_{2}$ more efficiently than compared to the $\mathrm{Bi}-550 \mathrm{C}$ nanofiber. This indicates that under the sacrificial conditions the improved visible light absorption of the C-Bi550C nanofiber allowed for better photocatalytic generation. It is also proposed that the nano-crystallised carbon layer did not just provide the function of an improved absorption of irradiation it also increased the surface area for enhanced adsorption with the reaction environment $\left(127.884 \mathrm{~m}^{2} / \mathrm{g}-\right.$ Appendix F). This improved surface area consequentially resulted in an exponential generation of $\mathrm{H}_{2}$ during the onset of the evolution test (See insert of Figure 4.30). Moreover, through the synergistic effects due to the presence of the nano-crystallised carbon layer and the $\mathrm{Bi}_{2} \mathrm{Ti}_{4} \mathrm{O}_{11}$ crystal phase it allows the sequentially flow of photogenerated electrons-holes which inevitably increased the lifetime of the charge carriers for photocatalytic reactions resulting in a better overall efficiency. All the above results demonstrate that the significant absorption shift shown in Figure 4.29 is not due to the carbon found on the 
surface of the composite nanofiber but is ascribed to the doping of the carbonaceous species into the composite nanofiber.

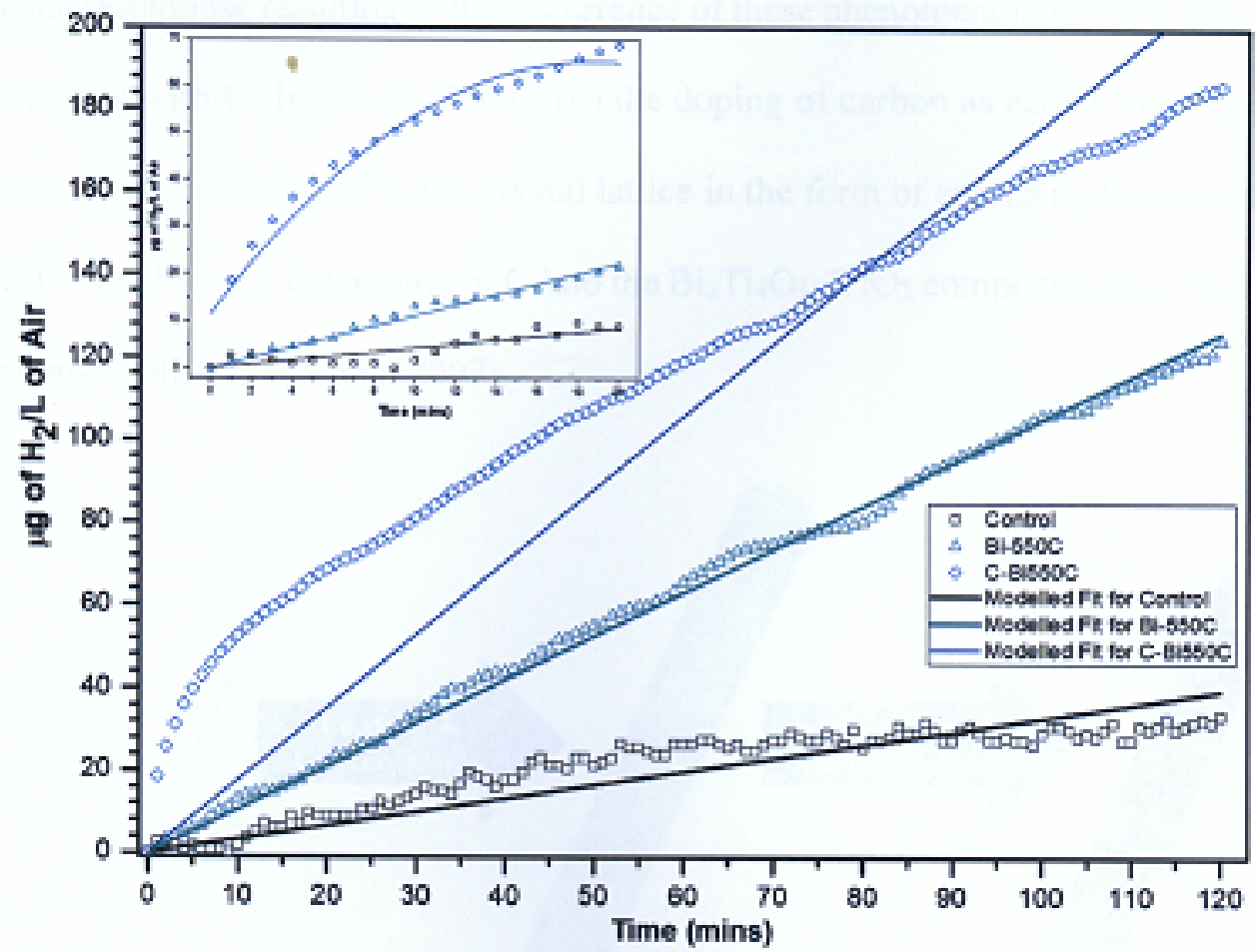

Figure $4.30-\mathrm{H}_{2}$ evolution comparison of the $\mathrm{Bi}-55 \mathrm{C}$ and $\mathrm{C}-\mathrm{Bi5} 50 \mathrm{C}$

4.5.2. Growth mechanism of Carbon Doped $\mathrm{Bi}_{2} \mathrm{Ti}_{4} \mathrm{O}_{11} / \mathrm{TiO}_{2}$ composite nanofiber

The proposed formation mechanism of the nano-crystallised carbon obtain through the use of an external carbon dopant is illustrated in Figure 4.31. The $\mathrm{Bi}_{2} \mathrm{Ti}_{4} \mathrm{O}_{11} / \mathrm{TiO}_{2}$ composite nanofiber was first immersed in a $0.2 \mathrm{M}$ solution of sucrose under ultrasonication. During the sonication process, it allowed for the homogenous dispersion and effective adsorption of the external carbon dopant into the composite nanofiber. This mixture was then filtered to separate the doped composite nanofiber from the sucrose solution. The doped nanofiber was then concentrated in air to allow the gradual formation of carbonaceous crystals on its surface and inside of the composite nanofiber. Thereafter, the sucrose doped composite nanofiber then underwent heat treatment under $\mathrm{N}_{2}$ conditions in order to decompose and carbonise the carbonaceous crystals into a 
conductive nano-crystallised carbon which doped itself into the $\mathrm{Bi}_{2} \mathrm{Ti}_{4} \mathrm{O}_{11} / \mathrm{TiO}_{2}$ composite nanofiber. During the heat treatment it is postulated that the carbonaceous crystals decompose resulting in the occurrence of these phenomenon; (i) the substitution of $\mathrm{O}$ anions with $\mathrm{C}$ (Irie et al., 2003), (ii) the doping of carbon as cation ions replacing $\mathrm{Ti}$ and (iii) the inclusion of $\mathrm{C}$ the crystal lattice in the form of anions and cations which collectively allowing the doping of $\mathrm{C}$ into the $\mathrm{Bi}_{2} \mathrm{Ti}_{4} \mathrm{O}_{11} / \mathrm{TiO}_{2}$ composite nanofiber $(\mathrm{Wu}$, Nishikawa, Ohtani, \& Chen, 2007).

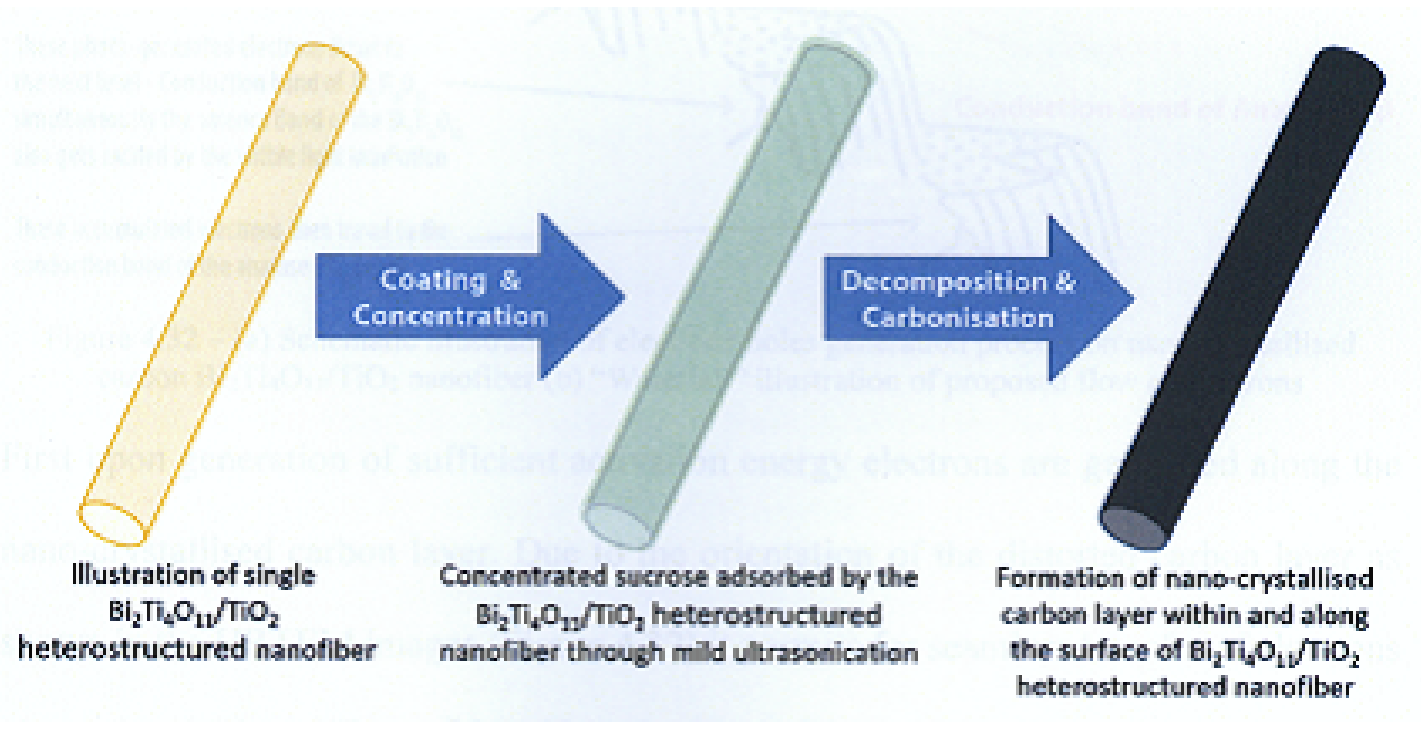

Figure 4.31 - Schematic illustration of nano-crystallisation process

As suggested in the earlier section the presence of the nano-crystallised carbon layer not only leads to an improved adsorption of visible light which allows for uptake and subsequent transfer of adsorbed electrons. Essentially, the nano-crystallised carbon layer does not only act as a good adsorbent but also provides a medium for the conducting and transfer of electrons. Figure 4.32 provides an illustration of the hypothesised mechanism for electrons transfer on the carbon-doped $\mathrm{Bi}_{2} \mathrm{Ti}_{4} \mathrm{O}_{11} / \mathrm{TiO}_{2}$ composite nanofiber. 

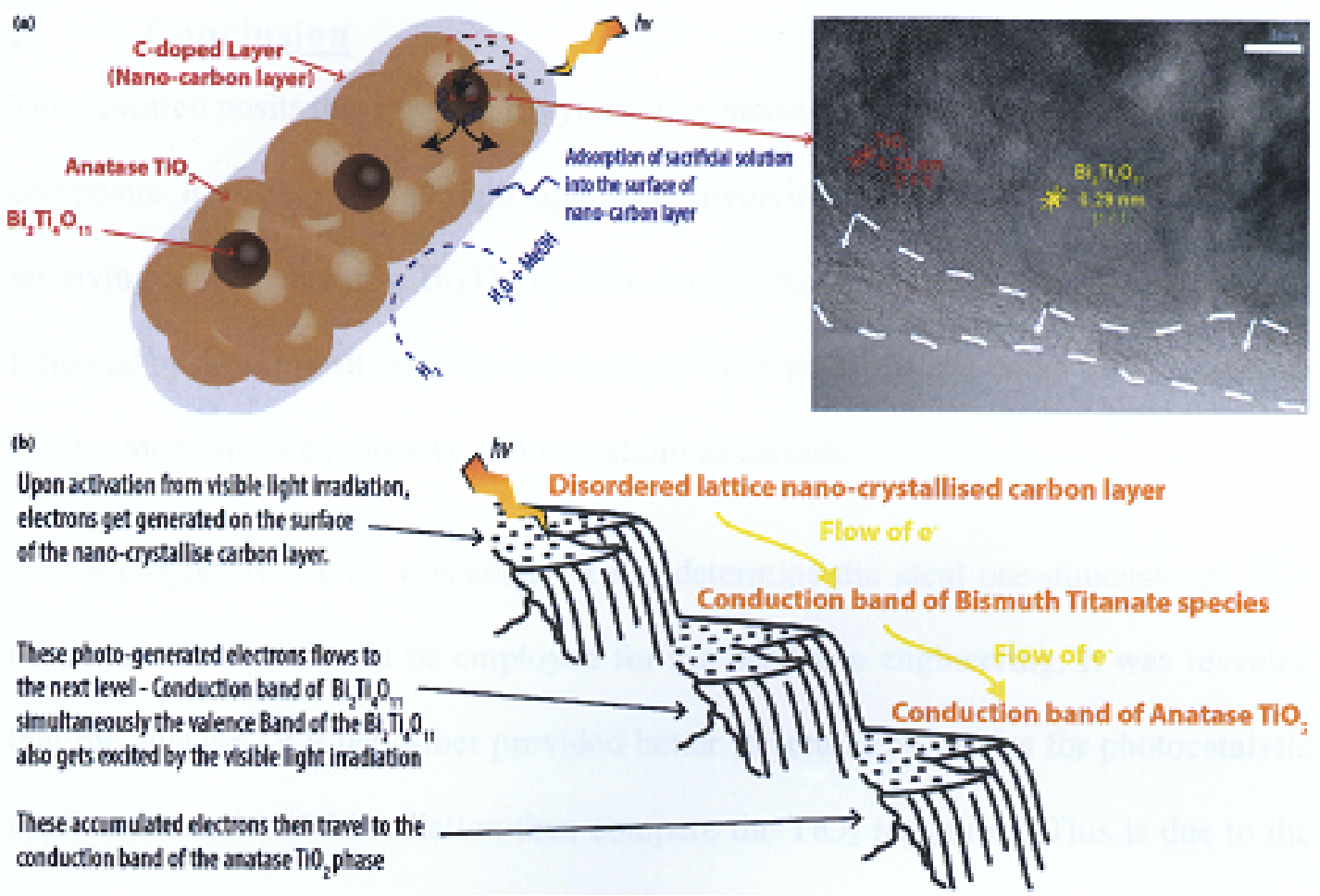

Figure 4.32 - (a) Schematic illustration of electrons-holes generation process on nano-crystallised carbon $\mathrm{Bi}_{2} \mathrm{Ti}_{4} \mathrm{O}_{11} / \mathrm{TiO}_{2}$ nanofiber (b) "Waterfall" illustration of proposed flow of electrons

First upon generation of sufficient activation energy electrons are generated along the nano-crystallised carbon layer. Due to the orientation of the distorted carbon layer as shown in the HRTEM images (Figure 4.32) it permits for seamless transfer of electrons along its lattice (Chen, Liu, Yu, \& Mao, 2011). Moreover, this allows the photogenerated electrons to flow to the conduction band of the $\mathrm{Bi}_{2} \mathrm{Ti}_{4} \mathrm{O}_{11}$ phase. Besides the generation of electrons along the nano-crystallised carbon layer, visible light also simultaneously causes the excitation of electron in the $\mathrm{Bi}_{2} \mathrm{Ti}_{4} \mathrm{O}_{11}$ phase. These light excited electrons migrate from the valence band to the conduction band. It is proposed that due to the band edge positions of the bismuth titanate phase in the composite nanofiber, the accumulated electrons on the conduction band then flows to the conduction band of the to the anatase $\mathrm{TiO}_{2}$. This causes the excitation of states which results in the separation of the holes and electrons which migrate to the surface for reactions. 


\section{Conclusion}

This research posits that possible to synthesis a nano-crystallised carbon $\mathrm{Bi}_{2} \mathrm{Ti}_{4} \mathrm{O}_{11} / \mathrm{TiO}_{2}$ composite nanofiber. In straight approach involving a two-step process. The first involving a synthesis of a $\mathrm{Bi}_{2} \mathrm{Ti}_{4} \mathrm{O}_{11} / \mathrm{TiO}_{2}$ composite through electrospinning. This is followed by decomposition of the external carbon dopant, sucrose under a $\mathrm{N}_{2}$ calcination environment into a conductive nano-crystallised carbon.

First a progressive study was conducted to determine the ideal one-dimensional $\mathrm{TiO}_{2}$ nanostructure that should be employed for the band-gap engineering. It was revealed that the anatase $\mathrm{TiO}_{2}$ nanofiber provided better structural properties for photocatalytic application under UV irradiation than compare the $\mathrm{TiO}_{2}$ nanotubes. This is due to the long fibrous morphology which permitted better electron transfer and more efficient suppression to the recombination of electron-hole pairs. A subsequent optimisation study was conducted to determine the stability of an adjusted precursor to form structurally sound and photocatalytic functional $\mathrm{TiO}_{2}$ nanofiber. This was done to accommodate the dissolution of metal oxide salts (Bismuth Nitrate Pentahydrate) in the electrospinning precursor. Through this study it is revealed that an anatase phase $\mathrm{TiO}_{2}$ nanofiber was achieved from the precursor with the nanofiber calcined at $550^{\circ} \mathrm{C}$ demonstrating the best photocatalytic performance. Moreover, during the formation of the bismuth composite nanofiber, it has demonstrated the stability of the precursor solution. It was discovered that it allowed for improved solvent contact between the pentahydrate Bismuth salt resulting in the formation of sol-gel ready for electrospinning. The composite was attributed with a $\mathrm{Bi}_{2} \mathrm{Ti}_{4} \mathrm{O}_{11}$ crystal phase confirmed from the XRD analysis and TEM analysis. Further from the EDS study it showed the homogeneous dispersion of the Bi elements on the nanofiber signifying that the bismuth salt was well dispersed in the stable the electrospinning sol-gel. From subsequent characterisation 
studies, it revealed that the $\mathrm{Bi}_{2} \mathrm{Ti}_{4} \mathrm{O}_{11} / \mathrm{TiO}_{2}$ composite nanofiber calcined a $550^{\circ} \mathrm{C}$ had an observed band-gap of $3.08 \mathrm{eV}$ which was narrowed down from $3.3 \mathrm{eV}$ (TNF550C). The decrease in optical band-gap allowed for an improved adsorption of the visible light spectrum. This widening of the adsorption spectra is attributed to the formation of the $\mathrm{Bi}_{2} \mathrm{Ti}_{4} \mathrm{O}_{11}$ crystal phase. Moreover, the presence of the $\mathrm{Bi}_{2} \mathrm{Ti}_{4} \mathrm{O}_{11}$ crystal phase also aided in the suppression of recombination of photogenerated electron-holes which inevitably increased the lifetime of the charge carrier thus enhancing the overall photocatalytic efficiencies.

From the comparative study of the calcination temperature, it was found that both the surface area and crystalline properties played significant role in collectively enhancing the photocatalytic performance of the $\mathrm{Bi}_{2} \mathrm{Ti}_{4} \mathrm{O}_{11} / \mathrm{TiO}_{2}$ composite nanofiber under visible light irradiation. The composite nanofiber calcined at $550^{\circ} \mathrm{C}$ provided the best structural and crystalline properties for the photocatalytic oxidation of $\mathrm{AO} 7$ under visible light irradiation. Moreover, comparing the photocatalytic $\mathrm{H}_{2}$ generation ability of the TNF550C and the Bi-550C it further corroborate the fact that the formation of the heterojunction between the anatase $\mathrm{TiO}_{2}$ and $\mathrm{Bi}_{2} \mathrm{Ti}_{4} \mathrm{O}_{11}$ phase enhances its overall photocatalytic efficiency.

In the successive study of the nano-crystallised carbon $\mathrm{Bi}_{2} \mathrm{Ti}_{4} \mathrm{O}_{11} / \mathrm{TiO}_{2}$ composite nanofiber it showed that after the formation of the nano-crystallised carbon $\mathrm{Bi}_{2} \mathrm{Ti}_{4} \mathrm{O}_{11} / \mathrm{TiO}_{2}$ composite nanofiber exhibited the improvement in absorption of visible light from the reduction in optical band-gap from $3.08 \mathrm{eV}$ to $2.55 \mathrm{eV}$. The doping process which attributed to the decomposition of the sucrose under $\mathrm{N}_{2}$ thermal treatment resulted in the formation of a conductive nano-crystallised carbon layer which was doped into the $\mathrm{Bi}_{2} \mathrm{Ti}_{4} \mathrm{O}_{11} / \mathrm{TiO}_{2}$ composite nanofiber. It is suggested formation of the nano- 
crystallised carbon $\mathrm{Bi}_{2} \mathrm{Ti}_{4} \mathrm{O}_{11} / \mathrm{TiO}_{2}$ composite nanofiber is a result to the these three phenomenon; (i) the substitution of $\mathrm{O}$ anions with $\mathrm{C}$, (ii) the doping of carbon as cation ions replacing $\mathrm{Ti}$ and (iii) the inclusion of $\mathrm{C}$ the crystal lattice in the form of anions and cations. The characterisation study, the nano-crystallised carbon layer was approximately $2.5 \mathrm{~nm}$ thin along the fringes of the nanofiber. The continuity of the lattice structure suggests that the nano-crystallised carbon layer is integrated with the lattice of the composite nanofiber. The $\mathrm{H}_{2}$ generation tested conducted under visible light also demonstrated that the presence of the nano-crystallised carbon layer not only increased the absorption of the visible light irradiation but also allowed for improved adsorption of reactants resulting in a more efficient generation of $\mathrm{H}_{2}$ under sacrificial conditions.

In sum from this research, the findings made by the author demonstrated the potential sucrose as an external carbon dopant in the formation of a nano-crystallised carbon $\mathrm{Bi}_{2} \mathrm{Ti}_{4} \mathrm{O}_{11} / \mathrm{TiO}_{2}$ composite nanofiber. The presence of the nano-crystallised carbon, $\mathrm{Bi}_{2} \mathrm{Ti}_{4} \mathrm{O}_{11}(117)$ and anatase $\mathrm{TiO}_{2}(101)$ phases mutually benefit each other as it allows for a more efficient flow of photogenerated electron. Collectively the formation of the 3 different cogs in the nano-crystallised carbon $\mathrm{Bi}_{2} \mathrm{Ti}_{4} \mathrm{O}_{11} / \mathrm{TiO}_{2}$ composite nanofiber allowed for enhanced absorption of visible light and a more effective suppression of electron-hole pair recombination. Furthermore, the prospect of inclusively incorporating the advantageous properties of the metals (Bismuth) and non-metals (Carbon) dopants into a $\mathrm{TiO}_{2}$ nanostructure was presented for the first time. These findings would open various avenues of approach for nano-structural and physiochemical modifications as it is of great importance to utilise solar energy for water purification and energy harvesting. 


\section{Recommendations}

This thesis has covered the works pertaining to photocatalytic applications involving one-dimensional nano-crystallised carbon $\mathrm{Bi}_{2} \mathrm{Ti}_{4} \mathrm{O}_{11} / \mathrm{TiO}_{2}$ composite nanofiber. However, further studies are required to compliment the thesis. The recommendations for future research includes:

(i) Studying simultaneous cross-flow filtration and photocatalytic application through the formation of a functional membrane. It has been reported that corrugated membrane has remarkable flux enhancement compared to the flatsheet membrane.(Scott, Jachuck, \& Hall, 2001) This is suggested as it would reduce the problems arising from recovery of suspended photocatalyst.

(ii) Examining the photocatalytic reduction potential of the nano-crystallised carbon $\mathrm{Bi}_{2} \mathrm{Ti}_{4} \mathrm{O}_{11} / \mathrm{TiO}_{2}$ composite nanofiber. Given that properties of the composite nanofiber it would be favourable to employ the photocatalyst for various reduction reactions under visible light or solar conditions.

(iii) Further in-depth characterisation work can be considered to clearly determine a detailed and more precise molecular composition of the $\mathrm{Bi}$ and $\mathrm{C}$ elements with respect to the $\mathrm{Ti}$ elements in the nano-crystallised carbon $\mathrm{Bi}_{2} \mathrm{Ti}_{4} \mathrm{O}_{11} / \mathrm{TiO}_{2}$ composite nanofiber.

(iv) Establish theoretical correlation between the AO7 degradation and the $\mathrm{H}_{2}$ generation performance of the nano-crystallised carbon $\mathrm{Bi}_{2} \mathrm{Ti}_{4} \mathrm{O}_{11} / \mathrm{TiO}_{2}$ composite nanofiber is prepared at various calcination temperature. 


\section{References}

Akpan, U. G., \& Hameed, B. H. (2009). Parameters affecting the photocatalytic degradation of dyes using TiO2-based photocatalysts: a review. J Hazard Mater, 170(2-3), 520-529. doi:10.1016/j.jhazmat.2009.05.039

Albu, S. P., Ghicov, A., Macak, J. M., \& Schmuki, P. (2007). $250 \mu \mathrm{m}$ long anodic TiO2 nanotubes with hexagonal self-ordering. physica status solidi (RRL) - Rapid Research Letters, 1(2), R65-R67. doi:10.1002/pssr.200600069

Aldhous, P. (2003). Atlas of a thirsty planet. Nature, 422(6929), 252-253.

Aldhous, P. (2003). The world's forgotten crisis. Nature, 422(6929), 251. doi:10.1038/422251a

Ansari, S. A., \& Cho, M. H. (2016). Highly Visible Light Responsive, Narrow Band gap TiO2 Nanoparticles Modified by Elemental Red Phosphorus for Photocatalysis and Photoelectrochemical Applications. Sci Rep, 6, 25405. doi:10.1038/srep25405

Arana, J., Melian, J. A. H., Rodriguez, J. M. D., Diaz, O. G., Viera, A., Pena, J. P., . . Jimenez, V. E. (2002). TiO2-photocatalysis as a tertiary treatment of naturally treated wastewater. Catalysis Today, 76(2-4), 279-289. doi:Pii S0920-5861(02)00226-2

Doi 10.1016/S0920-5861(02)00226-2

Bae, E., \& Ohno, T. (2009). Exposed crystal surface-controlled rutile $\mathrm{TiO}_{2}$ nanorods prepared by hydrothermal treatment in the presence of poly(vinyl pyrrolidone). Applied Catalysis $B$ Environmental, 91(3-4), 634-639. doi:10.1016/j.apcatb.2009.06.034

Bai, H., Juay, J., Liu, Z., Song, X., Lee, S. S., \& Sun, D. D. (2012). Hierarchical SrTiO3/TiO2 nanofibers heterostructures with high efficiency in photocatalytic $\mathrm{H} 2$ generation. Applied Catalysis B: Environmental, 125, 367-374. doi:10.1016/j.apcatb.2012.06.007

Bai, H., Liu, Z., \& Sun, D. D. (2012a). Facile preparation of monodisperse, carbon doped single crystal rutile TiO2 nanorod spheres with a large percentage of reactive (110) facet exposure for highly efficient H2 generation. Journal of Materials Chemistry, 22(36), 18801-18807.

Bai, H., Liu, Z., \& Sun, D. D. (2012b). A hierarchically structured and multifunctional membrane for water treatment. Applied Catalysis B: Environmental, 111-112(0), 571-577. doi:10.1016/j.apcatb.2011.11.009

Barborini, E., Conti, A. M., Kholmanov, I., Piseri, P., Podestà, A., Milani, P., . . Sancrotti, M. (2005). Nanostructured TiO2 Films with $2 \mathrm{eV}$ Optical Gap. Advanced Materials, 17(15), 1842-1846. doi:10.1002/adma.200401169

Beranek, R., Hildebrand, H., \& Schmuki, P. (2003). Self-Organized Porous Titanium Oxide Prepared in $\mathrm{H}[\mathrm{sub} 2] \mathrm{SO}$ [sub 4]/HF Electrolytes. Electrochemical and Solid-State Letters, 6. doi:10.1149/1.1545192

Bradbury, S. (2016). Transmission electron microscope (TEM). In TEM (Ed.).

Brunauer, S., Emmett, P. H., \& Teller, E. (1938). Adsorption of gases in multimolecular layers. Journal of the American Chemical Society, 60(2), 309-319. doi:DOI 10.1021/ja01269a023

$\mathrm{Cao}, \mathrm{C}$. H., Xiao, L., Chen, C. H., \& Cao, Q. H. (2015). Synthesis of novel $\mathrm{Cu} 2 \mathrm{O} / \mathrm{BiOCl}$ heterojunction nanocomposites and their enhanced photocatalytic activity under visible light. Applied Surface Science, 357, 1171-1179. doi:10.1016/j.apsusc.2015.09.121

Cao, T., Li, Y., Wang, C., Shao, C., \& Liu, Y. (2011). A Facile in Situ Hydrothermal Method to SrTiO3/TiO2 Nanofiber Heterostructures with High Photocatalytic Activity. Langmuir, 27(6), 2946-2952. doi: $10.1021 / 1 \mathrm{a} 104195 \mathrm{v}$

Cao, T., Li, Y., Wang, C., Zhang, Z., Zhang, M., Shao, C., \& Liu, Y. (2011). Bi4Ti3O12 nanosheets/TiO2 submicron fibers heterostructures: in situ fabrication and high visible light photocatalytic activity. Journal of Materials Chemistry, 2l(19), 6922. doi: $10.1039 / \mathrm{c} 1 \mathrm{jm} 10343 \mathrm{a}$

Centi, G., \& Perathoner, S. (2009). Catalysis: Role and Challenges for a Sustainable Energy. Topics in Catalysis, 52(8), 948-961. doi:10.1007/s11244-009-9245-x

Chen, X., Liu, L., Yu, P. Y., \& Mao, S. S. (2011). Increasing Solar Absorption for Photocatalysis with Black Hydrogenated Titanium Dioxide Nanocrystals. Science, 331(6018), 746-750. doi:10.1126/science.1200448

Chen, X., Lou, Y., Dayal, S., Qiu, X., Krolicki, R., Burda, C., . . Becker, J. (2005). Doped Semiconductor Nanomaterials. Journal of Nanoscience and Nanotechnology, 5(9), 1408-1420. doi:10.1166/jnn.2005.310

Chen, X., \& Mao, S. S. (2007). Titanium dioxide nanomaterials: synthesis, properties, modifications, and applications. Chem Rev, 107(7), 2891-2959. doi:10.1021/cr0500535 
Chen, X., \& Selloni, A. (2014). Introduction: titanium dioxide (TiO2) nanomaterials. Chem Rev, 114(19), 9281-9282. doi:10.1021/cr500422r

Chen, X., Shen, S., Guo, L., \& Mao, S. S. (2010). Semiconductor-based photocatalytic hydrogen generation. Chem Rev, 110(11), 6503-6570. doi:10.1021/cr1001645

Choi, Y., Umebayashi, T., \& Yoshikawa, M. (2004). Fabrication and characterization of C-doped anatase $\mathrm{TiO}_{2}$ photocatalysts. Journal of Materials Science, 39(5), 1837-1839. doi:10.1023/b:jmsc.0000016198.73153.31

Chong, M. N., Jin, B., Chow, C. W. K., \& Saint, C. (2010). Recent developments in photocatalytic water treatment technology: A review. Water research, 44(10), 2997-3027. doi:http://dx.doi.org/10.1016/j.watres.2010.02.039

Chow, J., Kopp, R. J., \& Portney, P. R. (2003). Energy resources and global development. Science, 302(5650), 1528-1531. doi:10.1126/science.1091939

Chronakis, I. S. (2005). Novel nanocomposites and nanoceramics based on polymer nanofibers using electrospinning process-A review. Journal of Materials Processing Technology, 167(2-3), 283-293. doi:10.1016/j.jmatprotec.2005.06.053

Cohen, G., \& Heikkila, R. E. (1974). The generation of hydrogen peroxide, superoxide radical, and hydroxyl radical by 6 -hydroxydopamine, dialuric acid, and related cytotoxic agents. J Biol Chem, 249(8), 2447-2452.

Davis, S. J., Caldeira, K., \& Matthews, H. D. (2010). Future $\mathrm{CO}_{2}$ emissions and climate change from existing energy infrastructure. Science, 329(5997), 1330-1333. doi:10.1126/science. 1188566

Devi, L. G., \& Kavitha, R. (2013). A review on non metal ion doped titania for the photocatalytic degradation of organic pollutants under UV/solar light: Role of photogenerated charge carrier dynamics in enhancing the activity. Applied Catalysis B-Environmental, 140, 559-587. doi:10.1016/j.apcatb.2013.04.035

Di Paola, A., Bellardita, M., \& Palmisano, L. (2013). Brookite, the Least Known TiO2 Photocatalyst. Catalysts, 3(1), 36-73. doi:10.3390/catal3010036

Esch, T. R., Bredow, T., \& Gadaczek, I. (2014). Surface structures and thermodynamics of low-index of rutile, brookite and anatase - A comparative DFT study. In b. a. a. f. 1. t. r. The primitive cells of rutile (Ed.).

Feng Yao, W., Wang, H., Hong Xu, X., Feng Cheng, X., Huang, J., Xia Shang, S., . . Wang, M. (2003). Photocatalytic property of bismuth titanate Bi12TiO20 crystals. Applied Catalysis A: General, 243(1), 185-190. doi:http://dx.doi.org/10.1016/S0926-860X(02)00564-1

Fujishima, A., \& Honda, K. (1972). Electrochemical Photolysis of Water at a Semiconductor Electrode. Nature, 238(5358), 37-+. doi:DOI 10.1038/238037a0

Fujishima, A., Rao, T., \& Tryk, D. (2000). Titanium dioxide photocatalysis. Journal of Photochemistry and Photobiology ....

Gaya, U. I., \& Abdullah, A. H. (2008). Heterogeneous photocatalytic degradation of organic contaminants over titanium dioxide: A review of fundamentals, progress and problems. Journal of Photochemistry and Photobiology C-Photochemistry Reviews, 9(1), 1-12. doi:10.1016/j.jphotochemrev.2007.12.003

Georges, K., Thornton, A., \& Sadle, R. (2009). Transforming wastewater treatment to reduce carbon emissions Retrieved from http://publications.environmentagency.gov.uk/PDF/SCHO1209BRNZ-E-E.pdf

Göpel, W., Anderson, J. A., Frankel, D., Jaehnig, M., Phillips, K., Schäfer, J. A., \& Rocker, G. (1984). Surface defects of TiO2(110): A combined XPS, XAES AND ELS study. Surface Science, 139(2), 333-346. doi:http://dx.doi.org/10.1016/0039-6028(84)90054-2

Gratzel, M. (2001). Photoelectrochemical cells. Nature, 414(6861), 338-344.

H. Reneker, D., \& Chun, I. (1996). Nanometre diameter fibres of polymer, produced by electrospinning. Nanotechnology, 7(3), 216.

Halmann, M., Ulman, M., \& Aurian-Blajeni, B. (1983). Photochemical solar collector for the photoassisted reduction of aqueous carbon dioxide. Solar Energy, 31. doi:10.1016/0038092X(83)90145-7

Hou, J., Wang, Z., Jiao, S., \& Zhu, H. (2011). 3D Bi12TiO20/TiO2 hierarchical heterostructure: synthesis and enhanced visible-light photocatalytic activities. J Hazard Mater, 192(3), 17721779. doi:10.1016/j.jhazmat.2011.07.013

Hou, J. G., Qu, Y. F., Krsmanovic, D., Ducati, C., Eder, D., \& Kumar, R. V. (2010). Hierarchical assemblies of bismuth titanate complex architectures and their visible-light photocatalytic activities. Journal of Materials Chemistry, 20(12), 2418-2423. doi:10.1039/b923124b

Hwang, N., \& Barron, A. (2011). BET Surface Area Analysis of Nanoparticles. Retrieved from http://cnx.org/content/m38278/1.1/ 
Ibhadon, A. O., \& Fitzpatrick, P. (2013). Heterogeneous Photocatalysis: Recent Advances and Applications. Catalysts, 3(1), 189-218. doi:10.3390/catal3010189

Inagaki, M., Hirose, Y., Matsunaga, T., Tsumura, T., \& Toyoda, M. (2003). Carbon coating of anatasetype $\mathrm{TiO}<\mathrm{sub}>2</$ sub $>$ through their precipitation in PVA aqueous solution. Carbon, 4I(13), 2619-2624.

Inagaki, M., Kojin, F., Tryba, B., \& Toyoda, M. (2005). Carbon-coated anatase: the role of the carbon layer for photocatalytic performance. Carbon, 43(8), 1652-1659. doi:10.1016/j.carbon.2005.01.043

Inoue, T., Fujishima, A., Konishi, S., \& Honda, K. (1979). Photoelectrocatalytic reduction of carbon dioxide in aqueous suspensions of semiconductor powders. Nature, 277. doi: $10.1038 / 277637 \mathrm{a} 0$

Irie, H., Watanabe, Y., \& Hashimoto, K. (2003). Carbon-doped Anatase $\mathrm{TiO}_{2}$ Powders as a Visible-light Sensitive Photocatalyst. Chemistry Letters, 32(8), 772-773. doi:10.1246/cl.2003.772

Jagtap, N., Bhagwat, M., Awati, P., \& Ramaswamy, V. (2005). Characterization of nanocrystalline anatase titania: an in situ HTXRD study. Thermochimica Acta, 427(1-2), 37-41. doi:10.1016/j.tca.2004.08.011

Khan, S. U. M., Al-Shahry, M., \& Ingler, W. B. (2002). Efficient Photochemical Water Splitting by a Chemically Modified n-TiO2. Science, 297(5590), 2243-2245. doi:10.1126/science.1075035

Khataee, A. R., \& Kasiri, M. B. (2010). Photocatalytic degradation of organic dyes in the presence of nanostructured titanium dioxide: Influence of the chemical structure of dyes. Journal of Molecular Catalysis a-Chemical, 328(1-2), 8-26. doi:10.1016/j.molcata.2010.05.023

Konstantinou, I. K., Sakkas, V. A., \& Albanis, T. A. (2002). Photocatalytic degradation of propachlor in aqueous $\mathrm{TiO} 2$ suspensions. Determination of the reaction pathway and identification of intermediate products by various analytical methods. Water research, 36(11), 2733-2742. doi:Pii S0043-1354(01)00505-X

Doi 10.1016/S0043-1354(01)00505-X

Kudo, A., \& Miseki, Y. (2009). Heterogeneous photocatalyst materials for water splitting. Chem Soc Rev, 38(1), 253-278. doi:10.1039/b800489g

Kulkarni, A., Bambole, V. A., \& Mahanwar, P. A. (2010). Electrospinning of Polymers, Their Modeling and Applications. Polymer-Plastics Technology and Engineering, 49(5), 427-441. doi:10.1080/03602550903414019

Lazar, M. A., Varghese, S., \& Nair, S. S. (2012). Photocatalytic Water Treatment by Titanium Dioxide: Recent Updates. Catalysts, 2(4), 572-601. doi:10.3390/catal2040572

Leadley, D. (2010). Transmission Electron Microscopy (TEM). Retrieved from United Kingdom: https:/www2.warwick.ac.uk/fac/sci/physics/current/postgraduate/regs/mpags/ex $5 /$ techniques/s tructural/tem/

Lee, K., Kim, J., Kim, H., Lee, Y., Tak, Y., Kim, D., \& Schmuki, P. (2009). Effect of Electrolyte Conductivity on the Formation of a Nanotubular TiO2 Photoanode for a Dye-Sensitized Solar Cell. Journal of the Korean Physical Society, 54(3), 1027. doi:10.3938/jkps.54.1027

Lee, S. S., Bai, H., Liu, Z., \& Sun, D. D. (2013). Optimization and an insightful properties-Activity study of electrospun $\mathrm{TiO} 2 / \mathrm{CuO}$ composite nanofibers for efficient photocatalytic $\mathrm{H} 2$ generation. Applied Catalysis B: Environmental, 140-141, 68-81. doi:10.1016/j.apcatb.2013.03.033

Li, D., \& Xia, Y. (2003). Fabrication of Titania Nanofibers by Electrospinning. Nano Letters, 3(4), 555560. doi: $10.1021 / \mathrm{n} 10340390$

Linsebigler, A. L., Lu, G. Q., \& Yates, J. T. (1995). Photocatalysis on Tio2 Surfaces - Principles, Mechanisms, and Selected Results. Chemical Reviews, 95(3), 735-758. doi:DOI $10.1021 / \mathrm{cr} 00035 \mathrm{a} 013$

Liu, G., Hoivik, N., Wang, K., \& Jakobsen, H. (2012). Engineering TiO2 nanomaterials for CO2 conversion/solar fuels. Solar Energy Materials and Solar Cells, 105, 53-68. doi:http://dx.doi.org/10.1016/j.solmat.2012.05.037

Liu, G. H., Hoivik, N., Wang, K. Y., \& Jakobsen, H. (2012). Engineering TiO2 nanomaterials for CO2 conversion/solar fuels. Solar Energy Materials and Solar Cells, 105, 53-68. doi:10.1016/j.solmat.2012.05.037

Liu, Z., Sun, D. D., Guo, P., \& Leckie, J. O. (2006). An Efficient Bicomponent TiO2/SnO2 Nanofiber Photocatalyst Fabricated by Electrospinning with a Side-by-Side Dual Spinneret Method. Nano Letters, 7(4), 1081-1085. doi:10.1021/n1061898e

Lu, X., Wang, C., \& Wei, Y. (2009). One-dimensional composite nanomaterials: synthesis by electrospinning and their applications. Small, 5(21), 2349-2370. doi:10.1002/sm11.200900445 
Macak, J. M., Albu, S. P., \& Schmuki, P. (2007). Towards ideal hexagonal self-ordering of TiO2 nanotubes. physica status solidi (RRL) - Rapid Research Letters, 1(5), 181-183. doi:10.1002/pssr.200701148

Macak, J. M., Hildebrand, H., Marten-Jahns, U., \& Schmuki, P. (2008). Mechanistic aspects and growth of large diameter self-organized TiO2 nanotubes. Journal of Electroanalytical Chemistry, 621 . doi:10.1016/j.jelechem.2008.01.005

Macak, J. M., Sirotna, K., \& Schmuki, P. (2005). Self-organized porous titanium oxide prepared in Na2SO4/NaF electrolytes. Electrochimica Acta, 50(18), 3679-3684. doi:10.1016/j.electacta.2005.01.014

Macak, J. M., Tsuchiya, H., Ghicov, A., Yasuda, K., Hahn, R., Bauer, S., \& Schmuki, P. (2007). TiO2 nanotubes: Self-organized electrochemical formation, properties and applications. Current Opinion in Solid State and Materials Science, 11. doi:10.1016/j.cossms.2007.08.004

Macak, J. M., Tsuchiya, H., \& Schmuki, P. (2005). High-aspect-ratio TiO2 nanotubes by anodization of titanium. Angew Chem Int Ed Engl, 44(14), 2100-2102. doi:10.1002/anie.200462459

Macak, J. M., Tsuchiya, H., Taveira, L., Aldabergerova, S., \& Schmuki, P. (2005). Smooth Anodic TiO2 Nanotubes. Angewandte Chemie International Edition, 44(45), 7463-7465. doi:10.1002/anie.200502781

Madhugiri, S., Sun, B., Smirniotis, P. G., Ferraris, J. P., \& Balkus, K. J. (2004). Electrospun mesoporous titanium dioxide fibers. Microporous and Mesoporous Materials, 69(1-2), 77-83. doi:10.1016/j.micromeso.2003.12.023

Microscopes. (2016). The Transmission Electron Microscope. Retrieved from http://www.nobelprize.org/educational/physics/microscopes/tem/

Murugesan, S., Huda, M. N., Yan, Y. F., Al-Jassim, M. M., \& Subramanian, V. (2010). BandEngineered Bismuth Titanate Pyrochlores for Visible Light Photocatalysis. Journal of Physical Chemistry C, 114(23), 10598-10605. doi:10.1021/jp906252r

$\mathrm{Ng}$, J., Pan, J. H., \& Sun, D. D. (2011). Hierarchical assembly of anatase nanowhiskers and evaluation of their photocatalytic efficiency in comparison to various one-dimensional $\mathrm{TiO} 2$ nanostructures. Journal of Materials Chemistry, $21(32), 11844$. doi:10.1039/c ljm $11088 \mathrm{~h}$

Ng, J., Xu, S. P., Zhang, X. W., Yang, H. Y., \& Sun, D. D. (2010). Hybridized Nanowires and Cubes: A Novel Architecture of a Heterojunctioned TiO2/SrTiO3 Thin Film for Efficient Water Splitting. Advanced Functional Materials, 20(24), 4287-4294. doi:10.1002/adfm.201000931

$\mathrm{Ng}$, J. W., Pan, J. H., \& Sun, D. D. (2011). Hierarchical assembly of anatase nanowhiskers and evaluation of their photocatalytic efficiency in comparison to various one-dimensional $\mathrm{TiO} 2$ nanostructures. Journal of Materials Chemistry, 2I(32), 11844-11853. doi: $10.1039 / \mathrm{c} 1 \mathrm{jm} 11088 \mathrm{~h}$

O'Regan, B., \& Gratzel, M. (1991). A low-cost, high-efficiency solar cell based on dye-sensitized colloidal TiO2 films. Nature, 353(6346), 737-740.

Oh, G. Y., Ju, Y. W., Kim, M. Y., Jung, H. R., Kim, H. J., \& Lee, W. J. (2008). Adsorption of toluene on carbon nanofibers prepared by electrospinning. Sci Total Environ, 393(2-3), 341-347. doi:10.1016/j.scitotenv.2008.01.005

Pan, J. H., Dou, H. Q., Xiong, Z. G., Xu, C., Ma, J. Z., \& Zhao, X. S. (2010). Porous photocatalysts for advanced water purifications. Journal of Materials Chemistry, 20(22), 4512-4528. doi: $10.1039 / \mathrm{b} 925523 \mathrm{k}$

Paz, Y. (2010). Application of TiO2 photocatalysis for air treatment: Patents' overview. Applied Catalysis B: Environmental, 99(3-4), 448-460. doi:http://dx.doi.org/10.1016/j.apcatb.2010.05.011

Phairat, U., Dena, M., Amornvadee, V., \& Paitoon, T. (2006). Photocatalytic Process for CO 2 Emission Reduction from Industrial Flue Gas Streams. Industrial \& Engineering Chemistry Research, 45. doi:10.1021/ie0505763

Pham, Q. P., Sharma, U., \& Mikos, A. G. (2006). Electrospinning of polymeric nanofibers for tissue engineering applications: a review. Tissue Eng, 12(5), 1197-1211. doi:10.1089/ten.2006.12.1197

Qu, J. P., Zhang, X. G., Wang, Y. G., \& Xie, C. X. (2005). Electrochemical reduction of CO2 on RuO2/TiO2 nanotubes composite modified Pt electrode. Electrochimica Acta, 50(16-17), 3576-3580. doi:10.1016/j.electacta.2004.11.061

Ramakrishna, S., Fujihara, K., Teo, W. E., Yong, T., Ma, Z. W., \& Ramaseshan, R. (2006). Electrospun nanofibers: solving global issues. Materials Today, 9(3), 40-50. doi:Doi 10.1016/S13697021(06)71389-X 
Reddy, M. V., Jose, R., Teng, T. H., Chowdari, B. V. R., \& Ramakrishna, S. (2010). Preparation and electrochemical studies of electrospun $\mathrm{TiO} 2$ nanofibers and molten salt method nanoparticles. Electrochimica Acta, 55(9), 3109-3117. doi:10.1016/j.electacta.2009.12.095

Reyes-Coronado, D., Rodriguez-Gattorno, G., Espinosa-Pesqueira, M. E., Cab, C., de Coss, R., \& Oskam, G. (2008). Phase-pure TiO(2) nanoparticles: anatase, brookite and rutile. Nanotechnology, 19(14), 145605. doi:10.1088/0957-4484/19/14/145605

Roy, P., Berger, S., \& Schmuki, P. (2011). TiO2 nanotubes: synthesis and applications. Angewandte Chemie (International ed. in English), 50(13), 2904-2939. doi:10.1002/anie.201001374

Santato, C., Ulmann, M., \& Augustynski, J. (2001). Enhanced visible light conversion efficiency using nanocrystalline WO3 films. Advanced Materials, 13(7), 511-+. doi:Doi 10.1002/15214095(200104)13:7<511::Aid-Adma51 1>3.0.Co;2-W

Schimmel, H. G., Kearley, G. J., Nijkamp, M. G., Visser, C. T., Jong, K. P. d., \& Mulder, F. M. (2003). Hydrogen Adsorption in Carbon Nanostructures: Comparison of Nanotubes, Fibers, and Coals. Chemistry - A European Journal, 9(19), 4764-4770. doi:10.1002/chem.200304845

Scott, K., Jachuck, R. J., \& Hall, D. (2001). Crossflow microfiltration of water-in-oil emulsions using corrugated membranes. Separation and Purification Technology, 22-23(0), 431-441. doi:http://dx.doi.org/10.1016/S1383-5866(00)00180-5

Shang, M., Wang, W., Yin, W., Ren, J., Sun, S., \& Zhang, L. (2010). General strategy for a large-scale fabric with branched nanofiber-nanorod hierarchical heterostructure: controllable synthesis and applications. Chemistry, 16(37), 11412-11419. doi:10.1002/chem.201000639

Shannon, M. A., Bohn, P. W., Elimelech, M., Georgiadis, J. G., Marinas, B. J., \& Mayes, A. M. (2008). Science and technology for water purification in the coming decades. Nature, 452(7185), 301310. doi:10.1038/nature06599

Shi, H. F., Tan, H. Q., Zhu, W. B., Sun, Z. C., Ma, Y. J., \& Wang, E. B. (2015). Electrospun Cr-doped Bi4Ti3O12/Bi2Ti2O7 heterostructure fibers with enhanced visible-light photocatalytic properties. Journal of Materials Chemistry A, 3(12), 6586-6591. doi:10.1039/c4ta06736c

Shojaee, E., Abbasnejad, M., Saeedian, M., \& Mohammadizadeh, M. R. (2011). First-principles study of lattice dynamics of TiO2 in brookite and cotunnite structures. Physical Review B, 83(17), 174302. doi:ARTN 174302

10.1103/PhysRevB.83.174302

Takanabe, K., \& Domen, K. (2012). Preparation of Inorganic Photocatalytic Materials for Overall Water Splitting. ChemCatChem, 4(10), 1485-1497. doi:10.1002/cctc.201200324

Taninouchi, Y.-k., Uda, T., Awakura, Y., Ikeda, A., \& Haile, S. M. (2007). Dehydration behavior of the superprotonic conductor CsH2PO4 at moderate temperatures: 230 to $260^{\circ} \mathrm{C}$. Journal of Materials Chemistry, 17(30), 3182. doi:10.1039/b704558c

Taveira, L. V., Macák, J. M., Tsuchiya, H., Dick, L. F. P., \& Schmuki, P. (2005). Initiation and Growth of Self-Organized TiO[sub 2] Nanotubes Anodically Formed in NH[sub 4]F/(NH[sub 4])[sub 2]SO[sub 4] Electrolytes. Journal of The Electrochemical Society, 152(10), B405. doi: $10.1149 / 1.2008980$

Trunschke, A. (2013). Surface area and pore size determination. Retrieved from http://www.fhiberlin.mpg.de/acnew/department/pages/teaching/pages/teaching wintersemester $2013 \quad 2014$ lannette trunschke surface area and pore analysis 131101.pdf

Varghese, O. K., Paulose, M., LaTempa, T. J., \& Grimes, C. A. (2009). High-Rate Solar Photocatalytic Conversion of CO2 and Water Vapor to Hydrocarbon Fuels. Nano letters, 9(2), 731-737. doi: $10.1021 / \mathrm{n} 1803258 \mathrm{p}$

Wang, C., Shao, C., Wang, L., Zhang, L., Li, X., \& Liu, Y. (2009). Electrospinning preparation, characterization and photocatalytic properties of Bi2O3 nanofibers. $J$ Colloid Interface $S c i$, 333(1), 242-248. doi:10.1016/j.jcis.2008.12.077

Wang, J., \& Lin, Z. (2008). Freestanding TiO2Nanotube Arrays with Ultrahigh Aspect Ratio via Electrochemical Anodization. Chemistry of Materials, 20(4), 1257-1261. doi:10.1021/cm7028917

Wang, K., Cai, R., Yuan, T., Yu, X., Ran, R., \& Shao, Z. P. (2009). Process investigation, electrochemical characterization and optimization of $\mathrm{LiFePO} 4 / \mathrm{C}$ composite from mechanical activation using sucrose as carbon source. Electrochimica Acta, 54(10), 2861-2868. doi:10.1016/j.electacta.2008.11.012

Wang, W., Li, N., Chi, Y., Li, Y. J., Yan, W. F., Li, X. T., \& Shao, C. L. (2013). Electrospinning of magnetical bismuth ferrite nanofibers with photocatalytic activity. Ceramics International, 39(4), 3511-3518. doi:10.1016/j.ceramint.2012.10.175 
Wang, X., Li, Z., Shi, J., \& Yu, Y. (2014). One-dimensional titanium dioxide nanomaterials: nanowires, nanorods, and nanobelts. Chem Rev, 114(19), 9346-9384. doi:10.1021/cr400633s

Wang, X. P., \& Lim, T. T. (2010). Solvothermal synthesis of C-N codoped TiO2 and photocatalytic evaluation for bisphenol A degradation using a visible-light irradiated LED photoreactor. Applied Catalysis B-Environmental, 100(1-2), 355-364. doi:10.1016/j.apcatb.2010.08.012

Wu, G., Nishikawa, T., Ohtani, B., \& Chen, A. (2007). Synthesis and Characterization of CarbonDoped TiO2 Nanostructures with Enhanced Visible Light Response. Chemistry of Materials, 19(18), 4530-4537. doi: $10.1021 / \mathrm{cm} 071244 \mathrm{~m}$

Xu, J., Wang, W., Shang, M., Gao, E., Zhang, Z., \& Ren, J. (2011). Electrospun nanofibers of Bi-doped $\mathrm{TiO} 2$ with high photocatalytic activity under visible light irradiation. J Hazard Mater, 196, 426-430. doi:10.1016/j.jhazmat.2011.09.010

Xu, S. P., Ng, J. W., Du, A. J., Liu, J. C., \& Sun, D. D. (2011). Highly efficient TiO2 nanotube photocatalyst for simultaneous hydrogen production and copper removal from water. International Journal of Hydrogen Energy, 36(11), 6538-6545. doi:10.1016/j.ijhydene.2011.03.047

Xu, X., Fang, X., Zhai, T., Zeng, H., Liu, B., Hu, X., . . Golberg, D. (2011). Tube-in-Tube TiO2 Nanotubes with Porous Walls: Fabrication, Formation Mechanism, and Photocatalytic Properties. Small, 7(4), 445-449. doi:10.1002/smll.201001849

Yang, P. D., Zhao, D. Y., Margolese, D. I., Chmelka, B. F., \& Stucky, G. D. (1998). Generalized syntheses of large-pore mesoporous metal oxides with semicrystalline frameworks. Nature, $396(6707), 152-155$

Yang, S., Wang, P., Yang, X., Shan, L., Zhang, W., Shao, X., \& Niu, R. (2010). Degradation efficiencies of azo dye Acid Orange 7 by the interaction of heat, UV and anions with common oxidants: Persulfate, peroxymonosulfate and hydrogen peroxide. Journal of hazardous materials, $179(1-3), 552-558$. doi:http://dx.doi.org/10.1016/j.jhazmat.2010.03.039

Yasuda, K., \& Schmuki, P. (2007). Control of morphology and composition of self-organized zirconium titanate nanotubes formed in (NH4)2SO4/NH4F electrolytes. Electrochimica Acta, 52(12), 4053-4061. doi:10.1016/j.electacta.2006.11.023

Yun, S. M., Palanivelu, K., Kim, Y. H., Kang, P. H., \& Lee, Y. S. (2008). Preparation and characterization of carbon covered $\mathrm{TiO} 2$ using sucrose for solar photodegradation. Journal of Industrial and Engineering Chemistry, 14(5), 667-671. doi:10.1016/j.jiec.2008.02.010

Zhang, Q. H., Han, W. D., Hong, Y. J., \& Yu, J. G. (2009). Photocatalytic reduction of CO2 with $\mathrm{H} 2 \mathrm{O}$ on Pt-loaded TiO2 catalyst. Catalysis Today, 148(3-4), 335-340. doi:10.1016/j.cattod.2009.07.081

Zhang, W. F., He, Y. L., Zhang, M. S., Yin, Z., \& Chen, Q. (2000). Raman scattering study on anatase TiO 2 nanocrystals. Journal of Physics D: Applied Physics, 33(8), 912.

Zhang, X. M., Huo, K. F., Hu, L. S., Wu, Z. W., \& Chu, P. K. (2010). Synthesis and Photocatalytic Activity of Highly Ordered TiO2 and SrTiO3/TiO2 Nanotube Arrays on Ti Substrates. Journal of the American Ceramic Society, 93(9), 2771-2778. doi:10.1111/j.1551-2916.2010.03805.x

Zhou, J. K., Zou, Z. G., Ray, A. K., \& Zhao, X. S. (2007). Preparation and characterization of polycrystalline bismuth titanate $\mathrm{Bi} 12 \mathrm{TiO} 20$ and its photocatalytic properties under visible light irradiation. Industrial \& Engineering Chemistry Research, 46(3), 745-749. doi: $10.1021 / \mathrm{ie} 0613220$

Zhou, T., \& Hu, J. (2010). Mass Production and Photocatalytic Activity of Highly Crystalline Metastable Single-Phase Bi20TiO32 Nanosheets. Environmental science \& technology, 44(22), 8698-8703. doi:10.1021/es1019959 
Appendix A

\section{Stages of growth and Formation of $\mathrm{TiO}_{2}$ Nanotubes}

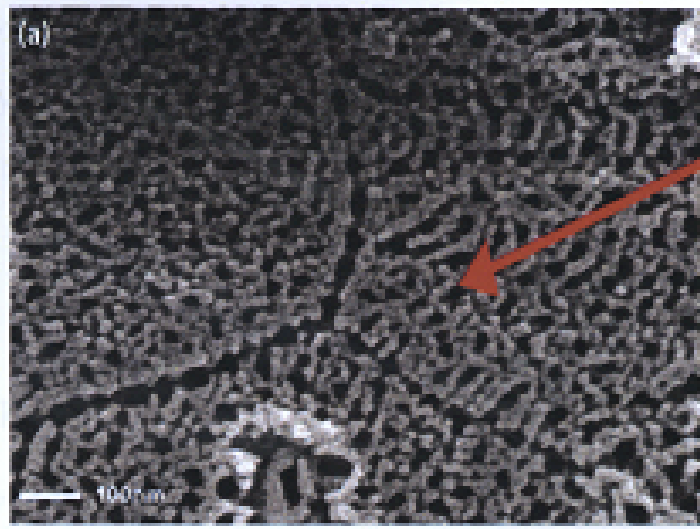

Time : 5 mins

Initial pore growth

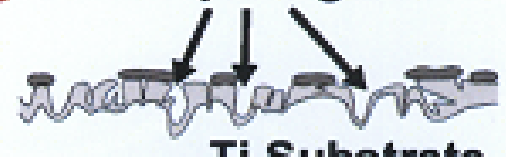

Ti Substrate

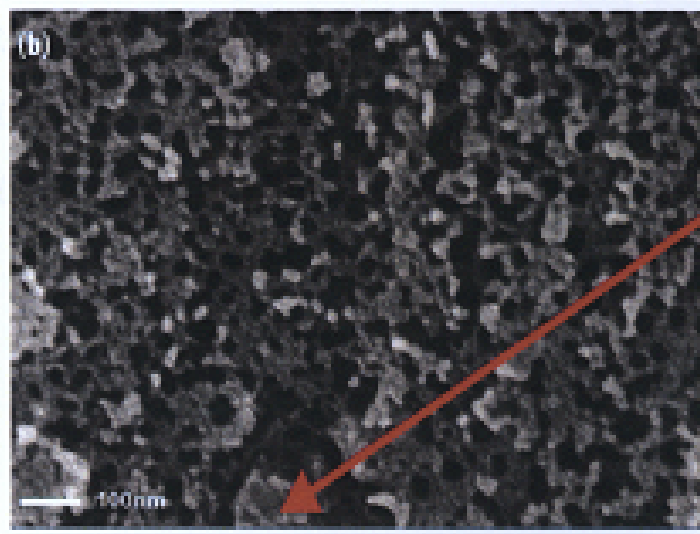

Time : 10 mins

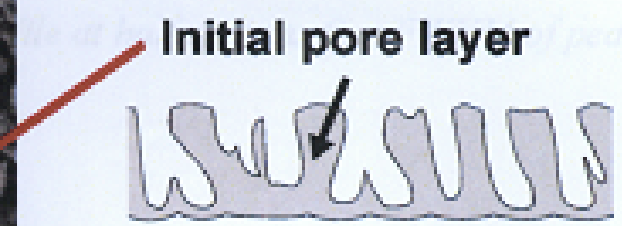

Ti Substrate

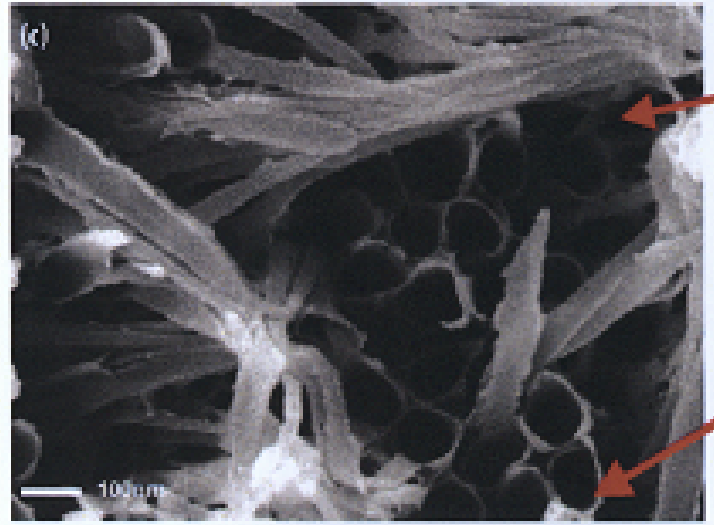

Time : $\mathbf{3 0}$ mins

Remaining initial
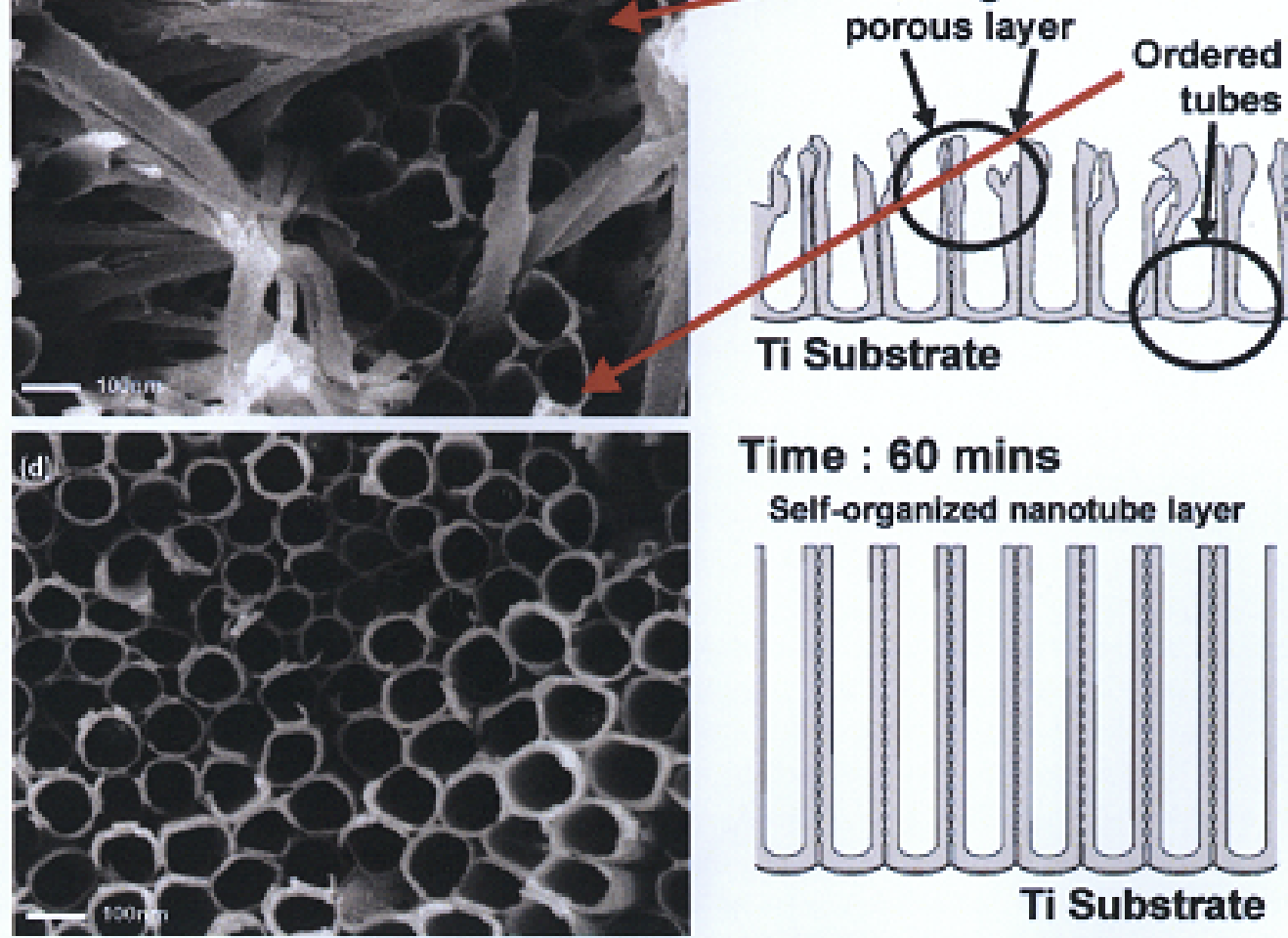

Time : 60 mins

Self-organized nanotube layer

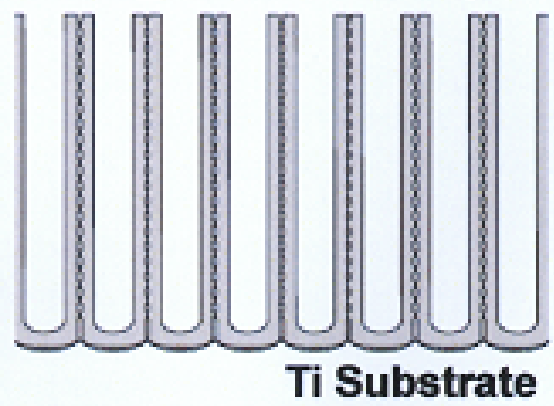

Formation of $\mathrm{TiO}_{2}$ nanotubes arrays and schematic diagram (right) adapted from (Taveira et al., 2005) 


\section{Appendix B}

\section{Scherrer Equation}

$\mathrm{X}$-ray diffraction is a convenient method for determining the mean size of nano crystallites in nano crystalline bulk materials. With the use of the Scherrer Equation, the average crystal size can be estimated as follows;

$$
D_{p}=\frac{0.94 \lambda}{\beta_{\frac{1}{2}} \cos \theta}
$$

Where,

$D_{p}$ is the average crystallite size

$\lambda$ is the $X$-ray Wavelength in nanometer $(\mathrm{nm})$

$\beta$ is the peak width of the diffraction peak profile at half radians (i.e. FWHM of peak)

$\theta$ is the Bragg Angle 
Appendix C

\section{$\underline{\text { BJH Pore Size Distribution of } \mathrm{TiO}_{2} \text { Nanofibers }}$}
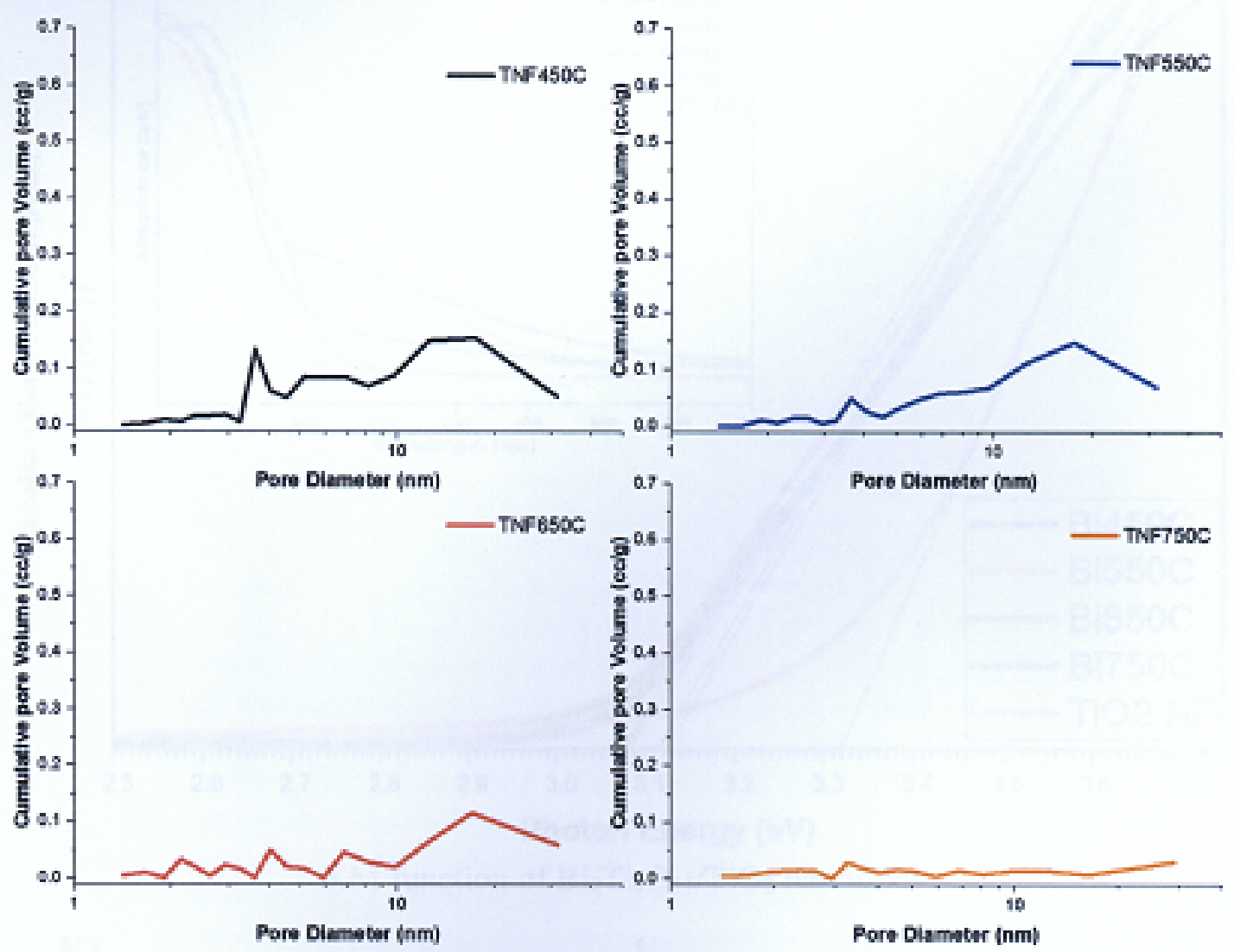

BJH Pore Size distribution of $\mathrm{TiO}_{2}$ nanofibers 


\section{Profiles of $\mathrm{Bi}_{2} \mathrm{Ti}_{4} \mathrm{O}_{11} / \mathrm{TiO}_{2}$ composite Nanofiber}

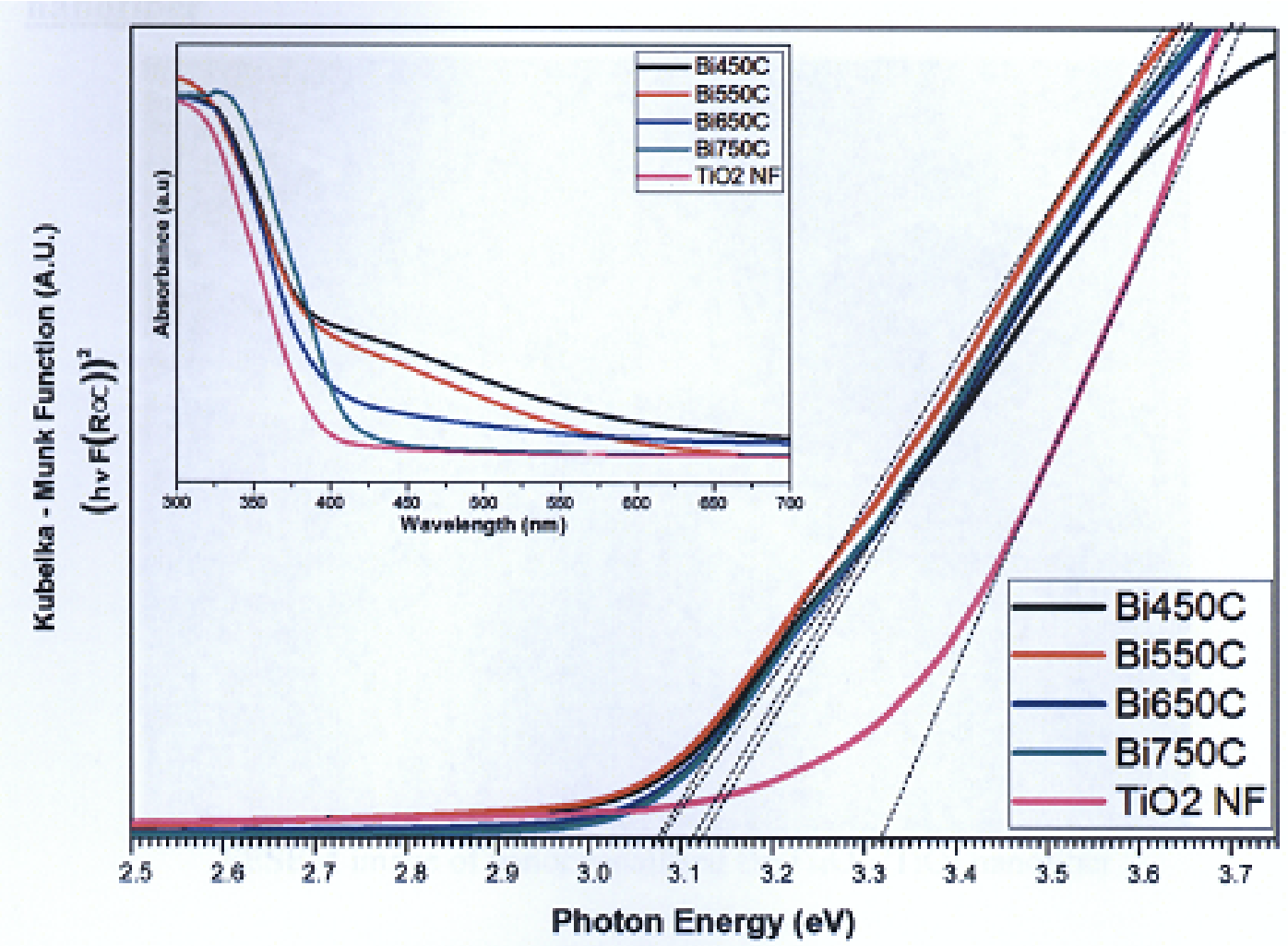

$\mathrm{KM}$ function of $\mathrm{Bi}_{2} \mathrm{Ti}_{4} \mathrm{O}_{11} / \mathrm{TiO}_{2}$ nanofiber
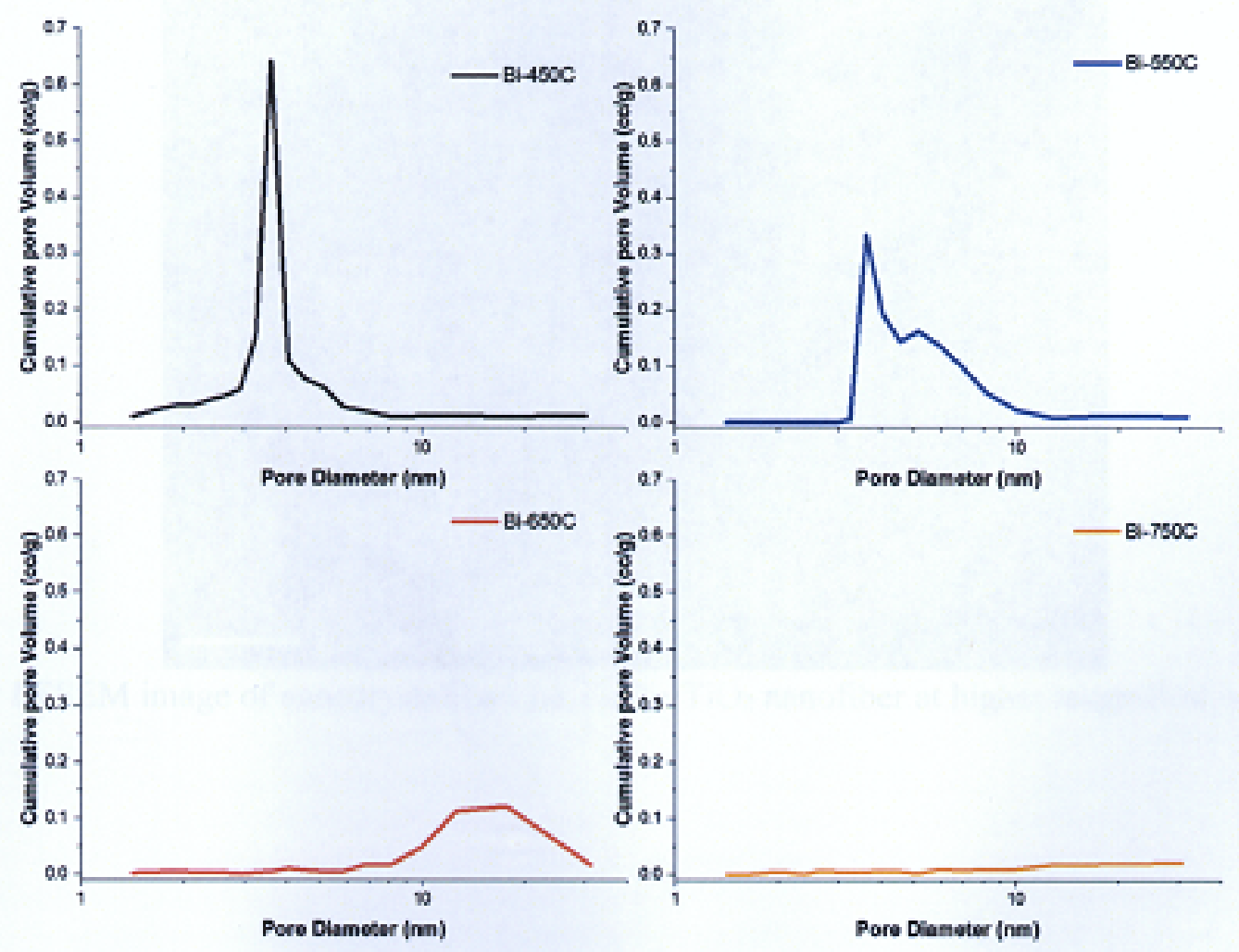

BJH Pore size estimation of $\mathrm{Bi}_{2} \mathrm{Ti}_{4} \mathrm{O}_{11} / \mathrm{TiO}_{2}$ nanofiber 
Appendix E

\section{FESEM images of nano-crystallised carbon $\mathrm{Bi}_{2} \mathrm{Ti}_{4} \mathrm{O}_{11} / \mathrm{TiO}_{2}$ composite nanofiber}

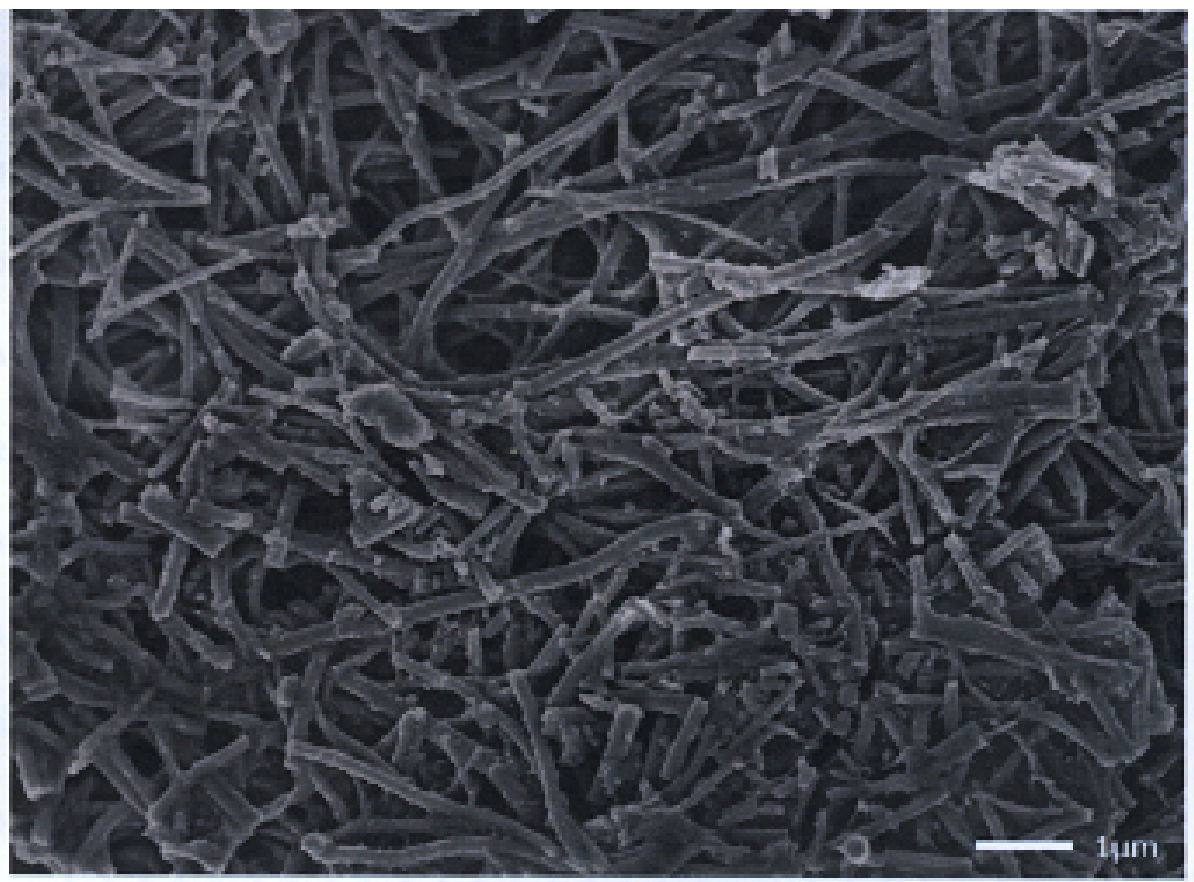

FESEM image of nanocrystallised $\mathrm{Bi}_{2} \mathrm{Ti}_{4} \mathrm{O}_{11} / \mathrm{TiO}_{2}$ nanofiber

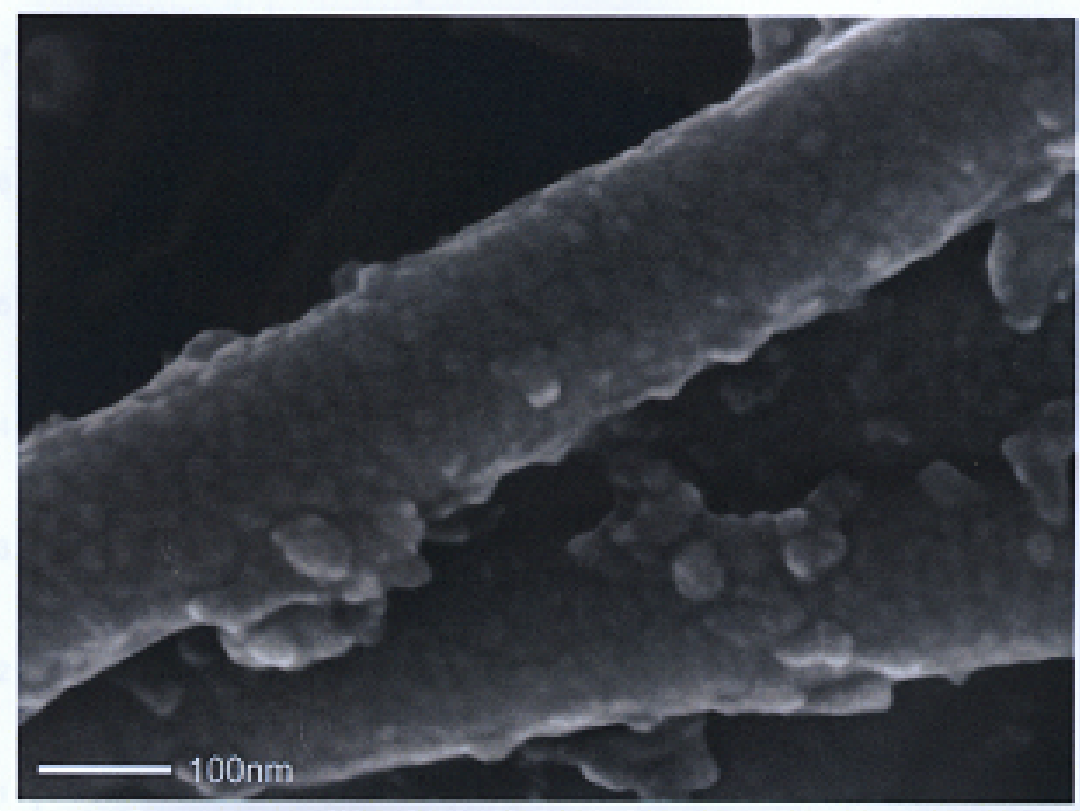

FESEM image of nanocrystallised $\mathrm{Bi}_{2} \mathrm{Ti}_{4} \mathrm{O}_{11} / \mathrm{TiO}_{2}$ nanofiber at higher magnification 
Appendix F

\section{Adsoprtion Properties of nanocrystallised carbon $\mathrm{TiO}_{2}-\mathrm{Bi}$ composite} nanofiber

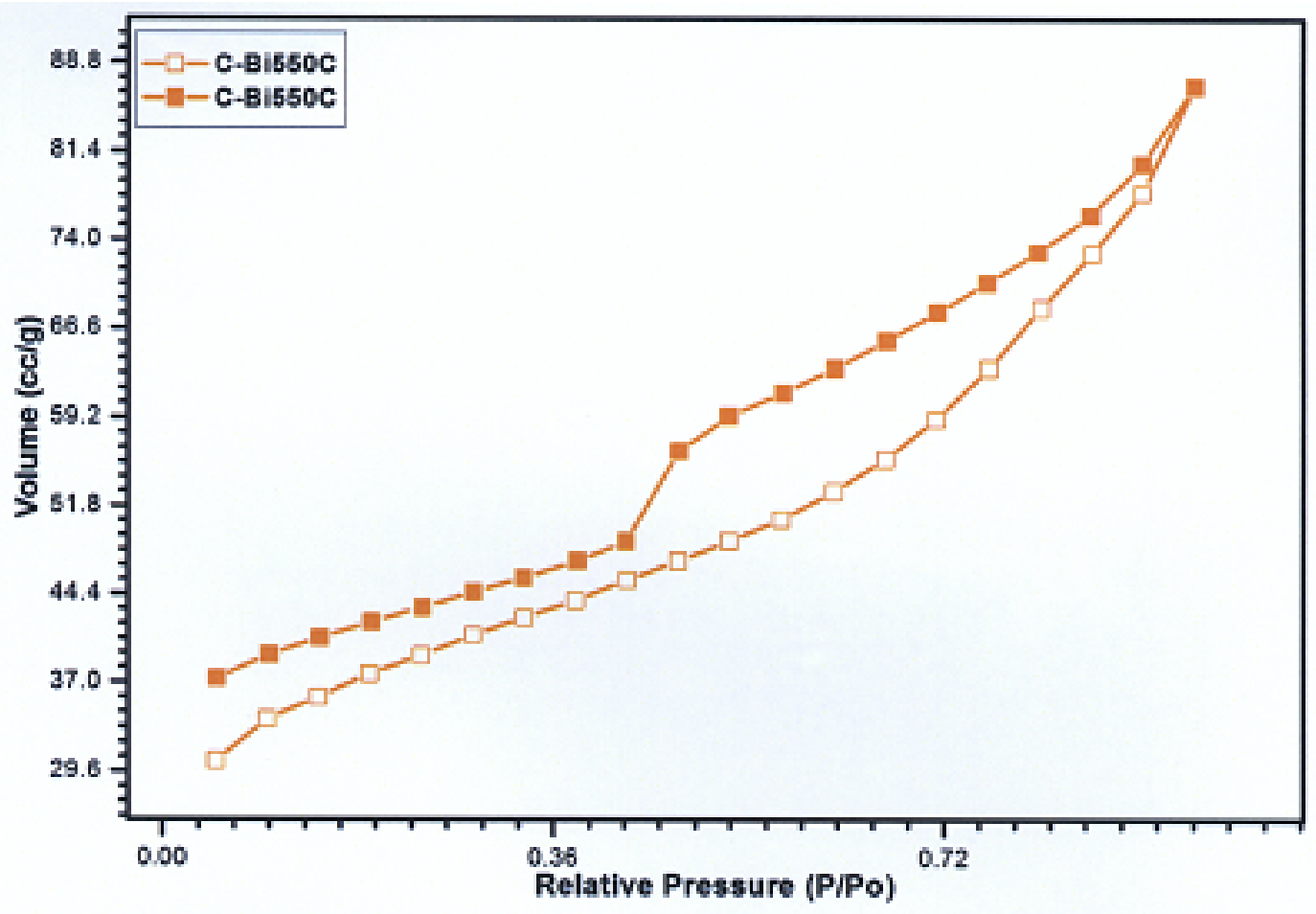

BET adsorption/desorption isotherm for C-Bi550C nanofiber

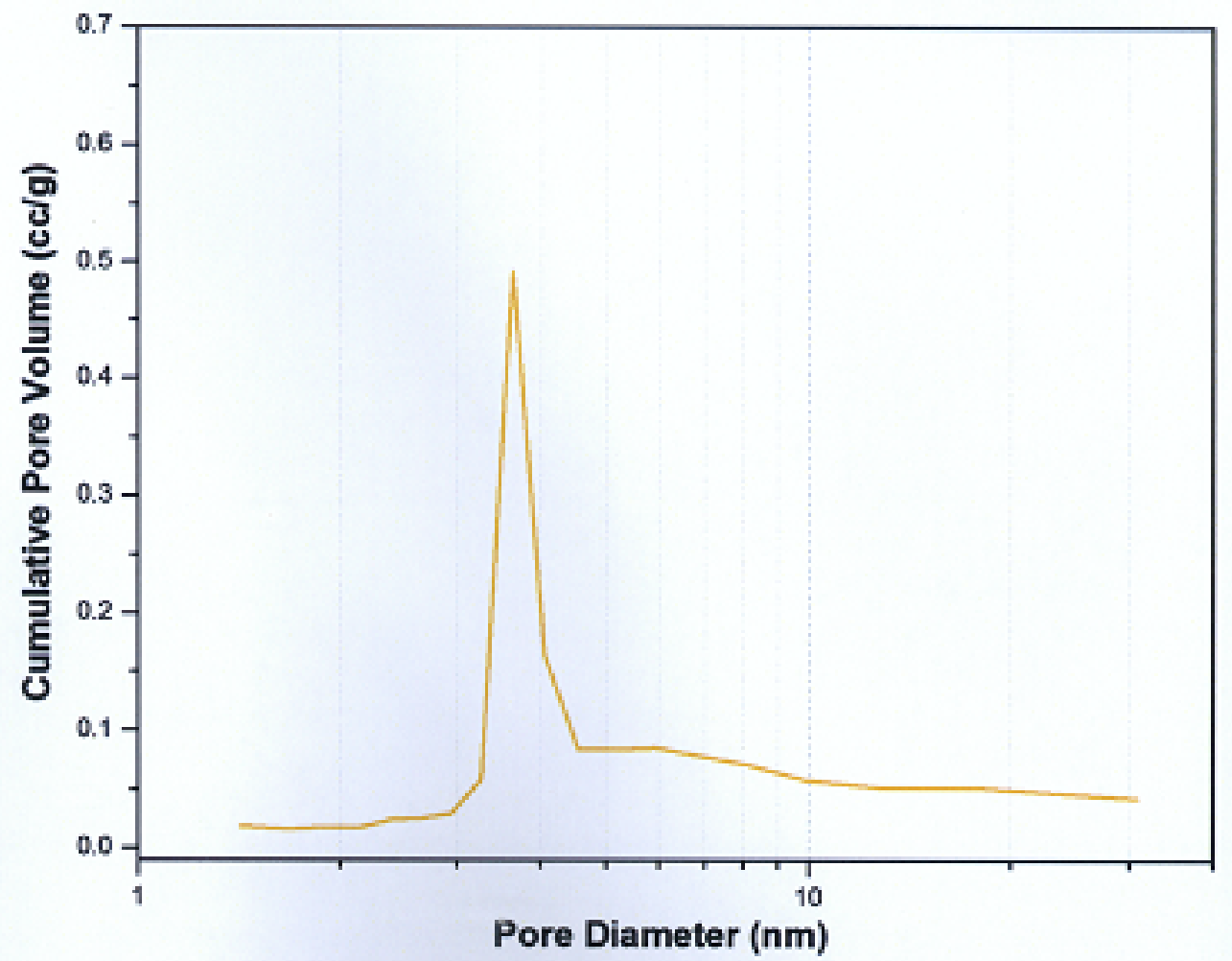

BJH Pore size distribution for C-Bi550C nanofiber 